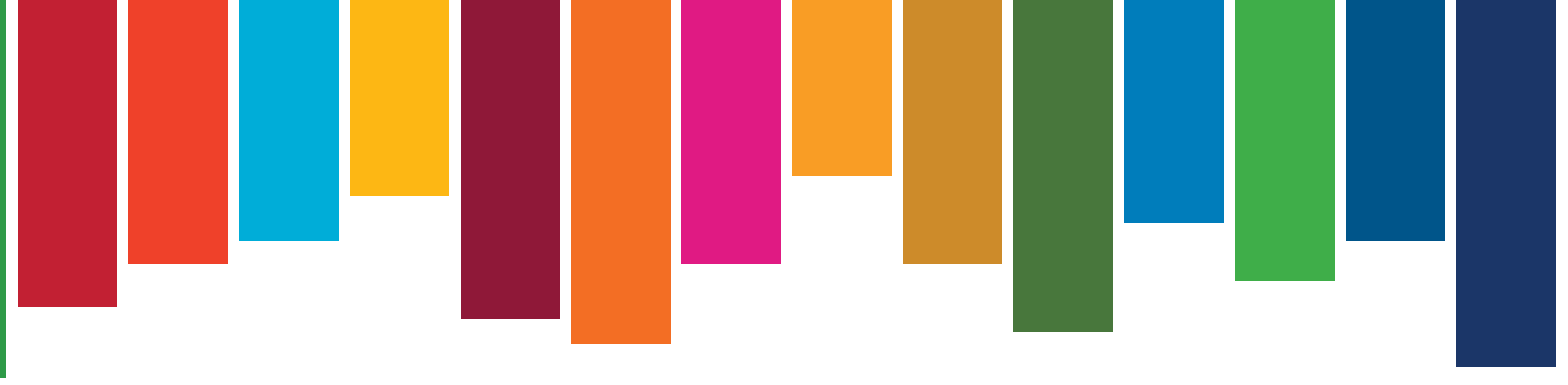

\title{
Transformation towards
}

\section{sustainable and resilient societies}

\section{in Asia and the Pacific}

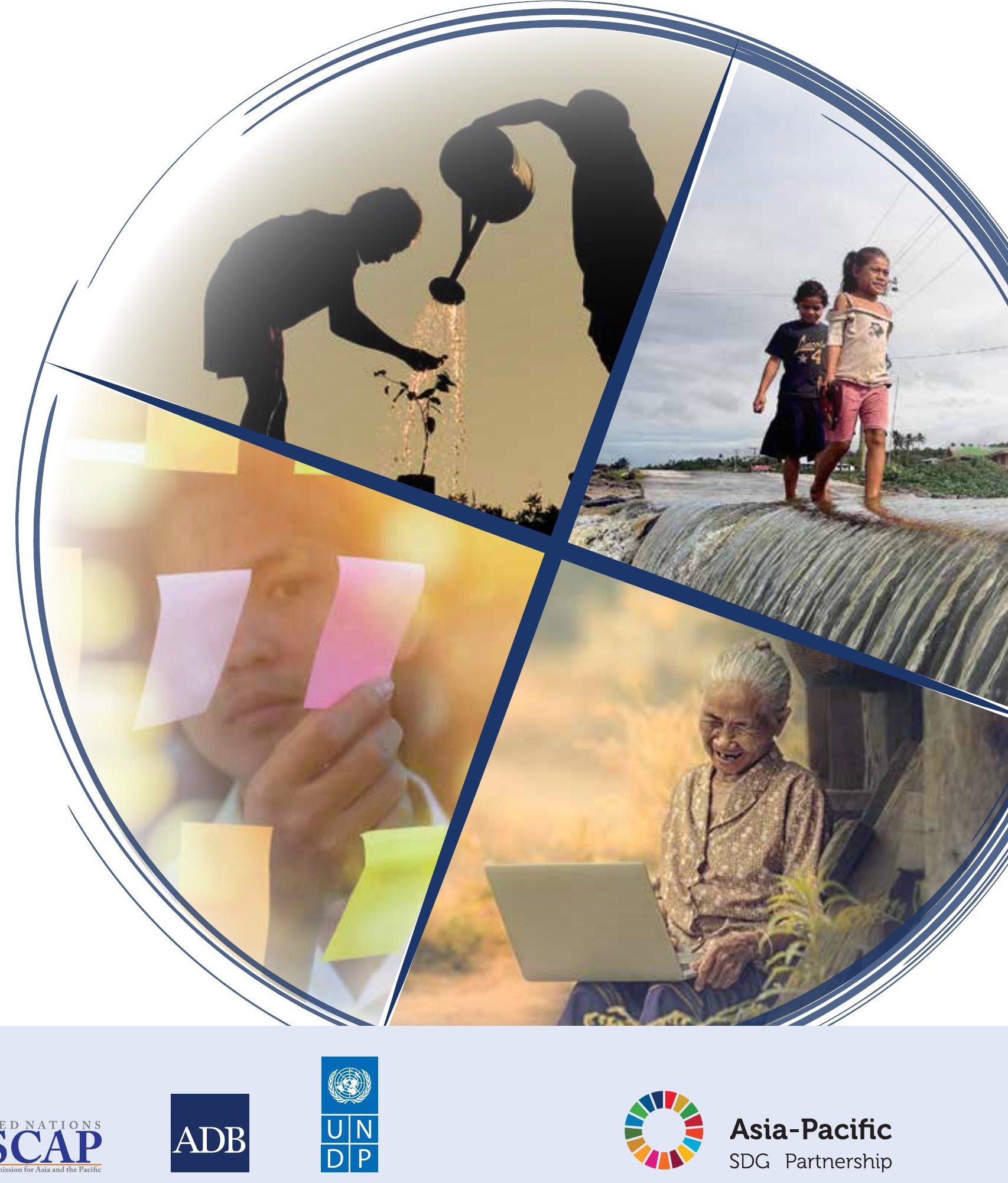


The Economic and Social Commission for Asia and the Pacific is the regional development arm of the United Nations and serves as the main economic and social development centre for the United Nations in the region. Its mandate is to foster cooperation between its 53 members and 9 associate members. ESCAP provides the strategic link between the global and country-level programmes and issues. It supports governments in consolidating regional positions and advocates regional approaches to meeting the unique socioeconomic challenges in a globalizing world. The ESCAP office is located in Bangkok.

The Asian Development Bank's vision is an Asia and Pacific region free of poverty. Its mission is to help its developing member countries reduce poverty and improve the quality of life of their people. Despite the region's many successes, it remains home to a large share of the world's poor. ADB is committed to reducing poverty through inclusive economic growth, environmentally sustainable growth and regional integration. Based in Manila, ADB is owned by 67 members, including 48 from the region. Its main instruments for helping its developing member countries are policy dialogue, loans, equity investments, guarantees, grants and technical assistance.

The United Nations Development Programme works in about 170 countries and territories, helping to achieve the eradication of poverty, and the reduction of inequalities and exclusion. We help countries to develop policies, leadership skills, partnering abilities, institutional capabilities and build resilience in order to sustain development results. 


\section{Transformation towards sustainable and resilient societies in Asia and the Pacific}




\section{Transformation towards sustainable and resilient societies in Asia and the Pacific}

(c) 2018 United Nations, Asian Development Bank, United Nations Development Programme Published in March 2018.

Printed in Thailand.

This is a co-publication of the United Nations (ESCAP), the Asian Development Bank (ADB) and the United Nations Development Programme (UNDP). This work is available open access by complying with the Creative Commons (CC) licence created for intergovernmental organizations, available at: http://creativecommons.org/licenses/by/3.0/igo/. The CC licence does not apply to non-United Nations (ESCAP and UNDP) or non-ADB copyright materials in this publication. Publishers who want to produce their own version of this publication must delete the original emblems from their edition and create a new cover design. Translations must bear the following disclaimer: "The present work is an unofficial translation for which the publisher accepts full responsibility."

Photocopies and reproductions of excerpts are allowed with proper credits. For queries related to the open access licence or queries and/or requests not covered by the open access licence, please contact the United Nations at permissions@un.org

ISBN 978-92-9261-114-9 (print), 978-92-9261-115-6 (electronic)

DOI: http://dx.doi.org/10.22617/TCS189274-2

\section{Cataloguing-In-Publication Data}

United Nations, Asian Development Bank, and United Nations Development Programme.

Transformation towards sustainable and resilient societies in Asia and the Pacific: Theme report for the Asia-Pacific Forum on Sustainable Development, 2018

Bangkok, Thailand: United Nations, 2018

1. Resilience 2. Asia-Pacific 3. Sustainable Development Goals 4. United Nations, Asian Development Bank, and United Nations Development Programme

The views expressed in this publication are those of the authors and do not necessarily reflect the views and policies of ADB or its Board of Governors or the Secretariat of the United Nations (ESCAP and UNDP) or the governments they represent. The United Nations (ESCAP and UNDP) and ADB do not guarantee the accuracy of the data included in this publication and accept no responsibility for any consequence of their use. Any reference to a commercial entity or product in this publication does not imply endorsement.

The designation of or reference to a particular territory or geographic area or the use of the term "country" in this document do not imply the expression of any opinion whatsoever on the part of the Secretariat of the United Nations, ADB or its Board of Governors, or the governments they represent, concerning the legal or other status of any country, territory, city or area, or of its authorities, or concerning the delimitation of its frontiers or boundaries. This publication follows the United Nations practice in references to countries. Where there are space constraints, some country names have been abbreviated. ADB recognizes "China" as the People's Republic of China; "Hong Kong” as Hong Kong, China; "Korea” as the Republic of Korea; and "Kyrgyzstan" as the Kyrgyz Republic.

All queries other than requests for translations and other uses not covered by the CC BY 3.0 IGO licence can be addressed to any of the co-publishing organizations as follows:

\section{Director}

Environment and Development Division

United Nations Economic and Social

Commission for Asia and the Pacific

5th Floor United Nations Building

Rajadamnern Nok Avenue

Bangkok 10200

Thailand

escap-esdd-evs@un.org

\section{Director}

Result Management and Aid Effectiveness Division Strategy Policy and Review Department Asian Development Bank 6 ADB Avenue Mandaluyong City Metro Manila 1550 Philippines sdgs@adb.org

\section{Practice Team Leader}

Inclusive Growth and Sustainable

Development

Bangkok Regional Hub

United Nations Development

Programme

3rd Floor United Nations Building

Rajadamnern Nok Avenue

Bangkok 10200 Thailand

AsiaPacific2030Agenda@undp.org

\section{Also available online at:} www.sdgasiapacific.net 


\section{Foreword}

The year that preceded the publication of this report was marked by dramatic political, social, environmental and economic changes in many countries around the world. The theme of the 2018 High-level Political Forum, 'Transformation Towards Sustainable and Resilient Societies', is therefore deeply resonant for policymakers, citizens and businesses in a changing Asia-Pacific region.

The countries of the Asia-Pacific region are, in a sense, well versed in transformation. They have dealt with financial crises in the last century, and seized opportunities to strengthen the foundations for economic resilience and dynamism. As our 2017 report pointed out, countries have made impressive gains in reducing income poverty, and the region has transformed from one of the poorest in the world to one that is now an engine of the global economy. That progress is not universal, however, nor is it guaranteed to continue. Further transformations that will allow us to realize the 2030 Agenda are urgently needed.

We live in a world of increasingly unpredictable and complex risks. Trends such as demographic change, rural-urban transitions, technology change and climate change are reshaping our region. We need to be much better prepared to deal with the interlinked impacts of long-term trends, and deal with the inevitable changes the future will bring. It is increasingly urgent to understand how best we can realize the transformations that will ensure that we achieve the Sustainable Development Goals (SDGs).

A stronger focus on resilience can support these efforts; for example, it will be essential to incorporate a stronger focus on risk and resilience into the region's strategies for financing development. Innovation will also be vital, enabling us to turn new challenges and risks into opportunities for transformation in line with the SDGs. Together, we must help people, institutions and the region 'bounce back' from new shocks and stresses by pursuing new and more sustainable development paths.

This report takes stock of the changing nature of risk in Asia and the Pacific, and the stresses, shocks and opportunities that are affecting a diverse region's prospects for achieving the SDGs. It quantifies the effects of selected natural hazards, commodity shocks and pollution shocks on the region's fundamental human systems. It highlights practical efforts being made by citizens, civil society, government and the private sector to build resilience capacities. It urges attention on the need to strengthen our ability to transform our societies if we are to achieve the SDGs.

We are pleased to issue this joint report as a contribution to the ongoing regional and global dialogue on pathways to achieving sustainable development.

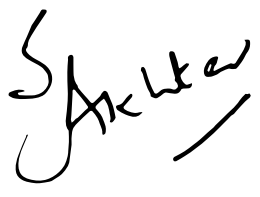

\section{Shamshad Akhtar}

Under-Secretary-General

of the United Nations and

Executive Secretary, ESCAP

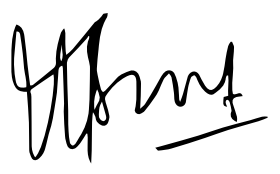

Bambang Susantono

Vice-President, Knowledge

Management and Sustainable

Development, ADB

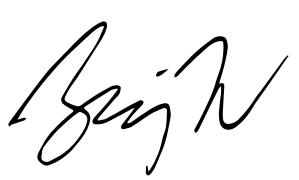

\author{
Haoliang Xu \\ United Nations Assistant \\ Secretary-General \\ UNDP Assistant Administrator and \\ Director for the Regional Bureau for \\ Asia and the Pacific
}




\section{Acknowledgements}

Transformation towards sustainable and resilient societies in Asia and the Pacific was prepared under the Asia-Pacific SDG Partnership of ESCAP, ADB and UNDP, under the guidance of a steering committee comprising Shamshad Akhtar (Executive Secretary, ESCAP and Under-Secretary-General of the United Nations), Bambang Susantono (Vice-President, Knowledge Management and Sustainable Development, ADB) and Haoliang Xu (United Nations Assistant Secretary-General, UNDP Assistant Administrator and Regional Director for Asia and the Pacific).

A technical team from the three organizations (Stefanos Fotiou, Arun Jacob, Hitomi Rankine, Katinka Weinberger and Kaveh Zahedi of ESCAP; Vivian Francisco, Smita Nakhooda and Bernard Woods of ADB; and Jaco Cilliers, Joseph D'Cruz, Seung Hee Kim, Hannie Meesters, Michaela Prokop and Bishwa Nath Tiwari of UNDP) guided the development of the text.

The core team of authors comprised Arun Jacob, Smita Nakhooda, Bishwa Nath Tiwari and Hitomi Rankine. Contributing authors included Milou Beerepoot, Marie Lisa Dacanay, Moortaza Jiwanji, Ali Kharrazi, Seung Hee Kim, Alice Lee, Deborah O'Connell, Heinz Schandl, Anshuman Varma and Li Yutong.

The report was enriched by the technical advice provided by external experts: Aditya Bahadur, Ali Kharrazi, Heinz Schandl, Deborah O'Connell and Lawrence Surendra. Staff members from ESCAP, ADB and UNDP also reviewed parts of the report and provided relevant technical inputs: Therese Bjork, Marta Perez Cuso, Yann Duval, Yukiko Ito, Srilata Kammila, Rohini Kohli, Pradeep Kurukulasuriya, Manoa Malani, Rebecca McNaught, Hannie Meesters, Koh Miyaoi, Mia Mikic, Channe Lindstrom Oguzhan, Caroline Petersen, Michaela Prokop, Vanessa Steinmayer, Arghya Sinha Roy and James P. Villafuerte.

Participants in a series of subregional consultations in East and North-East Asia (Beijing), North and Central Asia (Almaty), Pacific (Samoa), South and South-West Asia (Kathmandu) and South-East Asia (Bangkok), held during September and November 2017, also provided important perspectives for the report.

Alice Chen, Sylvain Delavergne, Samuel Hayden and Skyler Wiet provided research and data support. Tim Woods (Green Ink) edited the manuscripts; Cleone Baradas supported infographic and chart design; Paul Philpot (Green Ink) created the cover design and layout. Administrative and secretarial support was provided by Wipavee Kasemsawasdi, Aqira Bhatchayutmaytri and Chanerin Maneechansook.

Photo credits (cover and chapter separators): Chapter 1: SantiphotoSS/Shutterstock.com; Chapter 2: Luis Ascui/ADB; Chapter 3: Mcky Stocker/Shutterstock.com; Chapter 4: Shutter.O/Shutterstock.com. Support for communications, printing and publishing was provided by members of the communications teams at ESCAP (Ricardo Dunn, Katie Elles and Kavita Sukanandan), ADB (Harumi Kodama, Graham J. Dwyer, Erik Churchill, Reah Sy) and UNDP (Ang Chen, Mahtab Haider and Cedric Monteiro); the Publications Board of the United Nations, Office of the Executive Secretary, ESCAP; the ADB Office of Administrative Services; and the publishing team of ADB's Department of Communications. 


\section{Contents}

Foreword $\ldots, \ldots, \ldots, \ldots, \ldots, \ldots, \ldots, \ldots, \ldots, \ldots, \ldots, \ldots, \ldots, \ldots, \ldots, \ldots, \ldots, \ldots, \ldots, \ldots, \ldots, \ldots, \ldots, \ldots, \ldots, v$

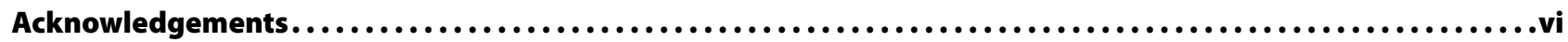

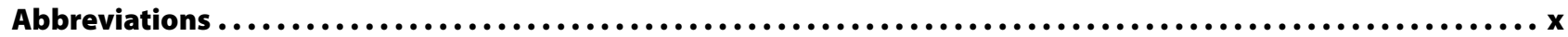

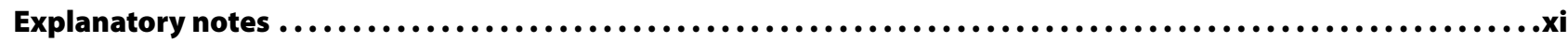

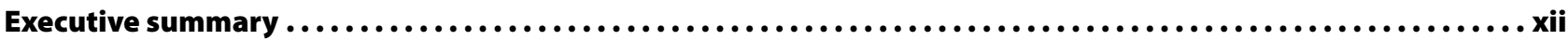

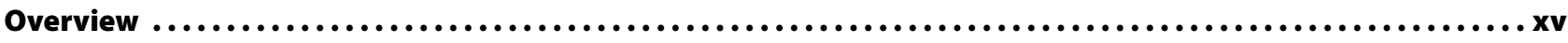

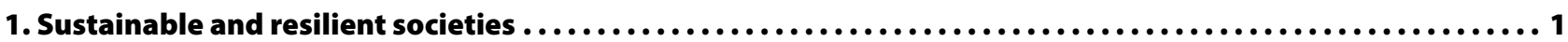

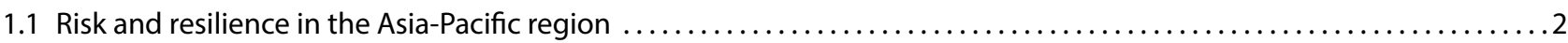

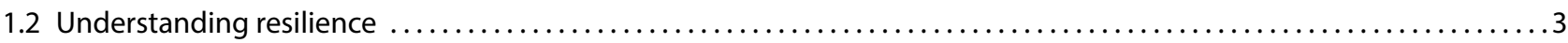

1.3 Building the resilience of human systems: An approach to support policy development ....................

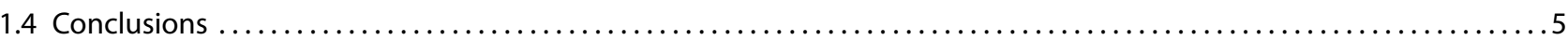

2. Understanding risk: What are the sources of emerging risk in the Asia-Pacific region,

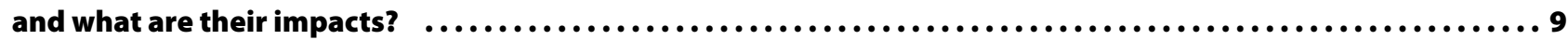

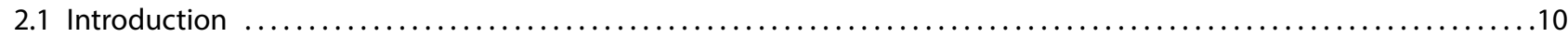

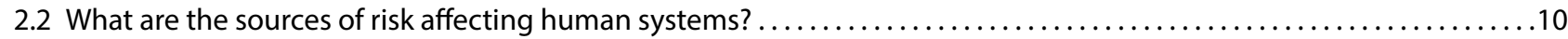

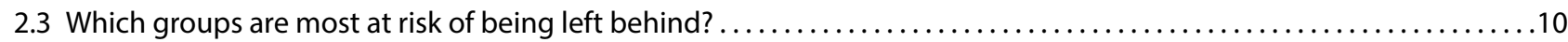

2.4 Assessing risk impacts: The vulnerabilities of human systems in the Asia-Pacific region . .....................11

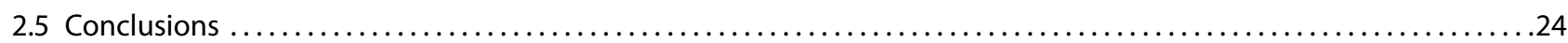

Special feature: Taking stock: Resilience targets and indicators in the SDGs $\ldots \ldots \ldots \ldots \ldots \ldots \ldots \ldots \ldots \ldots \ldots 25$

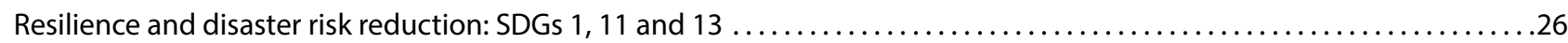

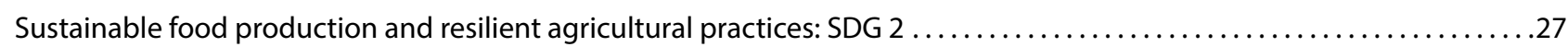

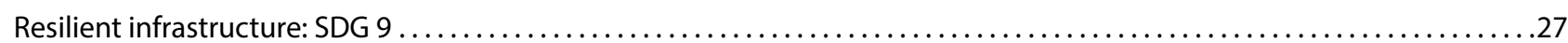

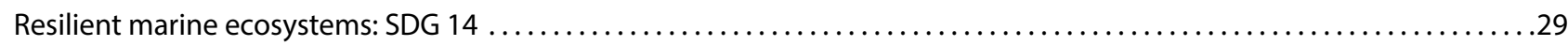

3. Building resilient societies: Getting ready for transformation $\ldots \ldots \ldots \ldots \ldots \ldots \ldots \ldots \ldots \ldots \ldots \ldots \ldots . \ldots . \ldots . \ldots 1$

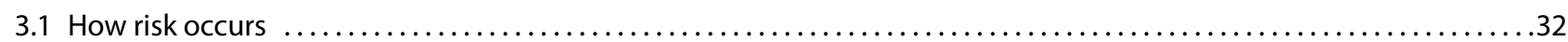

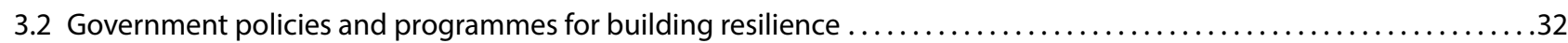

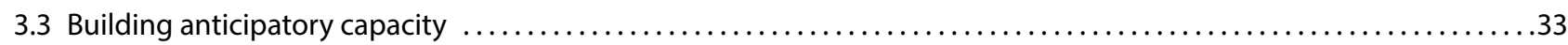

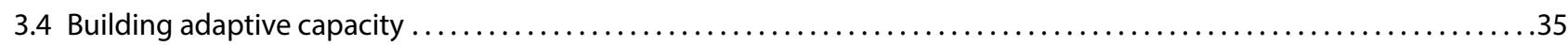

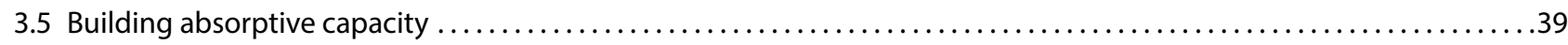

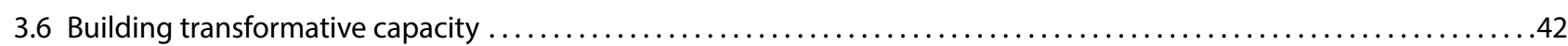

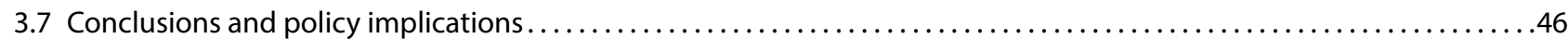

4. Enabling transformations towards sustainable and resilient societies $\quad \ldots \ldots \ldots \ldots \ldots \ldots \ldots \ldots \ldots \ldots \ldots \ldots, 49$

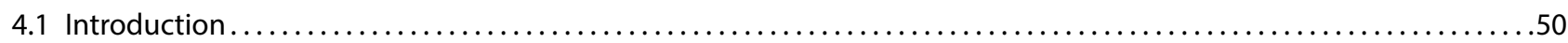

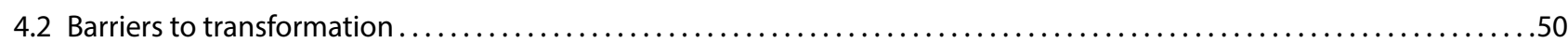

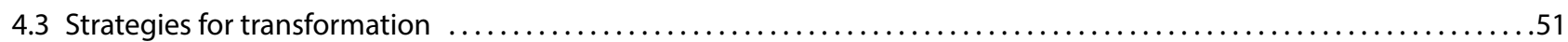

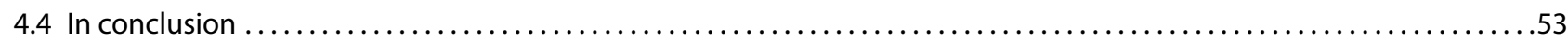

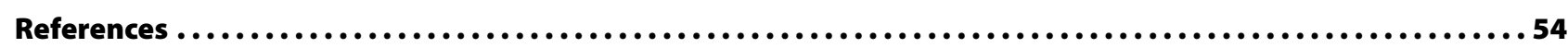

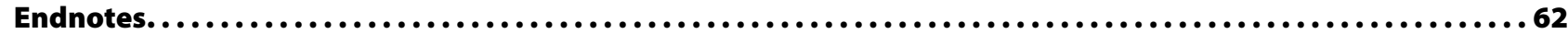




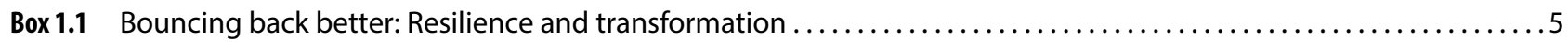

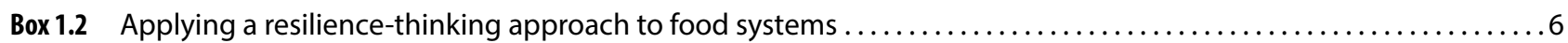

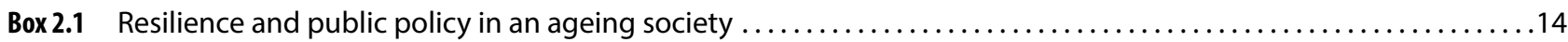

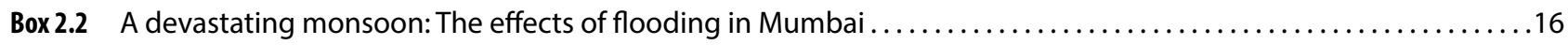

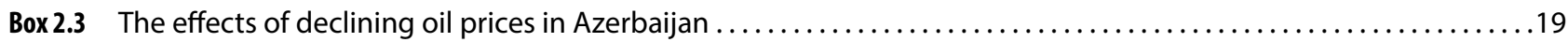

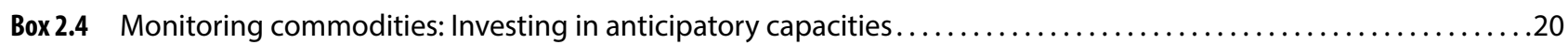

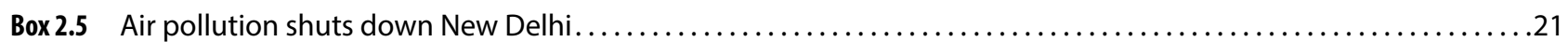

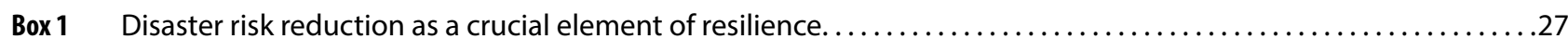

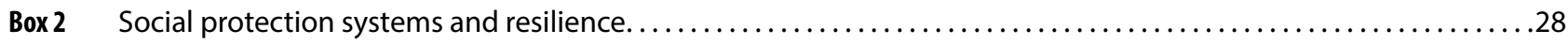

Box 3.1 Fighting dengue fever through an information campaign in the Philippines ..........................

Box 3.2 How the Republic of Korea's economy became more resilient after the 1997 and 2008 financial crises ..........36

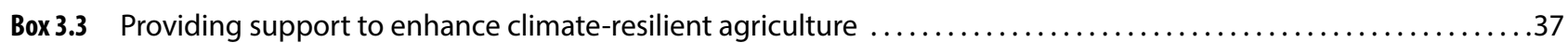

Box 3.4 Using remittances to build household-level adaptive capacity in the Eastern Brahmaputra sub-basin ..........37

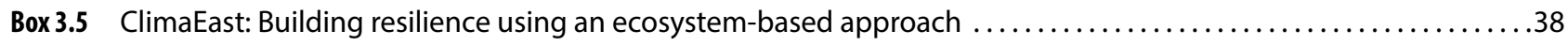

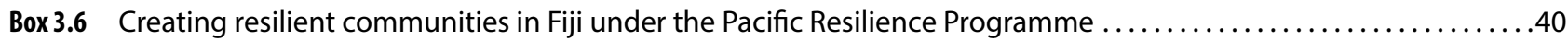

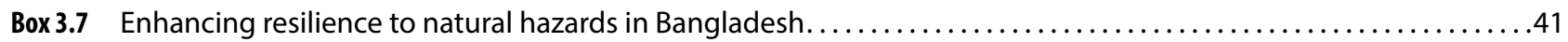

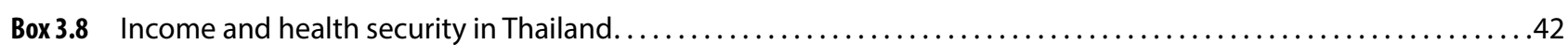

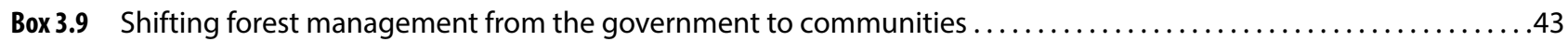

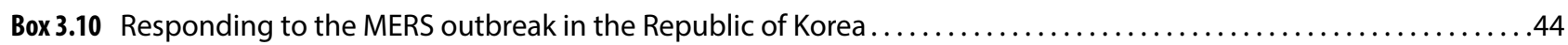

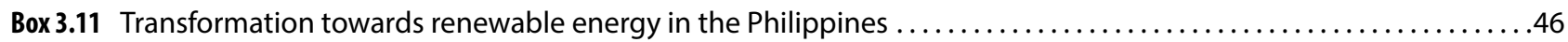

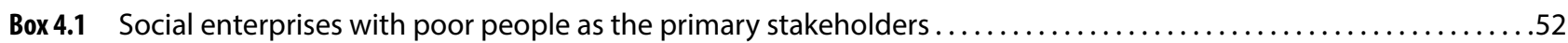

\section{Figures}

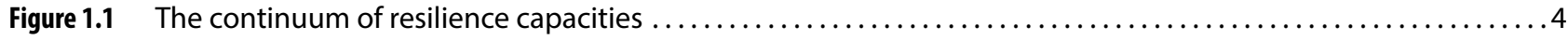

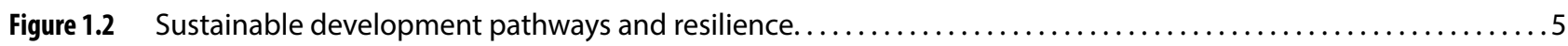

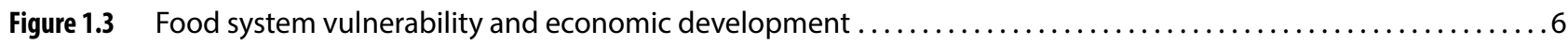

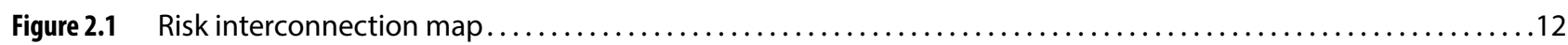

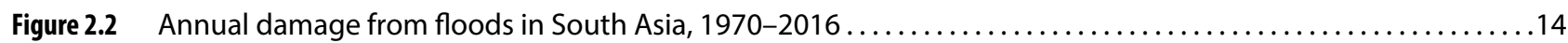

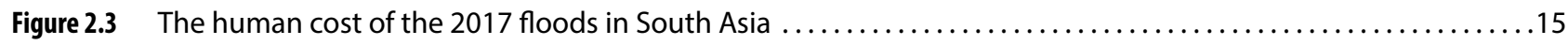

Figure 2.4 Crude oil price fluctuations and exports in subregions of the Asia-Pacific region, 2004-2017 ...........18

Figure 2.5 Energy prices and GDP growth in oil-exporting Central Asian countries , 1992-2016 .................19

Figure 2.6 $\mathrm{PM}_{2.5}$ levels at New Delhi pollution monitoring stations, October-December $2017 \ldots \ldots \ldots \ldots \ldots \ldots \ldots . \ldots \ldots$

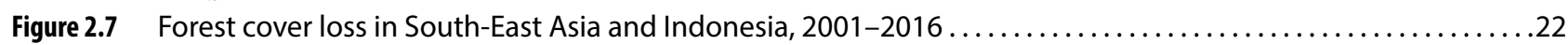

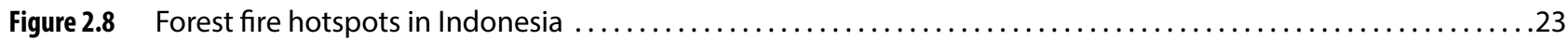

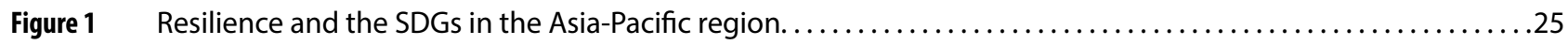

Figure 2 The increasing frequency of, and damages from, disasters in the Asia-Pacific region, 1970-2016..........26

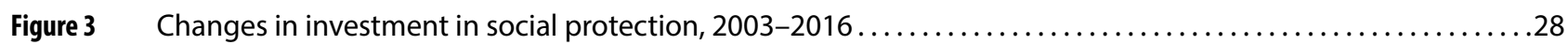

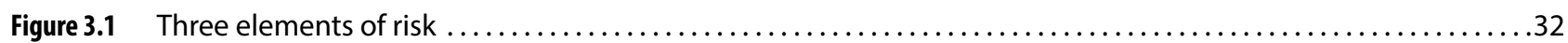

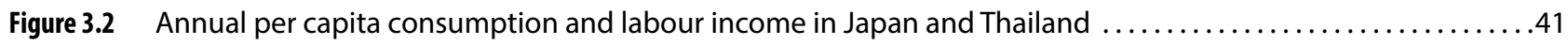

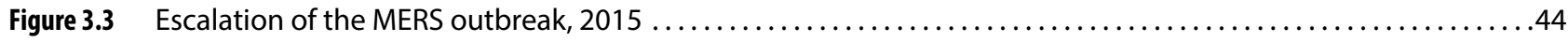




\section{Tables}

Table 2.1 Subregional perspectives on the risks that critical human systems face from selected drivers of change .......11

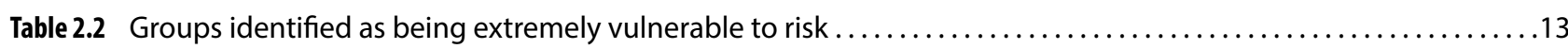

Table 3.1 Government policies and programmes for building resilience in the Asia-Pacific region $\ldots \ldots \ldots \ldots \ldots \ldots \ldots . \ldots \ldots$ 


\section{Abbreviations}

ADB Asian Development Bank

ASEAN Association of Southeast Asian Nations

ESCAP United Nations Economic and Social Commission for Asia and the Pacific

$\mathbf{C O}_{2}$ carbon dioxide

GDP gross domestic product

JPY Japanese yen

KCDC Korea Centers for Disease Control and Prevention

KRW Korean won

MERS Middle East Respiratory Syndrome

NAMA Nationally Appropriate Mitigation Action

NAP National Adaptation Plan

NAPA National Adaptation Programme of Action

n.d. no date

NDC Nationally Determined Contribution

PM particulate matter

ppp purchasing power parity

PTA Preferential Trade Agreement

RMB renminbi

SDG Sustainable Development Goal

THB Thai baht

UNDP United Nations Development Programme

UNFCCC United Nations Framework Convention on Climate Change

WEF World Economic Forum

WFP World Food Programme

WHO World Health Organization 


\section{Explanatory notes}

The Asia-Pacific region, unless otherwise specified, refers to the group of members and associate members of the Economic and Social Commission for Asia and the Pacific (ESCAP) that are within the Asia and the Pacific geographic region (the Asian Development Bank and the United Nations Development Programme, partners in this publication, have different regional compositions). Some countries are referred to by a shortened version of their official name in the figures, as indicated in brackets in the listing below.

Geographic subregions in this report are defined (unless otherwise specified), as follows: East and North-East Asia: China, Democratic People's Republic of Korea (DPR Korea), Japan, Mongolia, Republic of Korea; South-East Asia: Brunei Darussalam, Cambodia, Indonesia, the Lao People's Democratic Republic (Lao PDR), Malaysia, Myanmar, Philippines, Singapore, Thailand, Timor-Leste, Viet Nam; South and South-West Asia: Afghanistan, Bangladesh, Bhutan, India, Islamic Republic of Iran, Maldives, Nepal, Pakistan, Sri Lanka, Turkey; North and Central Asia: Armenia, Azerbaijan, Georgia, Kazakhstan, Kyrgyzstan, the Russian Federation, Tajikistan, Turkmenistan, Uzbekistan; Pacific: American Samoa, Australia, Cook Islands, Fiji, French Polynesia, Guam, Kiribati, Marshall Islands, Federated States of Micronesia, Nauru, New Caledonia, New Zealand, Niue, Northern Mariana Islands, Palau, Papua New Guinea, Samoa, Solomon Islands, Tonga, Tuvalu, Vanuatu.

Least developed countries: Afghanistan, Bangladesh, Bhutan, Cambodia, Kiribati, the Lao People's Democratic Republic, Myanmar, Nepal, Solomon Islands, Timor-Leste, Tuvalu and Vanuatu. Samoa was part of the group of least developed countries prior to its graduation in 2014; landlocked developing countries: Afghanistan, Armenia, Azerbaijan, Bhutan, Kazakhstan, Kyrgyzstan, Lao People's Democratic Republic, Mongolia, Nepal, Tajikistan, Turkmenistan and Uzbekistan; small island developing states: Cook Islands, Fiji, Kiribati, Maldives, Marshall Islands, Federated States of Micronesia, Nauru, Niue, Palau, Papua New Guinea, Samoa, Solomon Islands, Timor-Leste, Tonga, Tuvalu and Vanuatu.

Developing Asia-Pacific: ESCAP region, excluding Australia, Japan and New Zealand.

Developed or industrialized Asia-Pacific: Australia, Japan and New Zealand.

\section{Symbols and units}

- References to dollars (\$) are to United States dollars, unless otherwise stated.

- The dash (-) between dates signifies the full period involved, including the beginning and end years.

- Percentages do not necessarily add up to 100 per cent because of rounding.

- 'Tonnes' refers to metric tons.

- 'Barrels' in terms of oil refers to 42 United States gallons, or around 159 litres. 


\section{Executive summary}

People across the Asia-Pacific region live with diverse and interlinked risks. These risks are related to increasingly severe and complex shocks to the political, social, economic and ecological systems that underpin human development.

The impacts of such shocks often fall disproportionately on the most marginalized groups and communities, and so have the potential to undermine the region's potential for achieving the Sustainable Development Goals (SDGs).

The region's resilience must be tapped more effectively to deal with this complex risk landscape. Resilience enables individuals, communities and systems to survive, adapt and grow in the face of stress and shocks; to convert risks into opportunities; and to transform when conditions require it.

The actions required to strengthen resilience can be understood in terms of inter-related and complementary resilience capacities:

- Anticipatory capacity: the ability of human systems to anticipate and reduce the impact of shocks through preparedness and planning.

- Absorptive capacity: the ability of human systems to absorb and cope with the impacts of shocks and stresses.

- Adaptive capacity: the ability of human systems to change in response to multiple, long-term and future risks, and to learn and adjust after a shock materializes.

- Transformative capacity: the ability to take deliberate steps to change systems that create risks, vulnerability and/ or inequality.

This report presents a three-step approach for incorporating resilience thinking into policymaking to build resilience capacity. The approach: (1) identifies risks; (2) explores the potential impacts on human systems and vulnerable groups; and (3) identifies policies and institutional responses that build these resilience capacities.

The application of the three-step approach in the case of food systems reveals the emerging risks of climate change and demographic changes to these systems. For example, 73 per cent of food commodity trade networks in the Asia-Pacific region exhibited signs of weakening resilience in 1986-2013, and the report identifies policy options to strengthen the resilience capacities of food systems.

\section{The changing nature of risk in Asia and the Pacific}

Trends including demographic change, rural-urban transitions, increasing demand for natural resources, globalization and economic liberalization, climate change and technological progress are reshaping the Asia-Pacific region. These trends can create important opportunities for countries to make progress towards the SDGs, but also increase and complicate some of the risks to the human systems that define the ways that societies function.

An exploration of the first steps of the approach proposed in this report points to some emerging sources of risks in the region, and underlines the fact that each subregion faces different challenges. These sources of risk as highlighted in consultations 
include: the implications of ageing for financial systems; the impacts of rural-urban transitions and commodity shocks on financial and food systems; the looming impacts of pollution on health and economic productivity; the impacts of a changing climate on provisioning systems, and the potential for social conflict; and the implications of economic structure change for dietary patterns and for health-care burdens on government budgets.

Some groups or communities are disproportionately exposed to risks and are more vulnerable to the changing risk profile of the Asia-Pacific region - and specific analysis for each context is needed. This report assesses the impact of selected recurrent shocks to illustrate the diverse range of challenges to which human systems in the Asia-Pacific region must build their resilience. These include:

- Flooding: Asia and the Pacific is highly vulnerable to the effects of climate change, and highly exposed to natural hazards. Flooding is one of the most pervasive recurrent shocks, affecting South Asia in particular. Between 1970 and 2016, some 35 per cent of floods in the region occurred here; in August 2017 alone, intense monsoon rains affected 40 million people in Bangladesh, India and Nepal, claimed nearly 1,300 lives, put 1.1 million people in relief camps, and brought major cities to a standstill. By some estimates, floods could cost the subregion as much as $\$ 215$ billion each year by 2030.

- Commodity price shocks: Economic dependence on commodity exports impacts the resilience and vulnerability of financial and social systems and results in high carbon intensity. Oil price slumps in 2014 had severe economic and financial consequences in Central Asia. In Azerbaijan for example, for every 1 per cent change in crude oil prices, household expenditures changed by 0.94 per cent; economic growth rates dropped from 6 per cent to -3 per cent, and financial reserves shrank by 56 per cent in just two years. In some countries, youth unemployment increased. Reliance on oil also results in high carbon intensity, whereas economic diversification can support low carbon development.

- Pollution shocks: Pollution events that lead to severe, concentrated pollution within a short period of time can pose severe shocks to human systems. Welfare losses from exposure to ambient and household air pollution are estimated to have cost South and South-East Asia and the Pacific the equivalent of 7.5 per cent of regional gross domestic product. Recurrent transboundary smoke and haze in South-East Asia, caused by forest and peatland fires, has had severe social and economic effects in the subregion, affecting people in multiple countries. In 2015 alone, more than 500,000 cases of acute respiratory infection were recorded, while transport and logistics systems were disrupted, resulting in losses of up to $\$ 1.3$ billion, and total losses of about $\$ 16$ billion for the Indonesian economy.

\section{Building resilience capacities}

Fortunately, there are encouraging signs that many countries and communities are beginning to build resilience capacities to manage such shocks, and are already realizing the benefits. There are also initial emerging signs that countries are starting to look at policies and systems to build transformative capacities. This report provides several examples of where resilience has been successfully strengthened through appropriate actions.

- Anticipatory capacity: Knowledge, information and experience are essential elements of anticipatory capacity, and education and effective communication can play a vital role. Many countries have set up early warning systems to help them avoid or reduce the impact of hazards such as floods, landslides, storms and forest fires. However, the realization of anticipatory capacity requires translating information and knowledge into action, and needs to take social, cultural and gender considerations into account.

- Adaptive capacity: Diverse efforts that build adaptive capacity by reducing exposure and vulnerability are underway across the region, using a variety of measures including prudent macroeconomic and fiscal policies, integrating risk information into key sectoral policies (e.g. agricultural development), and mainstreaming risks (e.g. climate changerelated) into national planning and budgeting. Most countries in the region have begun to incorporate climate risk into national and sectoral planning, including through National Adaptation Plans and Nationally Determined Contributions, and in some cases, this information is being used to determine resource allocation. There are also more 
localized examples of building adaptive capacity. Further, diversifying income sources and forms of capital can help to build resilience at individual and household levels.

- Absorptive capacity: One crucial aspect of building absorptive capacity is to increase the options through which basic needs can be met in times of crisis. Many countries in the region are investing in social protection systems that can help build general resilience by providing income and health security, in particular to vulnerable populations. Some countries have universal old-age pension coverage.

- Transformative capacity: While much more needs to be done to achieve transformation towards the sustainable development required in the region, there are examples of important steps to change the underlying systems and build the capacity to make deliberate change. Examples include the transfer of responsibility for forest management to the communities that rely on these forests for their livelihoods, and the amendment of policies and regulations to promote renewable and clean energy. Larger-scale transformations can be triggered in response to a crisis, as in the case of public health emergency responses that have triggered a series of interventions, from creating awareness to planning and putting a new public health emergency system in place.

\section{Towards transformation}

The 2030 Agenda for Sustainable Development states global leaders' determination to "take the bold and transformative steps needed to shift the world on to a sustainable and resilient path". Transformation requires breaking through the 'path dependency' that defines the way things are done.

This report identifies three barriers to transformation that make change difficult. The first is inadequate human and institutional capacity; the second is institutional rigidity, which diminishes institutions' capacity to evolve; and the third is inadequate social momentum for change. Socio-cultural factors, gender and other dimensions of inequality, and imbalances in access to decision-making also affect prospects for transformation.

Taking into account experiences across the region, the scale of change needed, and the imperative to ensure inclusive transformation, four strategies for transformation towards sustainable and resilient societies are proposed: (1) transformative learning as part of the policy cycle; (2) deeper social engagement to promote broad-based stakeholder support for change; (3) social enterprise to connect poverty alleviation, sustainability and resilience-strengthening objectives with economic objectives; and (4) diversifying financing and investment to maximize options when crisis strikes or opportunities arise, and also to promote inclusion.

The many international agreements that countries in the Asia-Pacific region have signed - not least the 2030 Agenda provide a framework around which discussions can be based, efforts coordinated and progress measured. There is every reason to believe that the Asia-Pacific region can increase the resilience of its societies and pursue development pathways that truly leave no one behind. 


\section{Overview}

This report contributes to regional and global dialogue on the theme of the 2018 High-level Political Forum on Sustainable Development, 'Transformation towards sustainable and resilient societies', from an Asia-Pacific perspective. It explores how resilience thinking can strengthen public policy to enable the transformation towards sustainable societies envisaged by the 2030 Agenda for Sustainable Development.

Chapter 1 sets out the relevance of the theme for achieving the 2030 Agenda in the Asia-Pacific region, and the steps needed to build the four key resilience capacities: absorptive, adaptive, anticipatory and transformative. It presents a threestep approach for incorporating resilience into policymaking that: (1) identifies risks; (2) explores the potential impacts on human systems and vulnerable groups; and (3) identifies policies and institutional responses that build these resilience capacities.

Chapter 2 explores the first two steps, reviewing the main underlying sources of risks in the region. It assesses the impacts of various types of recurrent shocks on human systems in the region, with a focus on the most vulnerable people in society.

A Special Feature of the report takes stock of the situation in the region with respect to the SDGs that explicitly refer to resilience.

Chapter 3 supports the final step: the identification of policy and institutional responses. It shows how each of the four different types of resilience capacity can be built, presenting a range of examples of policies and programmes, from across the region, that have proven effective. It draws conclusions on the key characteristics that individuals, organizations and societies need to become resilient.

Chapter $\mathbf{4}$ concludes the report by considering opportunities to support transformation for resilience, particularly through regional cooperation. 



\subsection{Risk and resilience in the Asia-Pacific region}

People in Asia and the Pacific today face increasingly diverse and interlinked risks, which are increasing in severity. For example, recent projections from the Asian Development Bank (ADB) ${ }^{1}$ highlight the current and potential impacts of climate change in the Asia-Pacific region. Similarly, recent research from the Economic and Social Commission for Asia and the Pacific (ESCAP) ${ }^{2}$ shows how climate change magnifies the risks associated with disasters, while increasing the costs of protecting people against them. Trends such as demographic change, rural-urban transitions, increasing demand for natural resources, technology change and climate change are reshaping our region.

These large-scale processes and their interactions can have major effects on critical human systems. Human systems are the combination of political, social, economic and ecological systems that underpin human development. ${ }^{3}$ Combined, these trends are leading to increasingly complex and unpredictable outcomes for societies in the region, with disproportionate impacts on marginalized groups and communities which have the potential to undermine hard-won development gains. These developments make achieving the Sustainable Development Goals (SDGs) and the central aspiration of the 2030 Agenda for Sustainable Development - "to leave no one behind" - ever more challenging.

Furthermore, challenges that were once localized can now escalate into global crises, due to the increasingly integrated nature of human systems. For example, in 2007-2008 extreme weather and weather-related disasters in the Russian Federation and South Asia led to reduced wheat yields, which contributed to higher global prices for various food commodities. Protests and riots, triggered by rising prices, broke out in 48 countries; in some places, these exacerbated ongoing political crises. ${ }^{4}$

The Asia-Pacific region's resilience - its ability to absorb and recover from shocks, and to adapt and transform people's structures and means for living in the face of long-term stresses, change and uncertainty - must be 'tapped' more effectively to deal with this complex risk landscape. A resilient society not only responds to disruptions and crises by bringing human systems back to their previous state, but also tries to develop solutions that bring about a new state - one that is capable of addressing present and future challenges. ${ }^{5}$ In other words, resilience incorporates the ability of individuals, communities and systems to survive, adapt and grow in the face of stress and shocks; to convert risks into opportunities; and to transform when conditions require it. ${ }^{6}$
While several of the SDGs make specific reference to resilience (see the Special Feature on page 25), the relevance of resilience can be understood in the context of any of these goals. Take, for example, SDG 1: to end poverty in all forms everywhere. While economic growth can propel people above income poverty lines, shocks such as natural hazards exacerbated by climate change, industry relocations due to technological change, or health deterioration due to exposure to pollution - can all have effects on assets, livelihoods and well-being, and push people back into poverty. Resilience is about enabling the capacities of people to anticipate and bounce back when hit by such shocks.

Where possible, resilience should help people 'bounce forward' towards improved development outcomes. For instance, to anticipate potential job losses from technological disruptions, societies can provide vulnerable populations with training in specific skills that will allow them to find better jobs in other sectors.

Building resilience requires governance approaches, institutions and policies that are better geared to dealing with risk. As discussed in Chapter 3, the scale of risks and shocks is determined by three factors: hazards, exposure and the vulnerability of a society. Hazards refer to the possible occurrence of natural or human-induced physical events that could happen, with adverse effects on vulnerable and exposed elements. The hazard can be manifest as a slow trend (e.g. air pollution or sea level rise) or a shock (e.g. a cyclone or tsunami). When it occurs, it may create little impact (e.g. a cyclone in the middle of the ocean, where no people or critical ecosystems are exposed) or a disaster (e.g. a storm surge associated with a cyclone which engulfs coastal settlements, causing deaths, injury and property damage).

Poor policy choices can make a society exposed to hazards more vulnerable. ${ }^{7}$ Building resilience means being able to seize the opportunities for transformation that a crisis can sometimes present. Resilience is critical to facilitate the transition towards sustainable societies envisaged in the 2030 Agenda, and harnessing resilience will be the basis for achieving the SDGs.

This report focuses on how to make sustainable development processes resilient to emerging risks and stresses. It presents a three-step approach to help policymakers explore the theme of transformation towards sustainable and resilient societies. It examines how governments, communities and other stakeholders can manage complex risks; identifies critical systems and communities vulnerable to these risks; and provides insights into the links between 
resilience capacities and the transformations needed to achieve sustainable development. In doing so, it presents a regional perspective on the theme of the 2018 High-level Political Forum on Sustainable Development: transformation towards sustainable and resilient societies.

\subsection{Understanding resilience}

The Asia-Pacific region confronts complex risks that originate from multiple sources. One way to understand the impacts on society of these increasingly interconnected risks is to study their impacts on the human systems that are critical for the functioning of societies. Significant human systems ${ }^{8}$ include:

- economic systems, which determine how resources are allocated in societies, partly with the help of trade systems

- financial systems, which comprise the exchange and circulation of financial resources

- systems that provide social services, which include education, health and social security

- provisioning systems, which include food, energy and water

- the broader environmental systems that support life on earth.

All these systems are interlinked as they support and complement each other to create functioning societies. Broader regulatory systems, which include political arrangements, legal arrangements, cultural norms, scientific knowledge and communication, govern these links and interactions.

Societal resilience depends, in part, on the resilience of the human systems described. Affected systems at all scales countries, communities, households and individuals - need to define their responses to shocks and mobilize resources towards specific actions. These responses may reflect core principles of strengthening resilience, such as: maintain diversity and redundancy; ${ }^{9}$ manage connectivity; manage 'slow variables' (e.g. ageing) ${ }^{10}$ and feedbacks; foster complex adaptive systems thinking; encourage learning; broaden participation; and promote polycentric governance systems. ${ }^{11}$

The actions needed to strengthen the resilience of human systems can be understood in terms of resilience capacities, ${ }^{12}$ which include the following.

1. Anticipatory capacity: the ability of human systems to anticipate and reduce the impact of shocks through preparedness and planning. This can be seen in the proactive actions taken before an event, either to avoid or reduce exposure to a certain risk, or to minimise vulnerability to specific events.

2. Absorptive capacity: the ability of human systems to absorb and cope with the impacts of shocks and stresses. Absorptive capacity draws mainly on the available resources within human systems to recover from adverse conditions. Absorption refers to a system's ability to cope with shocks that have not been anticipated, and therefore have not been preceded by adaptive or transformative efforts, or to the residual exposure that has not been mitigated by these efforts.

3. Adaptive capacity: the ability of human systems to change in response to multiple, long-term and future risks, and to learn and adjust after a shock materializes. It describes the capability to take deliberate and planned decisions, even when conditions have changed or are about to change, to achieve a desired state.

4. Transformative capacity: the ability to take deliberate steps to change systems that create risks, vulnerability and/or inequality. Transformative capacities support people to invest and innovate, and can help societies to break away from the status quo, and shape their ability to identify opportunities for transformation.

These four capacities are not independent; they overlap and complement each other, forming a continuum (see Figure 1.1) that promotes different levels of change, ranging from persistence through incremental adjustments to transformational changes. ${ }^{13}$

The response of the Asia-Pacific region to the 1997 financial crisis illustrates the mutually supporting measures that can be put in place to build these resilience capacities. The 1997 crisis exposed the risks inherent in fast-globalizing economies and the vulnerabilities of the financial system. Macro-prudential policies and other tools were deployed, financial regulations overhauled, and regulatory oversight of financial institutions was strengthened. Efforts were made to address systemic factors that encouraged risktaking, and anticipatory capacity was enhanced through the establishment of early warning systems and institutions at the national and regional levels. Taken together, these actions strengthened resilience to the shocks accompanying a context of increased cross-border capital flows, greater integration with the rest of the world, more volatile external conditions and higher risk premiums. ${ }^{14}$

Human systems that have these fundamental resilience capacities are less likely to be undermined by shocks and stresses. ${ }^{15}$ Countries need to invest in analysis of emerging risks and their potential impacts on critical human systems 
Persistence

Incremental adjustment

Transformation

INTENSITY OF CHANGE

\section{Absorptive capacity}

Draws mainly on the available resources

\section{Adaptive capacity}

Improvements of existing systems
Transformational capacity

Creation of new systems

\section{Anticipatory capacity}

Prediction of disruptive events

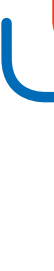

Source: Adapted from Béné and others, 2012, and Tanner and others, 2017

and, on this basis, determine the extent to which they need to strengthen their resilience capacities.

There may also be trade-offs among the four capacities identified, such as between adaptation and transformation. Adaptive capacity focuses on altering current systems to make them less vulnerable to risks and disruptions, while transformative capacity aims to strengthen ability to create new arrangements.

One good example is in the energy sector, where there is a need to transition from centralized, inefficient, fossil fuelbased systems to distributed, more efficient, renewable energy-based systems. Such a transition would allow countries in the Asia-Pacific region to achieve the SDGs on access to clean energy for all, to act on climate change and promote more sustainable consumption, while also increasing the resilience of the overall energy-provision system. It could, however, entail higher upfront capital costs in some cases, investments in capacity to manage new technologies and approaches, and measures to manage a fair transition for those who rely on conventional sources of energy for their livelihoods.

Box 1.1 describes this interaction between resilience and transformation in the context of the 2030 Agenda.

\subsection{Building the resilience of human systems: An approach to support policy development}

Operationalizing the concept of resilience can be challenging across different areas and sectors, and for policymakers. This section introduces a practical approach that applies resilience thinking to strengthen policymaking and the support provided by public institutions for sustainable development outcomes. This follows a three-step process: ${ }^{16}$

1. Identify the sources of existing and emerging risks to society

2. Map out the critical systems in society that these risks will affect, and establish who will be most vulnerable to the potential impacts of these risks

3. Formulate policy responses that can enhance specific resilience capacities.

Box 1.2 applies this approach to food systems. The analysis concludes that there are important potential trade-offs between policy measures that increase economic efficiency and those that may be necessary to safeguard resilience. It highlights the need to pay greater attention to the resilience of these systems through diversifying food supply sources, and the ways in which resilience thinking can inform future public policy. 


\section{Box 1.1 Bouncing back better: Resilience and transformation}

The relevance of the concept of resilience is illustrated in theoretical terms in Figure 1.2, which compares the development pathways of country A and country B. Initially, country A was on course to attain its SDG targets by 2030, while country B was following a pathway on which the SDGs were unachievable by 2030.

Both countries experienced shocks in year ' $\mathrm{t}_{1}$ ' and their differing resilience capacities meant they responded differently to this shock. Country A bounced back to its original development trajectory, meaning the SDGs were still attainable by 2030. Country $B$, on the other hand, utilized its transformative capacity to undertake systemic changes, moving to a new development trajectory that meant the SDGs were now attainable by 2030.

Hence, systemic transformations in response to shocks can bring countries closer to realizing their SDG targets. Such transformations include a fundamental shift to renewable energy sources; societal reorganization that leads to greater female participation in decision-making; and economic structural transformation away from an extractive industry-based economy to one that is driven by services and higher value-added industries.

Figure 1.2 Sustainable development pathways and resilience

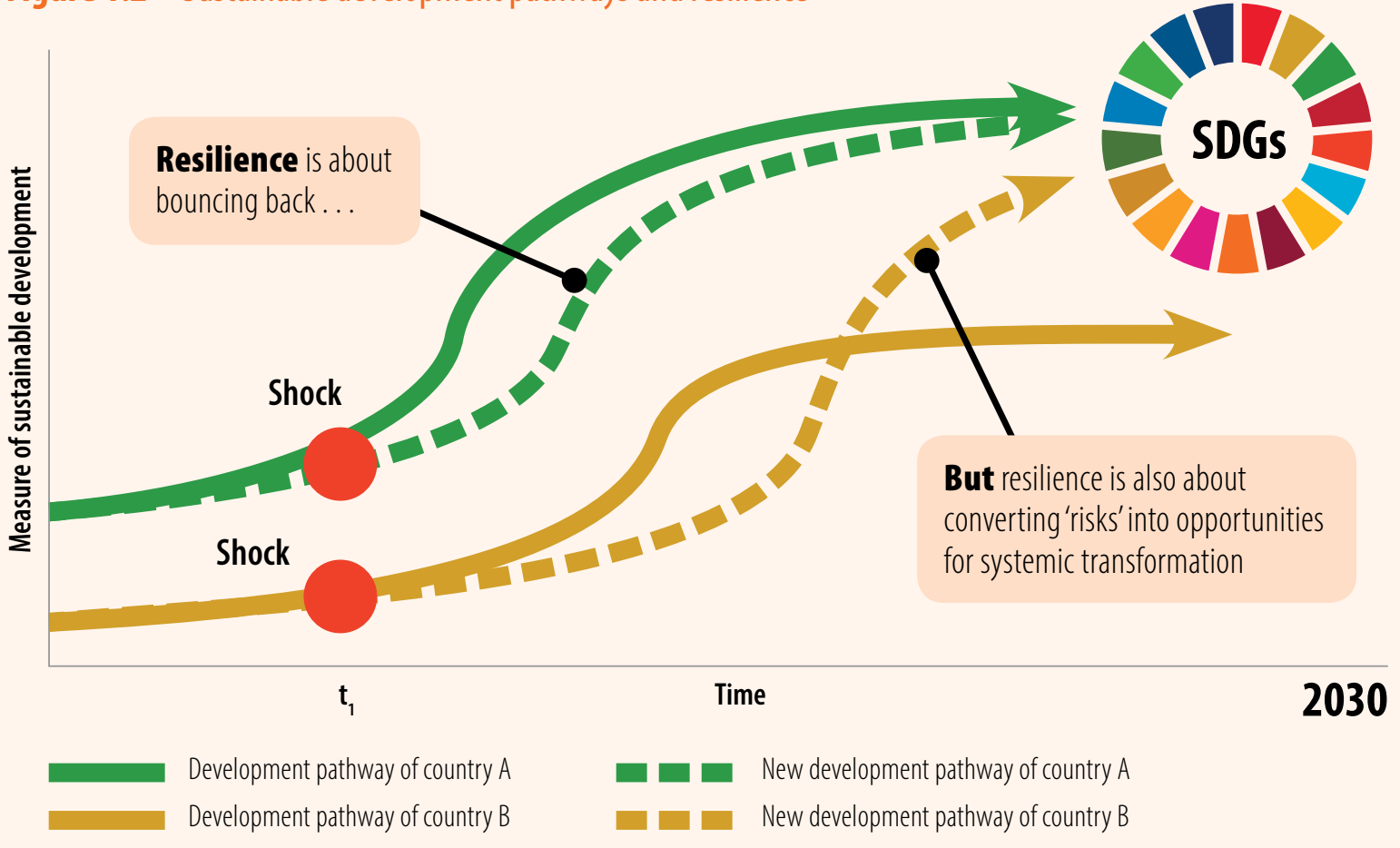

Source: Author's illustration

\subsection{Conclusions}

This chapter proposes an approach to addressing resilience in policymaking for the 2030 Agenda. Resilience thinking, informed by an assessment of risk, understanding of potential impacts, and risk-informed response efforts, can support better policymaking. The following chapters explore each stage of this approach. Chapter 2 explores steps 1 and 2, taking stock of emerging sources of risk in the Asia-Pacific region and assessing the impacts of various types of recurrent shocks on its human systems, with a focus on the most vulnerable groups in society. 


\section{Box 1.2 Applying a resilience-thinking approach to food systems}

\section{Step 1. What are the drivers of risk to regional food systems?}

Food systems, especially in the low-income countries in the Asia-Pacific region, are increasingly vulnerable to climate change, as well as to demographic change-induced risks. For example, climate change is expected to reduce yields and increase the cost of staple foods. ${ }^{17}$

Figure 1.3 plots the vulnerability of food systems in Asia-Pacific countries to climate change, alongside gross domestic product (GDP) per capita. This shows that the countries that are least prepared to face economic risks also have food systems that are most vulnerable to climate change. ${ }^{18}$

\section{Figure 1.3 Food system vulnerability and economic development}

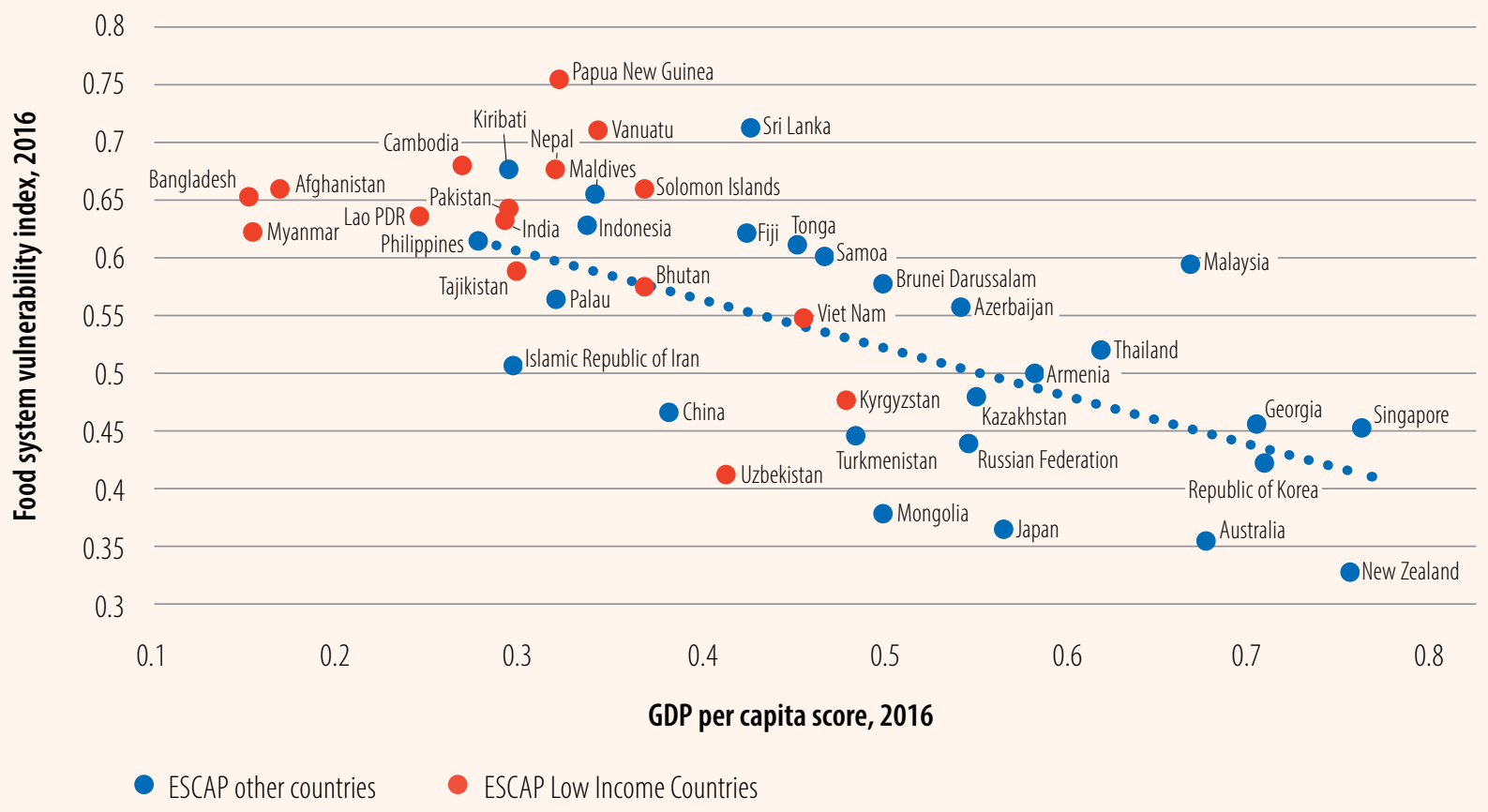

Source: ESCAP calculation, using data from the University of Notre Dame Global Adaptation Index Dataset (2016), https://gain.nd.edu/ourwork/country-index. See http://data.unescap.org/escap_stat/\#methodDefinition for the full list of ESCAP income groupings

\section{Step 2. How do these drivers impact the food system and who are most vulnerable?}

Trade systems are integral to regional food systems. Global trade in commodities is increasingly essential for food security, helping countries to diversify their nutritional base, maintain supplies, stabilize prices and provide alternative food options in times of shortage - an increasingly urgent issue, as factors such as climate change and population growth affect local production and availability. The use of global trade networks for food sourcing is so widespread that around 80 per cent of people now live in net food-importing countries. ${ }^{19}$

Analysis of the resilience of staple food commodity trade networks in the Asia-Pacific region between 1986 and $2015^{20}$ revealed that 73 per cent of these networks showed signs of weakening resilience or lowering redundancy. In other words, countries are becoming more reliant on fewer countries for their food imports. ${ }^{21}$ With this growing dependency on a limited number of suppliers, ${ }^{22}$ countries' vulnerability to supply disruptions may be increased, and they have fewer options to ensure an adequate and timely supply of food when disruptions in trade occur, whether due to political factors, natural 


\section{Box 1.2 Continued}

hazards, transport links or other factors. ${ }^{23}$ Furthermore, as trade networks become more efficient, they may become less resilient to natural and economic shocks, since a shock in one part of the system can be transmitted to the entire network.

The combination of increasing vulnerability and reduced resilience within food systems points to an increasing risk of food supply disruptions, including through food price fluctuations. It highlights important potential trade-offs between policy measures that increase economic efficiency and those that safeguard resilience. This has important implications for the region. For example, the food price shocks of 2007-2008 increased the depth of poverty in rural areas and led to higher rates of malnutrition. ${ }^{24} \mathrm{~A}$ repeat of this could undermine the ability of the region to meet several targets of the 2030 Agenda. For example, climate change and resulting food shortages have the potential to increase the number of malnourished children in South Asia by 7 million. ${ }^{25}$ These vulnerable groups and communities should be identified early on, and it is vital that they are placed at the core of society's efforts to strengthen resilience, in order to achieve the central aspiration of the 2030 Agenda - to leave no one behind.

\section{Step 3. How can we strengthen resilience capacities to address emerging risks?}

This analysis can inform the policy responses required to build the resilience capacities of food systems in the region. Analysis of the resilience characteristics of networks can help to identify potential policy solutions by revealing the systemlevel network configurations that affect resilience to potential shocks and disturbances.

- Anticipatory capacity: the region needs to closely monitor the emerging effects of climate change on its key food production areas. It is important to convey early on any climate anomalies, including variations in weather patterns, that can undermine the production potential of the main agricultural areas of the region. More research is needed to simulate and quantify the impacts of shocks on critical commodity networks.

- Absorptive capacity: community- or national-level food stocks can be created to tide over any unexpected food shortages.

- Adaptive capacity: plans related to national agriculture (including cropping patterns and the mix of inputs) and food security, as well as climate change strategies, need to reflect these potential impacts, particularly in the food production areas that are most vulnerable to climate change.

- Transformative capacity: one important lesson from the earlier analyses is that the trade networks that support the provision of food in the region are showing signs of weakening resilience. Countries need to deliberate jointly on how to integrate strategic provisions within trade agreements, especially preferential trade agreements, to increase the resilience of trade networks for critical commodities.

Sources: Author's compilation, using data from Kharrazi, 2018, and the University of Notre Dame Global Adaptation Index Dataset, 2016 



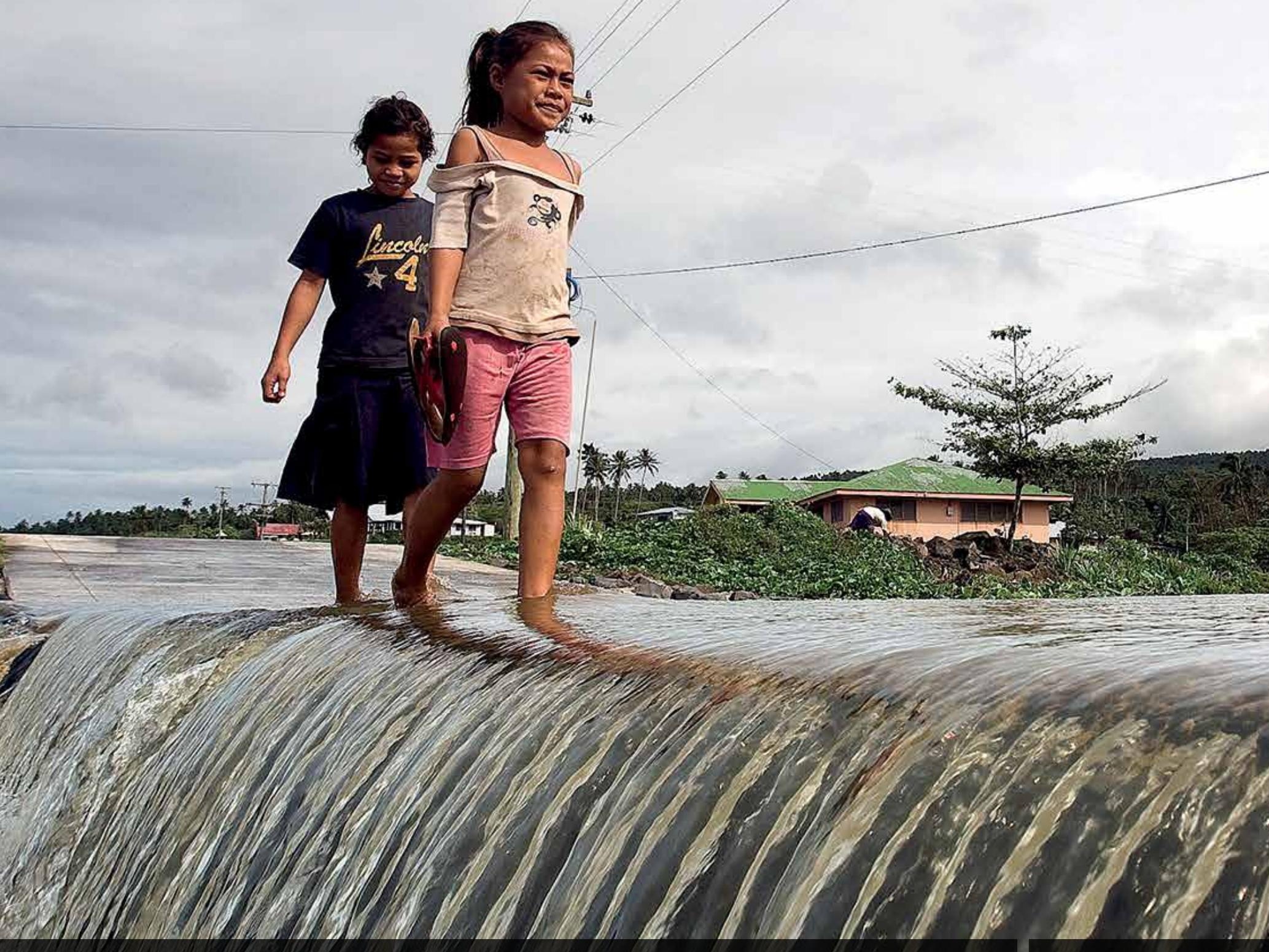

\section{Understanding risk: What are the sources of emerging risk in the Asia-Pacific region, and what are their impacts?}

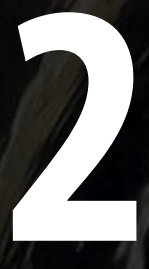




\subsection{Introduction}

The Asia-Pacific region faces many sources of risk, both exogenous and endogenous. Several trends are reshaping the region, including demographic change, rural-urban transitions, increasing demand for natural resources, globalization and economic liberalization, climate change and technological progress. These trends, which have been explored in previous reports on the SDGs by ESCAP, ADB and United Nations Development Programme (UNDP), often manifest slowly. They can create important opportunities for countries to make progress towards the SDGs, but also increase and complicate some of the risks facing the region. For example, economic and financial volatility have been drivers of the global economic system since the 1980s. This underlying volatility has led to shocks, in the form of economic crises in Asia in 1997 and globally in 2008.

There are many other shocks and stresses affecting the region, including political and security-related risks that have had severe effects in many countries. The shocks analysed in this report illustrate the diverse range of challenges to which the Asia-Pacific region must build its resilience. Strengthened governance and efforts to build peace in the context of SDG 16 play a vital role in strengthening resilience in the region.

Furthermore, risks can play out at various levels: they can affect individuals, businesses, households and communities, all the way up to nation states and regional communities. Countries have varying abilities to cope with such shocks, to adapt to future crises, or to transform their institutions to reduce their vulnerability. While societies also face risks from other sources, the ability of these trends to escalate risk is the focus of this report, due to their universal nature and potential scale.

This chapter examines the first two steps of the analytical framework introduced in Chapter 1. It explores some emerging sources of risks in the region, quantifies their impacts on critical human systems and identifies some of the groups in societies that will be disproportionately affected.

\subsection{What are the sources of risk affecting human systems?}

The interaction of various trends and the risks created for human systems were considered during a series of subregional consultations, held to prepare for the Asia-Pacific region's dialogue on the theme of the 2018 High-level Political Forum on Sustainable Development.
During the consultations, stakeholders discussed how to anticipate and deal with these risks. Table 2.1 summarizes these insights.

The consultations highlighted that while the most resonant trends and the exact nature of risks identified differed across subregions, there were several commonalities. This suggests that there is great scope for mutual learning within the region, which will further promote resilience.

Stakeholders also highlighted the interlinked and reinforcing nature of the risks posed by various trends on these critical human systems. Figure 2.1 highlights these links, drawing on a risk assessment conducted by the World Economic Forum (WEF) in 2018. ${ }^{26}$ This was conducted through the annual Global Risks Perception Survey, with respondents drawn from the global multi-stakeholder community. Survey respondents were asked to identify three to six pairs of global risks that they believed to be the most interconnected. The analysis of this highlights the variety of emerging risks that face the world, and their interlinked and reinforcing nature. ${ }^{27}$

\subsection{Which groups are most at risk of being left behind?}

While the trends identified in this chapter and their associated risks are likely to affect all people and systems in some way, the degree of impact will differ across regions and across layers of society. Some groups or communities are disproportionately exposed to risks and are more vulnerable to the changing risk profile of the Asia-Pacific region. It is vital, therefore, to identify vulnerable groups and make special efforts to strengthen their resilience. Table 2.2 provides some examples of at-risk groups identified during the subregional consultations.

The people who are most exposed to complex risks are often found in the intersections of these groups. For example, an elderly, unskilled urban migrant is highly unlikely to be able to respond adequately to the confluence of challenges posed by climate change, pollution and technological changes.

Identifying those at risk helps policymakers and other stakeholders to adopt targeted response measures. As an example, Japan has taken proactive steps to respond to the needs of its ageing society (see Box 2.1). Yet while there are many encouraging signs across the region, there is a need to continue to invest in transformative capacities to deal with the scale of the challenges presented across human systems. 


\section{Table 2.1 Subregional perspectives on the risks that critical human systems face from selected drivers of change}

\begin{tabular}{|c|c|c|}
\hline $\begin{array}{l}\text { Subregion } \\
\text { East and North-East Asia }\end{array}$ & $\begin{array}{l}\text { Trend } \\
\text { Demographic change }\end{array}$ & $\begin{array}{l}\text { Human systems affected } \\
\text { Social, financial }\end{array}$ \\
\hline \multicolumn{3}{|l|}{ Risks } \\
\hline \multicolumn{3}{|c|}{$\begin{array}{l}\text { Stakeholders highlighted the impacts of demographic changes, especially ageing. This is placing an increasing strain on the } \\
\text { subregion's social systems (e.g. health care, social security) as many societies lack sufficient resources to care and provide for } \\
\text { the elderly. Rapid ageing is also putting the financial system at risk, as the viability of pension systems is increasingly being } \\
\text { undermined as the ratio of pensioners to working-age people declines rapidly. }\end{array}$} \\
\hline Subregion & rend & Human systems affected \\
\hline North and $\mathrm{Ce}$ & $n$ & \\
\hline \multicolumn{3}{|l|}{ Risks } \\
\hline \multicolumn{3}{|c|}{$\begin{array}{l}\text { The impacts of rural-urban transitions, notably the migration of young people to cities, are linked to the resulting demand } \\
\text { for infrastructure. Where young people face unemployment, or precarious and informal work situations, they are not able } \\
\text { to contribute financially to a city's economy; this was seen as a risk to the financial system. At the same time, declines in the } \\
\text { agricultural labour force are having negative impacts on this sector, and declines in productivity brought about by the lack } \\
\text { of labour will potentially affect value chains across the subregion. }\end{array}$} \\
\hline
\end{tabular}

\begin{tabular}{l|l|l}
$\begin{array}{l}\text { Subregion } \\
\text { South-East Asia }\end{array}$ & $\begin{array}{l}\text { Trend } \\
\text { Increasing demand for natural resources }\end{array}$ & $\begin{array}{l}\text { Human systems affected } \\
\text { Environmental, social, economic }\end{array}$ \\
\hline
\end{tabular}

\section{Risks}

Increasing pollution, fuelled by the growing consumption of natural resources, is a reality in this subregion. The threat posed by mounting plastic waste, and recurrent episodes of cross-border haze from forest fires, were both raised by stakeholders. These threaten the environmental system, affect provisioning systems, and have damaging impacts on people's health. Increasing haze and pollution also affect the economic system, causing economic damage and reducing economic productivity.

\begin{tabular}{|c|c|c|}
\hline $\begin{array}{l}\text { Subregion } \\
\text { South and South-West Asia }\end{array}$ & $\begin{array}{l}\text { Trend } \\
\text { Climate change }\end{array}$ & $\begin{array}{l}\text { Human systems affected } \\
\text { Provisioning, social, economic }\end{array}$ \\
\hline \multicolumn{3}{|c|}{$\begin{array}{l}\text { Risks } \\
\text { The impacts of a changing climate on provisioning systems, notably food and water, and social systems were seen as potential } \\
\text { causes of social conflict and security risks. These risks could become more severe, given the existing tensions over sharing water } \\
\text { resources between countries and the high likelihood of cross-border mass migration caused by climate change. }\end{array}$} \\
\hline $\begin{array}{l}\text { Subregion } \\
\text { Pacific }\end{array}$ & $\begin{array}{l}\text { Trend } \\
\text { Globalization and economic liberalization }\end{array}$ & $\begin{array}{l}\text { Human systems affected } \\
\text { Social, economic, cultural }\end{array}$ \\
\hline \multicolumn{3}{|c|}{$\begin{array}{l}\text { Risks } \\
\text { Increasing globalization, including trade liberalisation, has led to an increased availability of cheaper, unhealthy food in the } \\
\text { Pacific islands, resulting in changes to dietary patterns. These changes have led to an alarming rise in non-communicable } \\
\text { diseases in the region. }{ }^{28} \text { This has increased the pressure on the health system, affected the economic system (due to reduced } \\
\text { human productivity and household financial stability) and reduced the overall well-being of the population. Increased cross- } \\
\text { cultural flows, which are promoted by globalization, are also threatening the region's unique culture and identity. }\end{array}$} \\
\hline
\end{tabular}

\subsection{Assessing risk impacts: The vulnerabilities of human systems in the Asia-Pacific region}

The changing nature of risk in the Asia-Pacific region is reshaping the challenge of creating resilient, sustainable societies. This section explores the second step of the approach described in Chapter 1 - mapping out the critical systems in society that these risks will affect, and establishing who will be most vulnerable to the potential impacts of these risks - by looking more closely at three recurrent shocks to human settlements and economic and environmental systems. 


\section{Figure 2.1 Risk interconnection map}

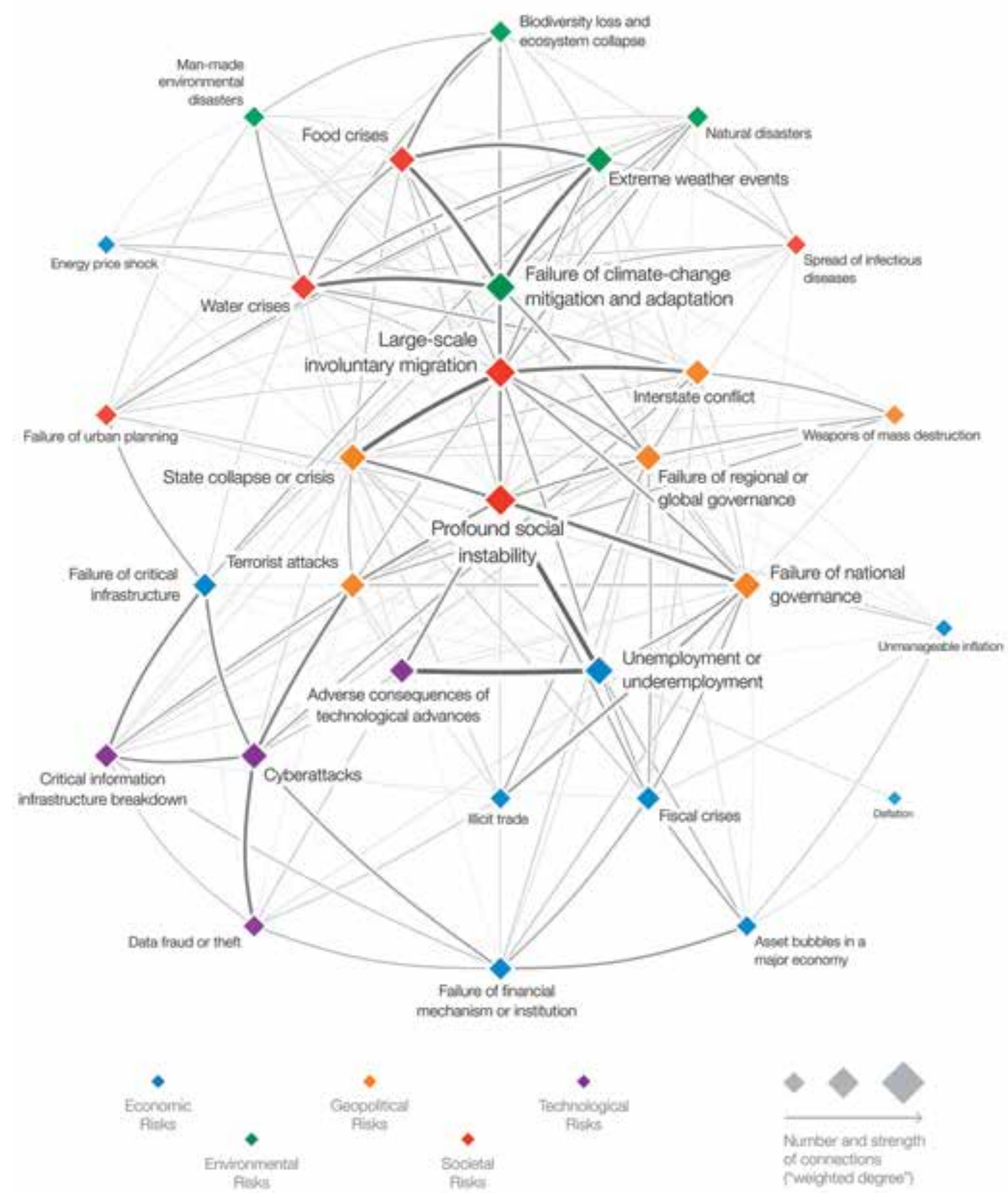

Source:WEF, 2018

First, given the emphasis on resilience to disasters in the SDGs, it reviews the impacts of flooding, with a focus on South and South-West Asia. ${ }^{29}$ Second, it considers the effects of commodity shocks, with a focus on recent oil price fluctuations in Central Asia. Third, it considers the effects of pollution, with a focus on recurrent air pollution and haze caused by forest fires in South-East Asia.
All three of these shocks can disrupt and even reverse progress towards the SDGs. While they cannot be fully eliminated, evidence suggests there is scope to substantially reduce and mitigate their effects by building up societies' resilience capacities. These issues are of relevance to all subregions of the Asia-Pacific region, although the specific vulnerabilities and resilience strategies vary. 
Table 2.2 Groups identified as being extremely vulnerable to risk

\begin{tabular}{|l|l|}
\hline $\begin{array}{l}\text { Vulnerable group } \\
\text { Elderly people }\end{array}$ & $\begin{array}{l}\text { As the proportion of elderly people in societies increases, social security and health systems } \\
\text { become stressed and could become unable to meet this group's needs adequately. The } \\
\text { migration of the working-age population to urban areas reduces the support system available } \\
\text { for the elderly, especially in rural areas, while changing societal values further reduce the level } \\
\text { of care available. These factors make elderly people vulnerable to many emerging risks. }\end{array}$ \\
\hline $\begin{array}{l}\text { Indigenous } \\
\text { populations }\end{array}$ & $\begin{array}{l}\text { Increasing demands for natural resources are leading to an increased risk of indigenous } \\
\text { communities being displaced from their ancestral lands, their culture threatened, or their } \\
\text { lands being polluted. }\end{array}$ \\
\hline Urban migrants & $\begin{array}{l}\text { Urban migrants, especially those working in the informal sector, are more exposed to the } \\
\text { impacts of climate change, as their homes - often informal settlements - tend to be in areas } \\
\text { more vulnerable to climate change. }\end{array}$ \\
\hline $\begin{array}{l}\text { People with } \\
\text { disabilities }\end{array}$ & $\begin{array}{l}\text { This group faces a higher risk of being left behind than others, in part due to the lack of basic } \\
\text { infrastructure, especially in the face of climate change-induced disasters triggered by natural } \\
\text { hazards. The interplay of disability and ageing complicates the situation further. }\end{array}$ \\
\hline Working-age women & $\begin{array}{l}\text { In many countries, social norms expect women to be the caregivers in households. With many } \\
\text { populations ageing, working-age women are likely to have to bear additional responsibilities } \\
\text { by taking care of the elderly. This reduces their time to engage in formal employment. }\end{array}$ \\
\hline Unskilled youth & $\begin{array}{l}\text { Young people in many countries are finding it extremely difficult to find gainful employment } \\
\text { that matches their aspirations and enables them to contribute meaningfully to society. }\end{array}$ \\
\hline
\end{tabular}

Source: Subregional consultations

\section{Flooding}

While the effects of climate change will be felt globally, the Asia-Pacific region will be especially affected, particularly by hydro-meteorological hazards. One of most pervasive recurrent shocks affecting the region in recent years has been flooding. South Asia in particular has suffered greatly: between 1970 and 2016, some 35 per cent of floods in the region occurred here, with devastating effects on people across this subregion. There were considerable financial losses in the subregion, as Figure 2.2 shows, but also major losses of life and impacts on people's well-being. ${ }^{30}$

As Figure 2.3 shows, the monsoon rains in 2017 claimed an estimated 1,200 lives in South Asia, and affected 40 million people across Bangladesh, India and Nepal. ${ }^{31}$ The resulting floods damaged and destroyed homes, schools and health facilities, while many areas became inaccessible due to damage to hundreds of kilometres of roads and railways, as well as bridges and airports. ${ }^{32}$ The floods also brought several major cities to a standstill (see Box 2.2). The total costs of the 2017 monsoon season in South Asia were estimated to be around $\$ 1.2$ billion. ${ }^{33}$

\section{Planning for a future with a higher risk of extreme events}

Flooding events in parts of the Asia-Pacific region are likely to increase in the future. Models and scenarios predict a rise in heavy and extreme precipitation events during annual monsoons, which fall from June to September, in East and South Asia. This will exacerbate economic impacts - by some estimates, floods could cost the subregion as much as $\$ 215$ billion each year by $2030^{34}$ - as well as human impacts. Extreme events such as more intense flooding and more severe droughts will be compounded by risk factors associated with rapid urbanization and coastal development, which increase exposure and vulnerability to these hazards. ${ }^{35}$ Women are often disproportionately affected by such events, including in their aftermath.

The relationships between the various factors that are likely to influence resilience, and the severity of flood and storm impacts (in terms of mortality rates, economic damage and affected populations, among other indicators) were explored for this report. This analysis revealed several policy-relevant insights. 


\section{Box 2.1 Resilience and public policy in an ageing society}

Based on its 1947 constitution, Japan's social security systems were instituted to be provided through public assistance and social insurance, which would protect individuals and households through health care, pensions and long-term care. Japan's demographic dividend started in the early 1930s, with the birth of the first 'baby-boomer' generation. This generation reached working age between 1960 and 1965, and contributed to social security systems through compulsory or taxedbased payments. Despite the economic slowdown in the 1980s, Japan's social security systems continued to be relatively successful, relying on its strong financial, social and human capital base.

By the late 1980s, however, Japan had one of the world's highest life expectancies and an ageing demographic. Concerns grew over the fiscal sustainability of the social security system, due in part to the breakdown of the tradition of informal caregiving by family members. By 2030 , the second baby-boomers will be elderly - one in three people will be over 65 , while one in five will be over 75 - which, combined with the already declining fertility, will lead to an ageing society. In anticipation of this, in 1989 the government prepared a 10-year strategic plan for the development of health and welfare services for the elderly; this was revised in 1994 and 1999.

In recent years, stresses on social security systems in Japan have evolved in unexpected directions. There has been an increase in crimes committed by elderly persons living in poverty, while families' resources have become increasingly stretched as they support elderly members. Given the increased participation of women in the workforce (among other factors), families were finding their responsibility to care for the elderly more difficult, with reports of neglect becoming more commonplace. Furthermore, Japanese society began to experience a phenomenon known as 'social hospitalization', where elderly persons were being admitted to hospitals not for medical reasons, but because they could not be looked after elsewhere.

As the need to provide care for the elderly continued to grow, the challenges of ageing became a focus of national dialogue and policymaking. Through this, social security systems became more open to innovation and experimentation. Public policy innovations included: efforts to address the stigma associated with traditional family roles in the provision of social care; the introduction of both premium and tax-based long-term care insurance systems (in 2000); the introduction of schemes to attract skilled migrants (in 2012); and investments in outreach and community-based support systems. In 2017, reforms were made to the pension system to bolster its financial security. Other options still under debate include more pro-natalist policies, the introduction of robotics and automation to supplant the labour shortage, and a rethinking of migration policies.

Together, these approaches may ensure that the social security needs of all generations can be met for the foreseeable future. At the same time, a close watch may be needed on whether more transformative approaches will eventually be required. What is certain, however, is that Japan is at the forefront of nations in terms of building resilience in an ageing society, and offers valuable lessons for other countries regarding how effective public policy can address these challenges.

Source: Ali Kharrazi, International Institute for Applied Systems Analysis (IIASA) and University of Tokyo

\section{Figure 2.2 Annual damage from floods in South Asia, 1970-2016}

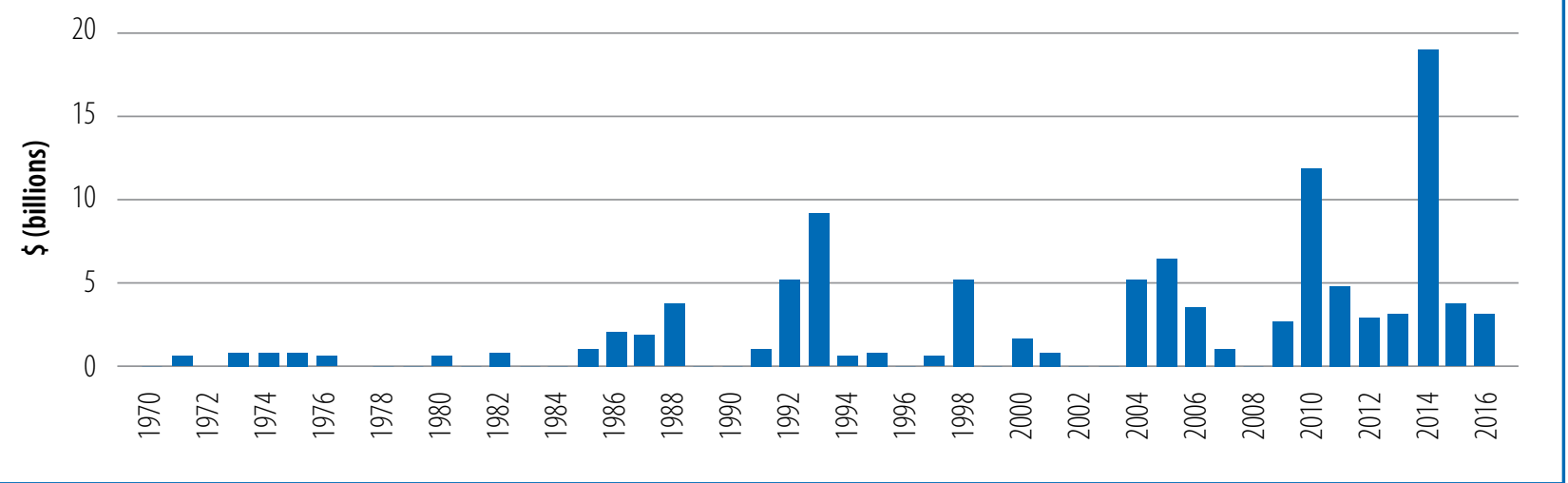

Source: EM-DAT, www.emdat.be

Note: South Asia includes Afghanistan, Bangladesh, Bhutan, India, Islamic Republic of Iran, Maldives, Nepal, Pakistan and Sri Lanka 


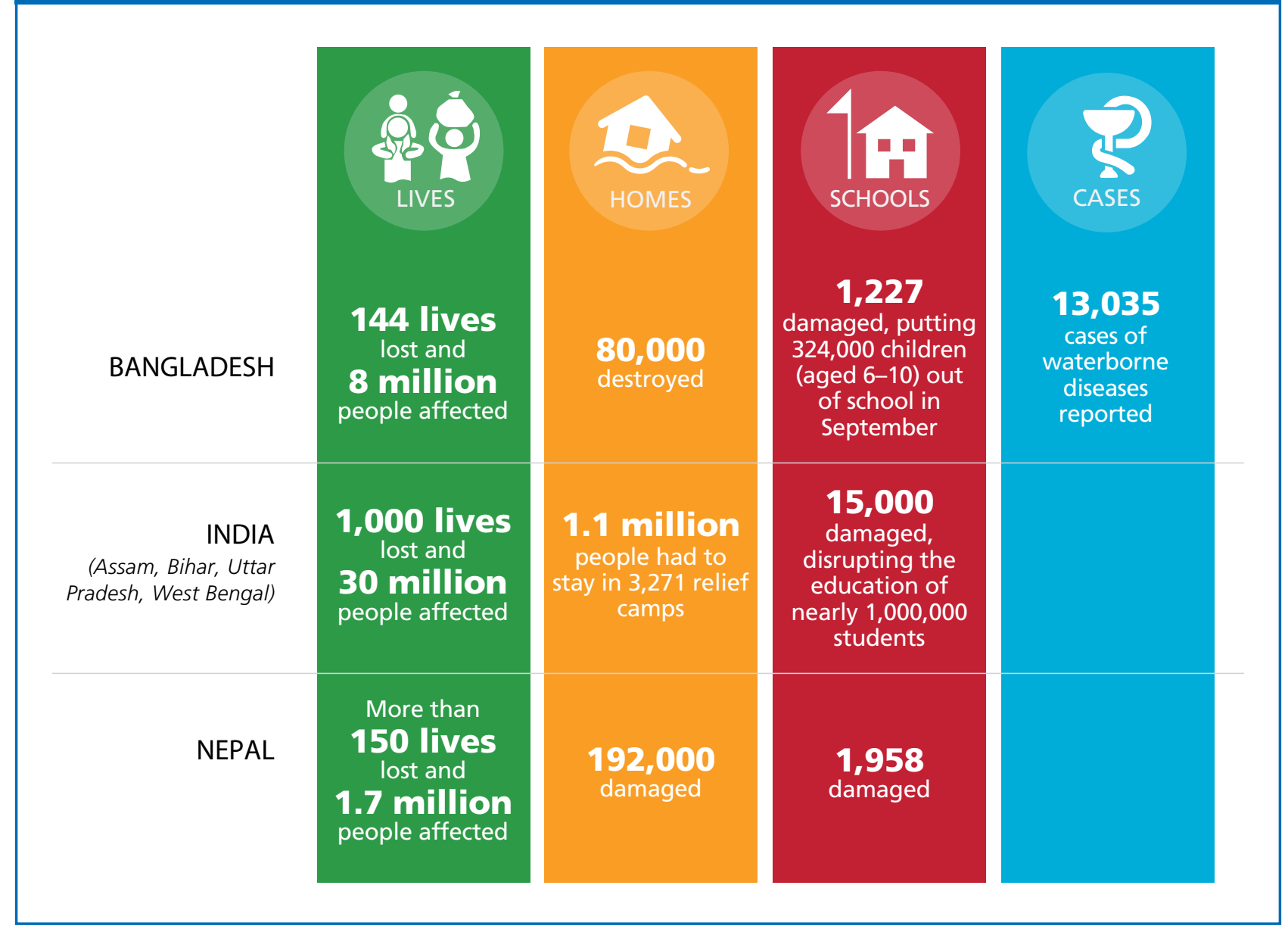

Sources: OCHA, 2017; Save the Children, 2017; UNICEF, 2017

Access to high-quality infrastructure is closely linked to the lower impacts from flooding events. Infrastructure can help build the absorptive and adaptive capacities of flood-affected communities. To do so effectively, infrastructure must be planned, designed, constructed and maintained with due consideration of current and future hazards, taking a systems approach. For example, access to electricity is negatively correlated with flood mortality rates, while the percentage of paved roads is negatively correlated with the number of people affected by floods and storms. These links are well recognized in wider studies on global risk. ${ }^{36}$ Secondary and cascading effects from infrastructure failures often occur: for example, in the aftermath of cyclone Aila in India, access to safe drinking water was substantially reduced. Inadequate infrastructure can also limit access routes for disaster response efforts and evacuations. ${ }^{37}$

Given the rapid rates of urbanization in the Asia-Pacific region, investment decisions that increase the resilience of urban infrastructure can have significant effects. There is a need to focus on the most vulnerable people within urban areas affected by flooding. Our analysis shows that higher mortality rates in flooding events are positively correlated with the percentage of the urban population living in slums. This highlights the imperative to find more inclusive approaches to urban development, ensuring access to finance, livelihoods and decision-making within cities.

Access to infrastructure services tends to be lowest in the poorest countries in the region, and for the poorest people within countries. For example, road coverage is likely to be provided for economic centres and richer neighbourhoods first. This reinforces the critical need to invest in more resilient infrastructure services for everyone across the AsiaPacific region, and to strengthen the resilience of existing critical infrastructure, in order to reduce the losses currently caused by flooding.

To achieve this, governments and associated stakeholders need to identify the critical infrastructure in their country, 
The effects of the August 2017 floods on Mumbai, India's richest city, highlighted the devastation that natural hazards can cause. The city received more than 300 millimetres of rainfall in 12 hours on 29 August, the heaviest rainfall since 26 July 2005, when 944 millimetres fell. This caused widespread impacts on Mumbai's people, transport systems and other infrastructure. The damage caused by flooding also took a significant toll in financial terms, with economic losses estimated to be more than $\$ 500$ million.

Mumbai was not completely unprepared for this event. In 2009, India adopted national guidelines on urban flood management, which were informed by the findings of a committee set up after the 2005 floods. Although the implementation of these guidelines was slow, there were some improvements to Mumbai's capacity to cope. For example, new pumping stations were installed, albeit on a delayed timeline.

However, these measures were insufficient to alleviate the impacts of the 2017 floods, and citizens had to find new ways to cope. Social networks and civil society organizations (e.g. religious groups) across the city were instrumental in this. For example, people used social media to offer support to those in need and created groups to help people access shelter and clothing. This support did not, however, reach the poorest people, such as slum dwellers and homeless people.

The need to take comprehensive measures to strengthen Mumbai's preparedness for, and resilience to, future flooding events remains paramount. Stakeholders have stressed the need to look beyond engineering solutions - although these will have a vital role to play - and pursue urban planning that allows for a greater role for green spaces and nature-based solutions. For example, policymakers must address the loss of protective mangroves, coastal wetlands and flood plains, which has reduced the region's natural ability to deal with floods by absorbing and storing water during heavy rainfall events.

Sources: AIDMI, 2017; Aon Benfield, 2017; Hallegatte and others, 2017; Joshi, 2017

assess its vulnerabilities, and take measures to increase its resilience. Proposed infrastructure investments need to be informed by spatial analyses of disaster and climate risks that provide information on location-specific exposure and vulnerabilities, as well as the proposed infrastructure's integration with existing infrastructure and overall urban or rural development. A greater focus on green solutions is needed, recognizing that ecosystems often provide vital services for local resilience.

The analysis also suggests that deaths from floods are negatively correlated with higher literacy rates. A wide body of literature highlights the importance of education in strengthening human capacity when facing natural hazards or climate-related risks, and the positive effects of formal education on reducing vulnerabilities. ${ }^{38}$ Education can help to build anticipatory, adaptive and transformative capacities. It can also directly reduce vulnerability by improving people's cognitive and problem-solving skills, and increasing their knowledge and perception of risk. Indirect effects from education are linked to improved development outcomes, such as poverty reduction, better access to information and greater social capital.

Information is an important factor generally in increasing resilience. There is a broad consensus on the need to build anticipatory capacity by investing in systems to provide better information at multiple levels. Improved hydrometeorological systems and early warning systems for extreme events have been a focus, and many countries in the Asia-Pacific region have made significant investments in such capacities, which are slowly beginning to yield results. These are likely to be aided in the future by technological innovations, such as mobile phone technologies that can monitor and disseminate information about natural hazards, and 'big data' and geospatial technology to support efforts to prepare for and adapt to possible shocks.

Information is of course necessary, but insufficient on its own. It needs to be combined with an ability to access relevant information, interpret it and use it to make decisions. Here, the needs of vulnerable groups, particularly women, need particular attention, as do cultural considerations that may affect how people act on the information that they may be provided with.

These findings highlight the inextricable links between sustainable development and efforts to manage disaster risk and improve resilience. Natural hazards have a debilitating effect on efforts to achieve the SDGs, washing away hard-earned investments in basic services and infrastructure. However, effective investments in these services can strengthen resilience to major natural hazard events. 


\section{Commodity shocks}

The recent volatility in commodity prices has tested the resilience of food, financial and social systems in the Asia-Pacific region. While many countries have benefited from recent reductions in energy prices, countries that are heavily dependent on commodity exports have suffered. Research suggests that increased integration and dependence on exports over the past decade may have intensified vulnerability to external shocks in the region, ${ }^{39}$ as commodity dependence can place fiscal and monetary stress on countries, cause economic disruptions, and put pressures on balances of payments. ${ }^{40}$

Commodity price-related shocks can also have direct impacts on poor people. The effects of food price rises can be especially hard for producers and for poor consumers for whom food constitutes a significant share of their expenditure. For example, unprecedented food price spikes in 2007-2008 saw world cereal prices rise by as much as 87 per cent as global food stocks plummeted. Estimates suggest that these effects, coupled with the global economic recession, pushed 100 million more people into hunger. ${ }^{41}$ Fuel price fluctuations can also affect the costs of the goods and services on which poor people depend, for example by increasing the costs of food production, which in turn increases the costs of basic food commodities.

In addition to these financial and economic effects, there are issues related to environmental sustainability. Many countries that rely on commodity exports, especially those reliant on oil and related exports, have highly carbon-intensive economies. Efforts to support economic diversification to reduce exposure to shocks may bring substantial environmental benefits, if they prioritize the development of lower-carbon, more environmentally sustainable sectors and activities.

\section{Oil shocks in North and Central Asia}

Many Central Asian countries are highly dependent on natural resource exports such as minerals, natural gas and oil. For instance, fuel exports make up 92 per cent of Azerbaijan's merchandise exports and 70 per cent of Kazakhstan's. Figure 2.4 charts the fluctuation of oil prices and merchandise exports across the region between 2004 and 2017, highlighting the substantial effects of oil price fluctuations on economic conditions in Central Asia in comparison to other subregions.

When oil prices are high, exports rise in parallel. But when the price falls, so do exports - and Central Asia has felt these effects more than other subregions. This economic reliance on fossil fuels has created major financial challenges in recent years. In addition, it poses an obstacle to much needed action on climate change in the region, through the pursuit of lower carbon paths to development. In many countries, however, the shocks to oil prices in 2014 prompted important efforts to explore paths to greater economic diversification.

In the early 2000s, per capita incomes in many Central Asian countries more than doubled, largely in response to high global oil prices. Average incomes increased four-fold in Azerbaijan, and tripled in countries including Armenia and Turkmenistan. Another effect of this resource boom was that wages in resource-intensive economies increased, raising production costs and making it more difficult to shift to non-oil industries. By 2011, several countries were forced to confront the negative effects of rising energy prices, which peaked by 2012. These included food price inflation of more than 20 per cent in Georgia and Kyrgyzstan, and of 15 per cent in Armenia. Energy price inflation exceeded 30 per cent in Uzbekistan.

In 2014, Central Asia was hit by a different type of shock: the plummeting price of oil. Prices fell from $\$ 110$ a barrel in July 2014 to around $\$ 50$ a barrel in early 2015 . This had severe economic and financial impacts on most countries in the subregion. Figure 2.5 shows the effects of energy price fluctuations on the GDP of the four most oil-dependent countries in Central Asia. While not all Central Asian economies are energy exporters, energy importers such as Kyrgyzstan and Tajikistan are dependent on remittances, mostly from the Russian Federation. Since the Russian Federation is also reliant on fuel exports and revenues, reductions in oil prices led to declining remittances in non-energy-exporting countries in Central Asia. ${ }^{42}$

Budget revenues have declined since 2014 in most oildependent countries, and fiscal balances have deteriorated. ${ }^{43}$ The effects have been particularly severe in Azerbaijan (see Box 2.3). GDP growth loosely tracks the rises and falls in energy prices, except in Uzbekistan. The Government of Uzbekistan took measures to manage external shocks, including fiscal buffers to boost spending, and monetary policies to ensure credit for the private sector expanded. ${ }^{44}$

Negative changes in budget revenues and fiscal balances create pressure to constrain spending on social welfare, thus making them a highly relevant issue even in countries where average income levels are relatively high. The impacts seen in Central Asia have prompted concern, both within these countries and among the wider development community that supports them, about prospects for sustaining income levels and recent employment gains. The International Monetary Fund points out that youth unemployment declined in oil-exporting nations from 2002, but commodity price fluctuations have disrupted this positive trend and, in some countries, youth unemployment has again increased. ${ }^{45}$ 


\section{Figure 2.4 Crude oil price fluctuations and exports in subregions of the Asia-Pacific region, 2004-2017}

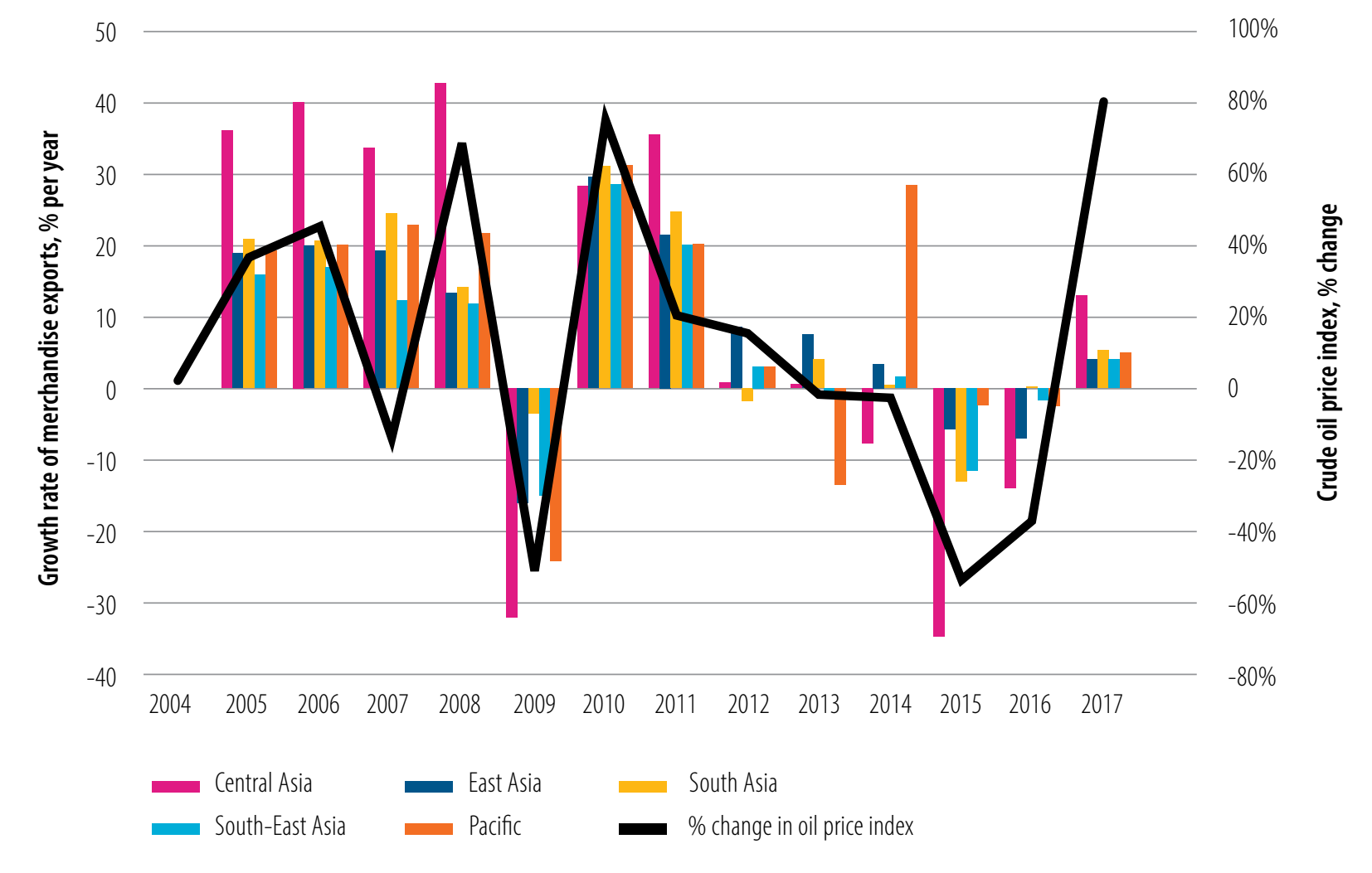

Sources: ADB's Asian Development Outlook (2010-2017) for export growth; IMF database on commodity prices for crude oil prices (petroleum), www.imf.org/external/np/res/commod/index.aspx

Notes:

- \% change of oil price index was computed year-on-year for January levels. Crude Oil Price index, $2005=100$, simple average of three spot prices: Dated Brent, West Texas Intermediate and Dubai Fateh

- For this figure, the following classifications apply: Central Asia (Afghanistan, Armenia, Azerbaijan, Georgia, Kazakhstan, Kyrgyzstan, Pakistan, Tajikistan, Turkmenistan and Uzbekistan); East Asia (China, Republic of Korea, and Mongolia); South Asia (Bangladesh, Bhutan, India, Maldives, Nepal and Sri Lanka); South-East Asia (Brunei Darussalam, Cambodia, Indonesia, Lao PDR, Malaysia, Myanmar, Philippines, Singapore, Thailand and Viet Nam); Pacific (Cook Islands, Fiji, Kiribati, Marshall Islands, Federated States of Micronesia, Nauru, Palau, Papua New Guinea, Samoa, Solomon Islands, Timor-Leste, Tonga, Tuvalu and Vanuatu)

Commodity shocks are not a new issue for countries in the Asia-Pacific region; they are a long-standing economic challenge. Nevertheless, these shocks have exposed Central Asia's financial vulnerability, and the need to strengthen the governance and operating frameworks for banks and financial institutions in the region. ${ }^{46}$ Encouragingly, there have already been considerable efforts to strengthen resilience to such shocks in the region. Anticipatory capacities have been strengthened through diverse global and national-level efforts, such as tools to track commodity prices and market conditions. Indeed, a major effort has been invested by both government and private sector actors in developing such tools (see Box 2.4).

Countries have sought to enhance both anticipatory and absorptive capacities related to the effects of commodity price fluctuations through fiscal and financial strategies, including countercyclical fiscal policy and stimulus programmes, cuts to interest rates and greater exchange-rate flexibility. ${ }^{47}$ Well-designed social protection programmes, with sufficient resources behind them, can also help. ${ }^{48}$ International financial institutions can and are playing an important role in helping countries to cope with this diversity of risks. For example, countercyclical lending windows can help cushion or mitigate the impacts of economic shocks.

Steps to build countries' adaptive capacity include modifying budget strategies and tax systems to better insulate them against the effects of commodity shocks, improve access to financial services for all segments of society (financial inclusion), and diversify the economy. 


\section{Figure 2.5 Energy prices and GDP growth in oil-exporting Central Asian countries, 1992-2016}

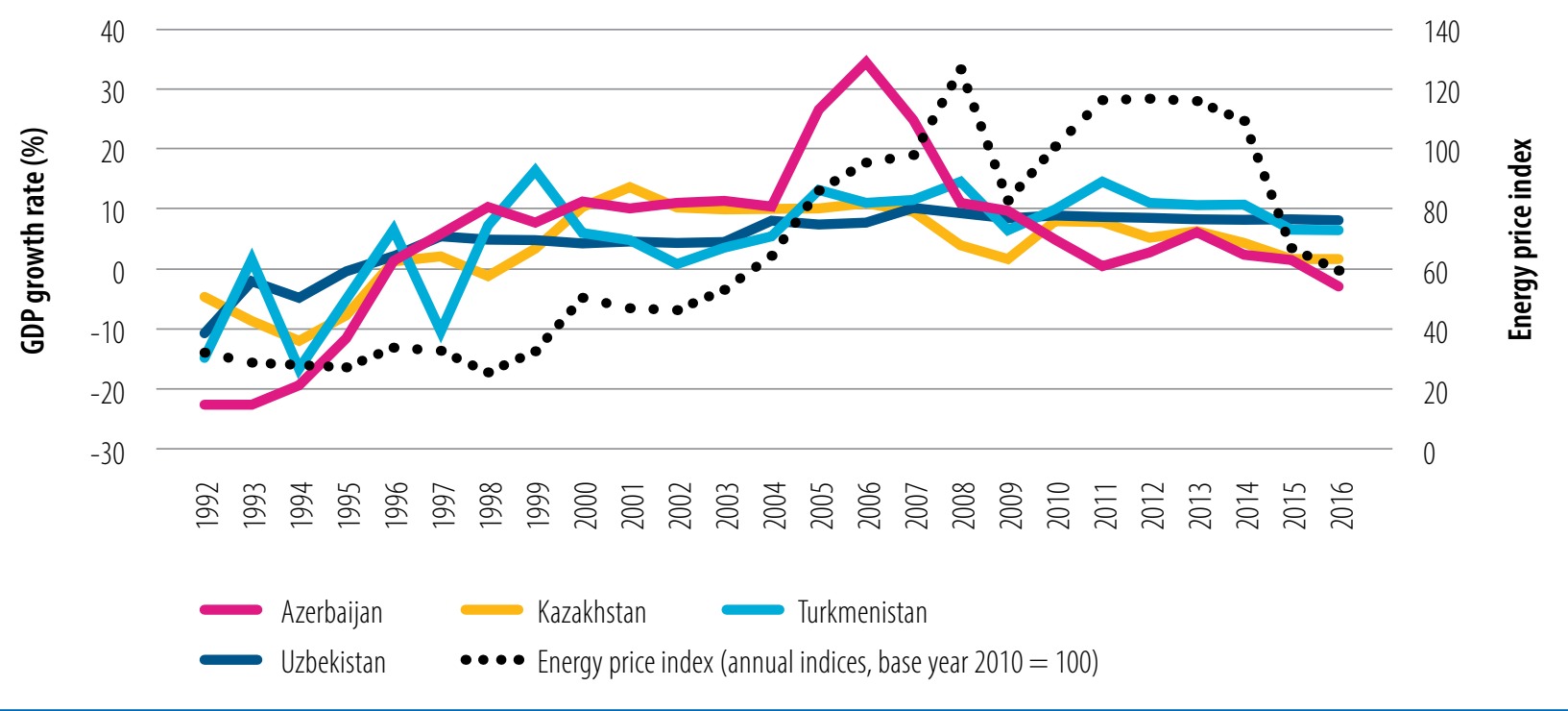

Source: World Development Indicators, http://databank.worldbank.org/data/databases/world-development-indicators; World Bank Commodity Price Data, http://databank.worldbank.org/data/databases/commodity-price-data

\section{Box 2.3 The effects of declining oil prices in Azerbaijan}

Oil comprises more than 90 per cent of Azerbaijan's exports, and energy price movements significantly affect the country's growth and trade. From 2008 to 2014, Azerbaijan enjoyed current account surpluses of at least $\$ 10$ billion each year. But energy prices started to decline, and the country suffered current account deficits in 2015 and 2016. The country's economic growth rate also shrank, from 6 per cent in 2013 to -3 per cent in 2016 (see Figure 2.5). Azerbaijan's total financial reserves moved with energy prices. From a peak of over \$15 billion in 2013-2014, these were down to \$6.5 billion in 2016.

Households are also affected by slumps in energy prices. Regression analysis conducted for this report suggests that for every 1 per cent change in crude oil prices, household expenditures change by 0.94 per cent. Similarly, for every percentage decrease in crude oil prices, food deficits per person increase by 1.53 per cent. Regression analyses show decreasing household expenditures for Kazakhstan, and increasing food deficits in Turkmenistan as oil and gas prices decrease.

Source: Authors'analysis, based on World Development Indicators and World Bank Commodity Price Data

There is, however, growing recognition of the need to focus on transformative capacity and approaches to deal with such shocks, and to take greater steps towards economic diversification. This also presents an opportunity to transform economies to be more environmentally sustainable. Several research and policy debates emphasize the need to invest in education and skills development to support greater innovation and economic diversification in the Asia-Pacific region. Spending on research and development is one indicator of the efforts of governments and the private sector to obtain competitive advantages in science, technology and knowledge, and the level of investment that a country is making in innovating for the future. ${ }^{49}$ However, in many commodity-dependent economies in the
Asia-Pacific region, general levels of spending on research and development are extremely low. These issues need addressing to capitalize on the opportunities presented by economic diversification to build resilience.

\section{Pollution}

Pollution has become a critically important development issue across the Asia-Pacific region, driven in large part by the paths to economic development that have been pursued across the region. Marine pollution is a major problem: in 2010 it was estimated that 4.8-12.7 million tonnes of plastic waste were dumped in the world's oceans, ${ }^{50}$ more than half of which entered from the coastal areas of China, Indonesia, the Philippines, Sri Lanka, Thailand and Viet Nam. 
Given the significance of commodity markets for economic development in countries all over the world, a wide range of public and private actors are involved in monitoring them. The monitoring and analysis of data (which vary by sector and commodity type) on price, demand and supply help these actors to anticipate and predict commodity shocks.

For example, a mix of public and private players monitor developments in oil markets very closely. The Joint Oil Data Initiative includes 90 countries and international organizations, representing about 90 per cent of global oil supply and demand, to provide comprehensive data on oil prices. Private companies such as Platts, Argus and ICIS also provide indepth data and market analysis on energy and petrochemical markets.

Stronger food price monitoring is essential, given its huge developmental significance in poorer countries. For example, the Food and Agriculture Organization of the United Nations system has invested significantly in data, market analysis and monitoring of physical fundamentals for food and other agricultural commodities. In addition, following the 2008 food price crisis, the Group of 20 launched the Agricultural Market Information System ${ }^{51}$ to enhance market transparency and reduce panic-driven price surges and the associated excessive volatility in prices.

Source: Fajarnes, 2011

Economic and environmental damage from plastic debris in the world's oceans has been estimated to cost $\$ 13$ billion a year. ${ }^{52}$ This includes the cost of clean-up operations and the drop in tourism revenues in coastal towns affected. The fishing industry is also affected by disruptions to ecological systems and damage to coral reefs. Microplastics ingested by marine wildlife can also be passed on to humans through the food chain. ${ }^{53}$ Freshwater, land, soil and chemical pollution and associated ecosystem protection are also significant challenges.

However, air pollution is perhaps the most pressing pollution issue for the region. In 2015, pollution ${ }^{54}$ caused an estimated 9 million premature deaths worldwide, equivalent to 16 per cent of all deaths, making pollution one of the most significant contributors to premature mortality. ${ }^{55}$ Air pollution was estimated to be responsible for 6.5 million of these deaths. With its fast-growing cities, the Asia-Pacific region is now home to 25 of the world's 30 most polluted cities in terms of particulate matter. ${ }^{56}$ Due to their vulnerability and lack of coping capacity, poor people, the elderly and the very young are disproportionately impacted by pollution exposure. Adults over 60 years of age suffer the largest number of pollution-related deaths. According to World Health Organization (WHO) estimates, a quarter of deaths of children under 5 years of age are due to pollution exposure..$^{57}$ Air pollution also has economic impacts. Welfare losses as a result of exposure to ambient and household air pollution are estimated to cost South Asia, South-East Asia and the Pacific the equivalent of about 7.5 per cent of their regional GDP.58

Events that lead to severe, concentrated pollution within a short period of time can be severe shocks to human systems.
For example, intense smog incapacitated New Delhi, India's capital city, in November 2017 (see Box 2.5), while recurrent transboundary smoke and haze in South-East Asia, caused by forest and peatland fires, have had severe social and economic effects in this subregion, affecting people in multiple countries.

\section{Forest and peatland fires in South-East Asia}

Deforestation and forest degradation are major issues for countries across the Asia-Pacific region, but the problem is particularly alarming in Indonesia, where more than 227,000 square kilometres - more than twice the size of the Republic of Korea - were lost between 2001 and 2016 (see Figure 2.7).

This trend is driven largely by the demand for natural resources from forests, and to clear land for producing food and other commodities; the burning of land to establish palm oil plantations is a key driver of deforestation in Indonesia. Much of this forest land is cleared using slashand-burn practices, as burning is still the cheapest way for businesses and farmers to clear land. This has further significant environmental impacts: South-East Asia is home to rich and biodiverse tropical rainforests, which are lost through these practices. Deforestation and forest degradation are also a leading source of greenhouse gas emissions from the region.

Indonesia also has the largest tropical peatland area in the world, most of which is in Sumatra and Kalimantan. Peatlands are easy targets for land conversion and acquisition, since they are uninhabited with no claims. Drained peatlands are also easy to burn. As a result, forest and peatland fires are exceptionally prevalent in Indonesia, where burning typically 


\section{Box 2.5 Air pollution shuts down New Delhi}

Air pollution is becoming increasingly serious in India, and debilitating smog in New Delhi during the winter months (November-February) is a recurring phenomenon. In November 2017, the city experienced an extremely severe shock from air pollution, with $\mathrm{PM}_{2.5}$ levels ${ }^{59}$ rising steeply (see Figure 2.6). Regular sources of ongoing pollution in the city - including industrial smoke stacks, hotels and restaurants using coal, vehicle emissions, and dust from construction and demolition sites - were compounded by seasonal events.

\section{Figure 2.6 $\quad \mathrm{PM}_{2.5}$ levels at New Delhi pollution monitoring stations, October-December 2017}

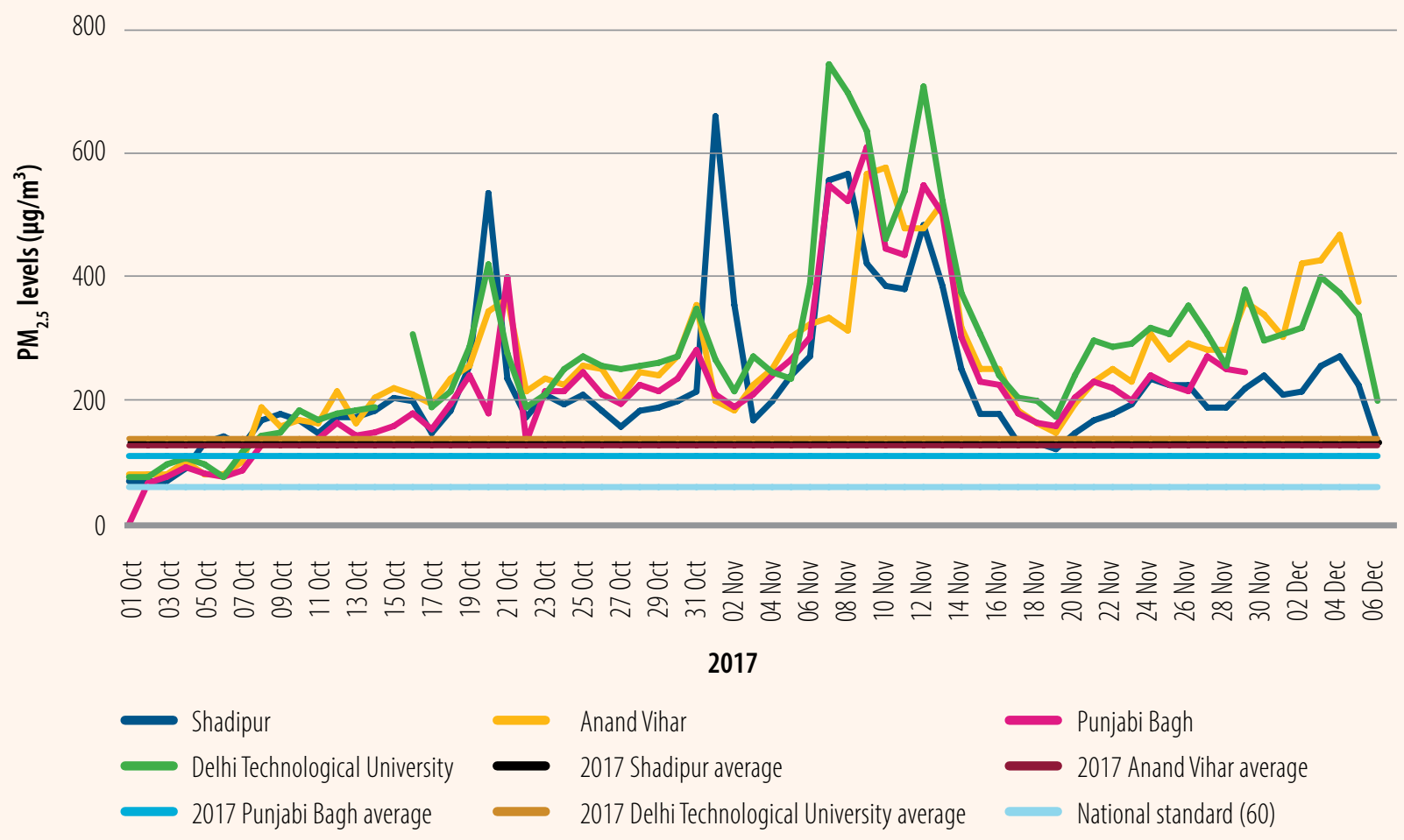

Source: Government of India Central Pollution Control Board, https://app.cpcbccr.com/ccr/\#/caaqm-dashboard-all/caaqm-landing

Farmers in nearby states were preparing their fields for planting by burning crop stubble; over a quarter of the particulate matter in New Delhi between October and November is attributed to the post-monsoon crop residue burning in neighbouring Punjab and Haryana states. Meanwhile, fireworks to celebrate the Diwali festival added to air pollution levels. Around this festival, levels of particulate matter nearly double and levels of potassium and barium can increase tenfold. ${ }^{60}$ Weather conditions further exacerbated the stress of these seasonal events in 2017, with cool dry air and slow winds trapping airborne pollutants.

The effects on everyday life were significant: for example, 4,000 schools had to be closed, affecting about 4 million students. At the height of the crisis, construction projects were suspended, trucks were banned in New Delhi, and a car-rationing scheme was put in place. Coal-fired power plants were also shut down. Even the sale of firecrackers during the Diwali festival was banned.

These emergency measures were inadequate, however, and underlying causes of this recurrent shock need to be addressed. These causes are well recognized, and were analysed in a report commissioned by the Department of Environment of the Government of New Delhi and the city's Pollution Control Committee. ${ }^{61}$ This report argued for a phased approach to address the multiple sources of pollutants affecting the city, starting with phasing out coal use in hotels and restaurants, and reducing the need to burn municipal solid waste by improving collection and disposal. Measures to reduce crop-residue burning, which is the cheapest way to clear fields in areas around the city, are also urgently needed.

Source: Sharma and Dikshit, 2016 
peaks between August and September, coinciding with the dry season when conditions are conducive to burning (Figure 2.8). This makes these areas fire'hotspots'. In addition, these areas' extensive oil palm and timber concessions are known to burn post-harvest residue and native vegetation to clear land. ${ }^{62}$ Combined, these trends cause serious air pollution. Furthermore, peatlands are a carbon sink, so burning them is especially greenhouse gas intensive.

The pollution from these fires resulted in serious episodes of haze in 1997-1998, 2006-2007, 2013 and 2015.63 Fires during these years were exacerbated by El Niño and Indian Ocean conditions that enhanced droughts. Drier conditions made it easier for fires to spread out of control. Farmers took advantage of the dry conditions to burn more land. September 2015 was the strongest El Niño on record (since 1997). ${ }^{64}$

The impacts were far-reaching, as particulates can travel thousands of kilometres, leading to transboundary pollution. Estimates suggest that 6 million people in Indonesia, Malaysia and Singapore were exposed to very unhealthy air quality levels, ${ }^{65}$ and 2 million were exposed to hazardous pollution levels for more than half of the September-October period in 2015..$^{66}$ More than 500,000 cases of acute respiratory infection were recorded, and 19 deaths were directly attributed to exposure to haze. ${ }^{67}$ Schools had to be closed, and a state of emergency was declared in six Indonesian provinces.
There were immediate and direct economic impacts from the 2015 haze. There were widespread disruptions to transport and logistics systems, including shipping cargo and flights. These in turn affected trade, incurring losses worth up to $\$ 1.3$ billion, with further losses in tourism revenue. The total cumulative cost to the Indonesian economy by 2016 was estimated to be $\$ 16.1$ billion. ${ }^{68}$

Interacting factors escalated the severity of the haze event in 2015. The potential rewards on offer from exporting palm oil as a commodity have increased economic incentives to burn forests for this practice. Despite laws to manage and regulate burning practices, poor enforcement and weak governance meant these have continued. ${ }^{69}$ At the same time, this environmentally damaging practice coincided with natural climatological factors, including droughts in parts of the subregion, which intensified the problem.

\section{Increasing resilience to address pollution}

As with the other shocks reviewed in this chapter, recognition of the severity of these impacts has led to regional cooperation to build anticipatory capacity, for example by investing in better systems to monitor pollution in general, and deforestation, forest degradation and forest fires specifically. Yet, while there has been encouraging progress, there is a continued need to invest in better quality and more transparent systems.

\section{Figure 2.7 Forest cover loss in South-East Asia and Indonesia, 2001-2016}

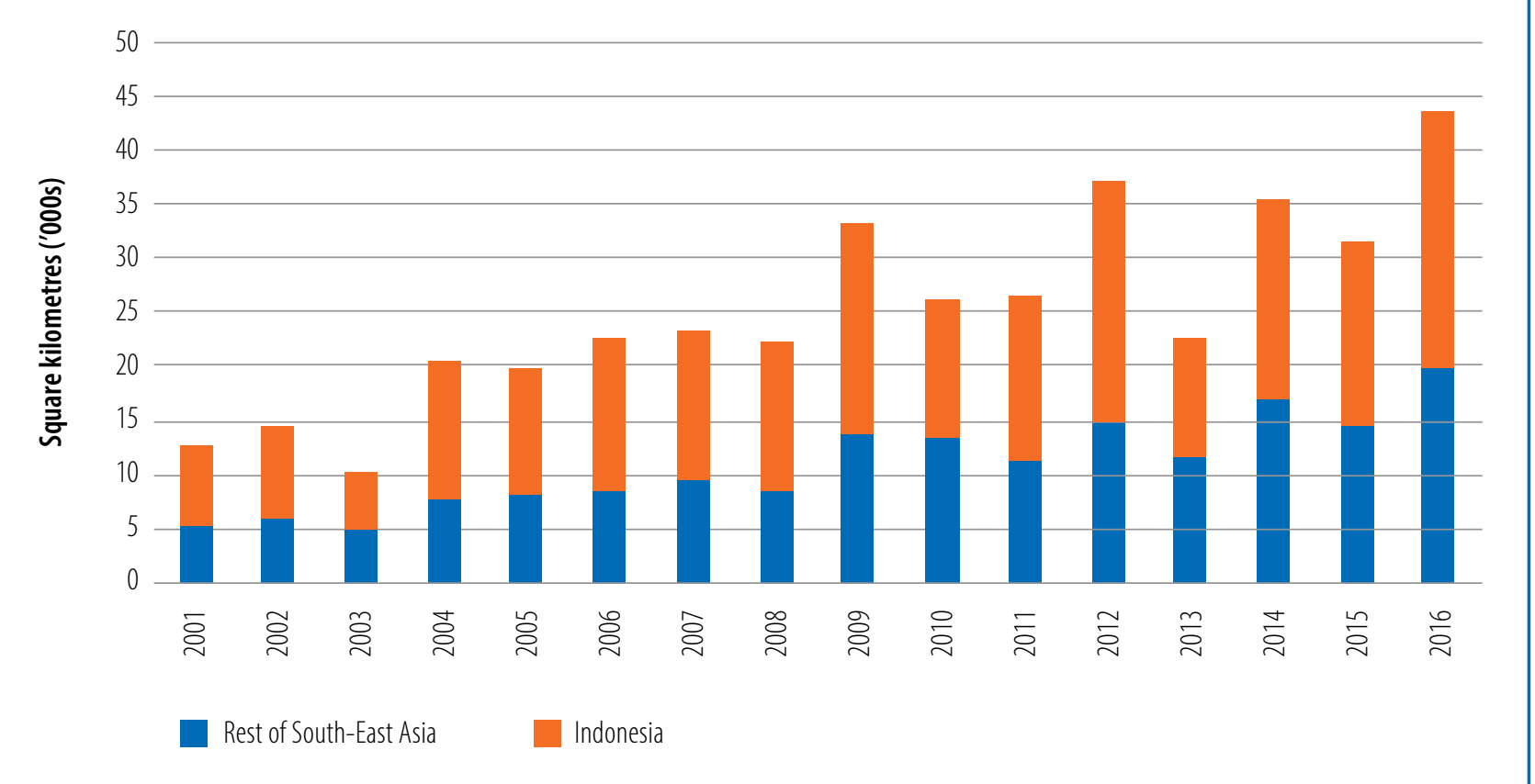

Source: Hansen and others, 2013 


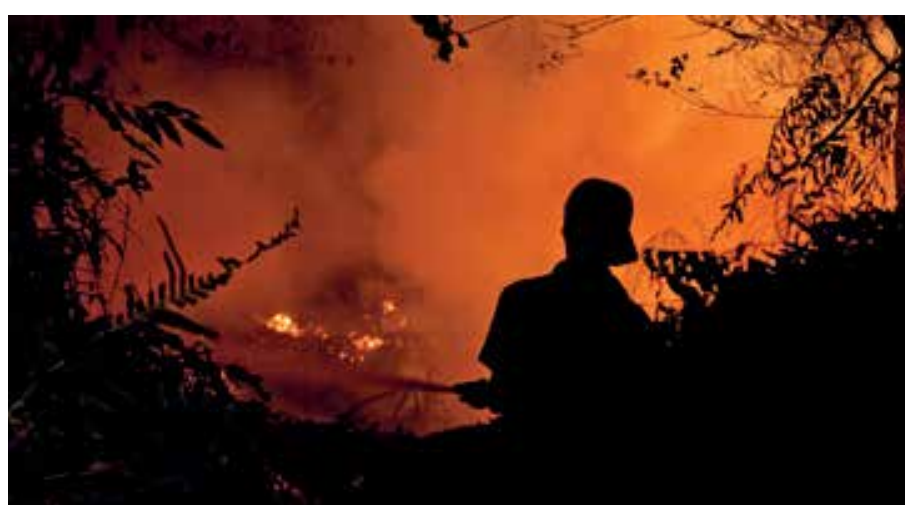

Source: Aulia Erlangga/CIFOR 2015
In Sumatra and Kalimantan (the Indonesian part of Borneo), there are extensive oil palm and timber concessions, where burning is common. Indonesia also has the largest area of tropical peatland in the world, most of which is in Sumatra and Kalimantan. But these are uninhabited and unproductive, making them targets for conversion to agriculture. Once drained, the dry peatland burns easily, and the fires are difficult to extinguish. Poor land management and governance allow burning to continue.
Fire hotspots peak when this burning coincides with the dry season (June to September). In very dry years - for example, during droughts, El Niño events or positive Indian Ocean Dipole conditions - the fires are even greater in scale and ferocity. In these years, farmers often take advantage of the dry conditions to burn more land, exacerbating the problem further.

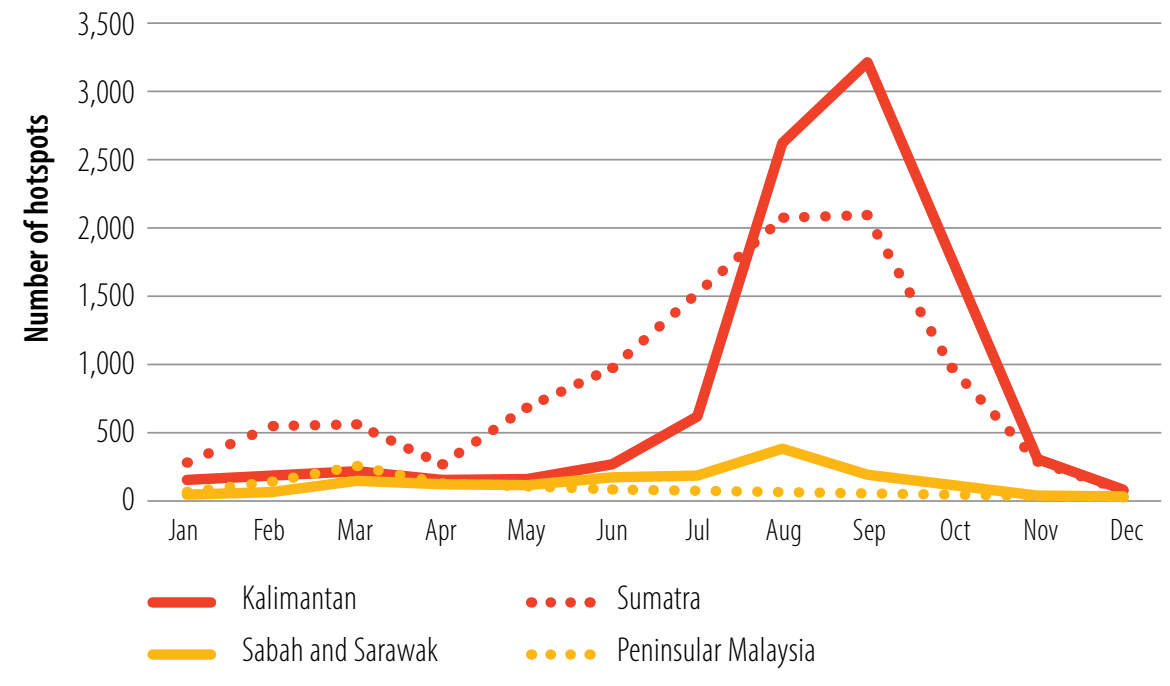

Source: ASEAN Specialized Meteorological Center

Better engagement with the communities who live closest to the forests and are most dependent on them for their livelihoods can also help. Measures could include involving them in monitoring activities to help make these more precise and relevant. There is a need to further strengthen anticipatory capacity in the region by investing in central data coordination systems that consolidate all pollution data in accessible, transparent and actionable formats. ${ }^{70}$

Tackling the pollution challenges facing the Asia-Pacific region requires improved adaptive capacities, including adopting regulations and legislation to control pollution more effectively. Some countries and cities (such as New Delhi, as noted in Box 2.5) have already taken initial regulatory measures to address individual point sources of pollution, or have commissioned studies to understand the sources of pollution and identify potential priorities for an action plan.

Improving access to health care is a substantial issue when considering how to increase the region's absorptive capacity for coping with pollution shocks. Preventing pollution-related health problems is the preferable solution, but health systems are increasingly having to care for people with pollution-related conditions.

The central issue, however, is the need to transform economic incentives, industrial and urban development systems, and land-use planning and management processes to value forest resources more greatly, and promote practices that sustain and maintain ecosystem services. Such steps can help to address the root causes of pollution and support more environmentally sustainable approaches to development. 


\subsection{Conclusions}

The nature of risk in the Asia-Pacific region is changing, with significant implications for critical human systems. The three categories of shock analysed in this chapter drive home the urgency for countries in the region to find effective transformation paths if they are to become sustainable, resilient societies.

Shocks have different effects on diverse groups in society, but data limitations make it difficult to provide a comprehensive analysis of how vulnerable groups are affected by specific events. Targeted efforts to better understand the effects of shocks and stresses on the poorest, most vulnerable groups in society are needed.

The interplay between these shocks and the trends and changing development contexts described in this chapter are likely to alter the ways in which some of these impacts manifest in the future, but also hold the potential to find more effective ways to manage shocks. Chapter 3 discusses some of the good practices in the region that are emerging in this context.

The severity of the effects of these shocks on diverse human system serves to strengthen increasingly well-accepted arguments for taking a more integrated approach to development; this will be necessary if the SDGs are to be achieved. Investing in practical, effective institutions that facilitate coordinated approaches to policy development and implementation is one vital element of such integration. The SDGs provide a starting point for a framework for considering links when conceptualizing and designing new development interventions. The Special Feature that follows takes stock of the resilience-related targets within the SDGs. 


\section{SPECIAL FEATURE \\ Taking stock: Resilience targets and indicators in the SDGs}

Several SDGs make explicit links to resilience, as Figure 1 shows, while numerous goals have targets and indicators that capture dimensions of resilience, even if the term is not expressly used. The SDGs focus on the resilience of poor and vulnerable groups (target 1.5), promoting resilient agricultural practices (target 2.4); investing in resilient infrastructure (targets 9.1 and 9.A); building resilient cities and human settlements (targets 11.B); increasing resilience to climate-related hazards and disasters triggered by natural hazards (targets 13.1 and 13.2); and strengthening the resilience of marine and coastal ecosystems (target 14.2).

The lack of available data to monitor progress across these targets is a major challenge, highlighting the importance of disaggregated data to achieving the 2030 Agenda ambition of leaving no one behind. Data are not widely available for 8 of the 11 indicators that make explicit reference to resilience. ${ }^{71}$ In addition, there is often a need for data points

\section{Figure 1 Resilience and the SDGs in the Asia-Pacific region}

\section{Several SDG targets have indicators related to disaster risk reduction}

On average, from 1990-2016, disasters:

- affected 185 million people each year meaning 48 in every 1,000 people

- killed 44,000 people each year

Disasters cost the region $\$ \mathbf{7 7 . 2}$ billion in 2016 - equivalent to 0.3 per cent of GDP
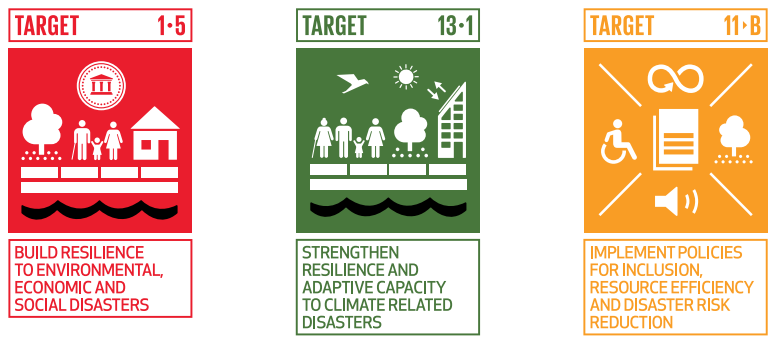

19 out of 49 countries* are still to report adopting

disaster risk reduction strategies in line with the Sendai Framework

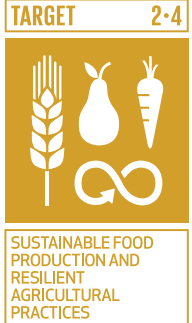

90 million hectares

of agricultural land were lost from 2000-2013

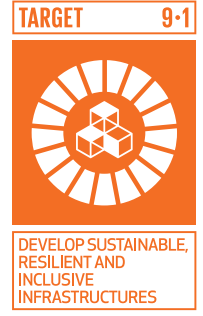

\$26 trillion will be needed to develop sustainable and resilient infrastructure between 2016 and 2030

Climate change adaptation already costs $\$ 41$ billion each year

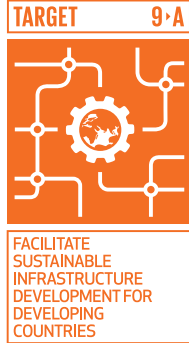

\$28 billion in official development assistance was provided for infrastructure in 2015

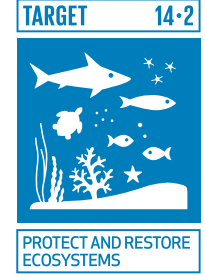

Only 11 per cent of marine areas are protected

Sources: ADB, 2017: Asia Pacific SDG Partnership Data Portal, http//data unescap.org/sdg/\#data/: ESCAP Database, http://data unescap.org/escap stat/\#data/; UN DESA SDG Indicators Global Database, https://unstats.un.org/sdgs/indicators/database/, Icons from the Global Goals for Sustainable Development, https://www.globalgoals.org/resources.

Note: * ESCAP member states, excluding non-regional members 
that complement officially agreed indicators to better capture resilience issues. For example, SDG 9 targets related to promoting resilient infrastructure capture people's access to road networks, but do not capture the extent to which these roads have been designed to be resilient to various shocks and stresses.

\section{Resilience and disaster risk reduction: SDGs 1, 11 and 13}

SDG 1 - to end poverty in all its forms everywhere - includes a target (1.5) to build the resilience of poor people and those in vulnerable situations, and reduce their exposure and vulnerability to climate-related extreme events and other economic, social and environmental shocks and disasters. SDG 11 - to make cities and human settlements inclusive, safe, resilient and sustainable - and SDG 13 to take urgent action to combat climate change and its impacts - include similar targets and use many of the same associated indicators. The SDGs therefore reflect a relatively holistic approach to disaster risk reduction and resilience from multiple lenses.

Countries in the Asia-Pacific region are extremely vulnerable to natural hazards such as earthquakes, floods, tsunamis and typhoons. $^{72}$ On average, 185 million people in the region are affected by disasters triggered by natural hazards every year. ${ }^{73}$ Indeed, people in the region are five times more likely to have been affected by natural hazards than those living elsewhere. ${ }^{74}$ From 1990 to 2016 , disasters triggered by natural hazards caused 1.8 million deaths worldwide, of which 65 per cent were in the Asia-Pacific region. They also rendered 101 million people in the region homeless, accounting for 89 per cent of the global total. ${ }^{75}$

Figure $2^{76}$ shows that as the region has developed economically, and GDP has grown, economic assets at risk have increased substantially. The exposure of these growing assets has also increased as economies have developed without sufficient consideration of disaster risk. From 2007 to 2016, the average economic damages from disasters triggered by natural hazards were estimated to be $\$ 76$ billion each year, more than twice the level in the preceding decade (1997-2006). ${ }^{77}$ Not only does the Asia-Pacific region have more to lose as its economies develop, it is also subject to increasing threats from natural hazards.

Hazards have been increasing in severity as well as frequency, and climate change is likely to make this situation worse in the future. While attention often focuses on intensive events, extensive low-intensity, high-frequency events, such as localized flooding and droughts, also take a major toll. ${ }^{78}$ The effects of these localized events are often largely absorbed by poor and vulnerable people.

SDGs 1 and 11 encourage countries to adopt, implement and localize disaster risk reduction strategies in line with the Sendai Framework for Disaster Risk Reduction 2015-2030.

\section{Figure 2 The increasing frequency of, and damages from, disasters in the Asia-Pacific region, 1970-2016}

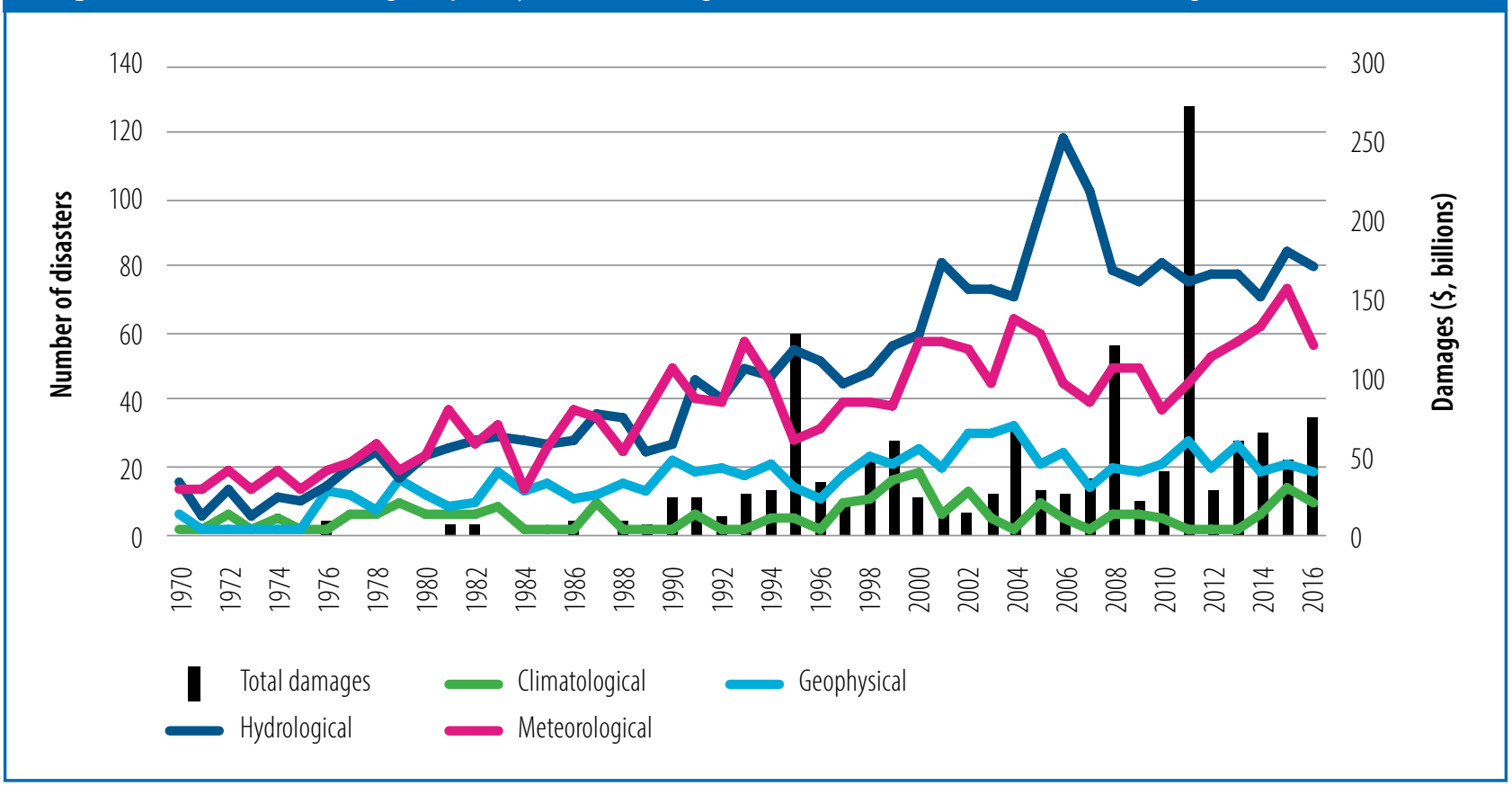

Source: EM-DAT, www.emdat.be 
While many countries have taken important steps to this end, a substantial number need to deepen their responses, particularly at a local level (see Box 1).

A growing body of evidence confirms that poor people are especially vulnerable to the impacts of natural hazards. Recent analysis from the World Bank, based on global data, suggests that the people who are among the poorest 20 per cent of the population (in income terms) experience only half of the per capita asset losses of a person with the average national income, but suffer well-being losses that are more than twice as large. ${ }^{79}$

People living in least developed countries in the Asia-Pacific region face a 60 per cent risk of poverty despite employment (compared to 12 per cent in Asia-Pacific as a whole) and are 10 times less likely to receive social insurance benefits..$^{80}$ Access to social protection systems is often particularly challenging for women. Between 2000 and 2015, lowincome and lower-middle-income countries in the AsiaPacific region lost almost 15 times more people per disaster event compared with high-income countries in the region. ${ }^{81}$ Social protection systems can play an important role in strengthening individual and community-level resilience (see Box 2).

\section{Sustainable food production and resilient agricultural practices: SDG 2}

Many countries in the Asia-Pacific region need to pay more attention to food security and the diversification of food systems, and to growth in the agricultural sector (target 2.4). About 90 million hectares of agricultural land were lost between 2000 and 2013 due to land degradation and conversion to other uses. Between 1992 and 2014, the amount of arable land in the region fell from 0.28 to 0.21 hectares per person. The region also has the world's highest rate of mineral fertilizer use, which can have negative environmental effects on soil quality, water quality and human health. ${ }^{82}$ In addition, in recent years the agriculture sector has borne almost 17 per cent of the total economic impacts from natural hazards. ${ }^{83}$ There is an urgent imperative to invest in the health of the ecosystems that underpin food production systems. Increasing economic integration has reshaped food production systems in the region.

\section{Resilient infrastructure: SDG 9}

The infrastructure needs of the region are diverse and substantial - projected at approximately \$26 trillion between 2016 and 2030 in the region's developing countries, particularly in the energy and transport sectors. ${ }^{84}$ The costs of adapting this infrastructure to climate change are estimated to be $\$ 41$ billion a year, mostly for transport infrastructure..$^{85}$ Poor people often have the least access to infrastructure, and it is essential to find more inclusive approaches to infrastructure development, including in urban areas.

SDG 9 focuses on the connectivity of transport and information and communications technology. There are scant data on the proportion of the rural population who live within two kilometres of an all-season road, the officially agreed indicator, but new research from the World Bank suggests that ratios vary substantially even across poorer countries in Asia and the Pacific, from 54 per cent in Nepal to 85 per cent in Bangladesh. ${ }^{86}$ On average, it is estimated that 40 per cent of the region's rural population (or 700 million people) do not have all-weather road access. ${ }^{87}$ The WEF Competitiveness Index suggests road quality in the AsiaPacific region has substantial room for improvement, with only China, Japan and Singapore having roads that are on par with 'the best in the world'.

As of 2016, some 97 per cent of the region's population are within range of mobile cellular signals. Rates are lower in the region's low-income economies, such as Nepal

\section{Box $1 \quad$ Disaster risk reduction as a crucial element of resilience}

As of 2015, some 19 countries had yet to report on whether they had developed risk reduction strategies in line with the Sendai Framework for Disaster Risk Reduction 2015-2030. These ranged from high-income countries, such as the Russian Federation and Singapore, to some of the least developed countries in the region, such as Cambodia, as well as small island developing states such as Solomon Islands and Tuvalu.

There is an urgent need for all countries to develop such frameworks, to help ensure that they are fully prepared for future disaster events, and that they reflect a holistic approach to reducing and managing disaster risk. The SDGs place a special emphasis on the need to develop local-level disaster risk reduction strategies. Under SDG 11, target 11.B monitors the number of local governments that have adopted disaster risk reduction plans in line with the Sendai Framework. As a rapidly urbanizing region, increasing the resilience of Asia-Pacific cities to stresses including climate change is imperative. 
Effective social protection systems can help strengthen the resilience of individuals and households to stresses and shocks in several ways. First, they build absorptive capacity for a shock by providing safety nets that allow people to meet their basic needs. Second, social protection systems may be designed to help build anticipatory capacity, including in the context of climate change, if designed to incentivize people to prepare and plan for shocks. They can also help to build adaptive capacity in the long term, if they help to promote sustainable livelihoods through interventions that build people's ability to earn an income or maintain a solid asset base.

SDG target 1.3 calls on all countries to establish nationally appropriate social protection systems and measures for all, including floors, and by 2030 achieve substantial coverage among poor and vulnerable people. It is, however, very challenging to establish effective social protection systems that create the right incentives for resilience-building efforts. Poor and vulnerable households are not homogeneous and may need different types of interventions to strengthen their resilience.

As countries in the Asia-Pacific region have grown richer, many have taken steps to expand various aspects of their social protection systems. In most countries, investment in such programmes has generally increased, as Figure 3 shows.

\section{Figure 3 Changes in investment in social protection, 2003-2016}

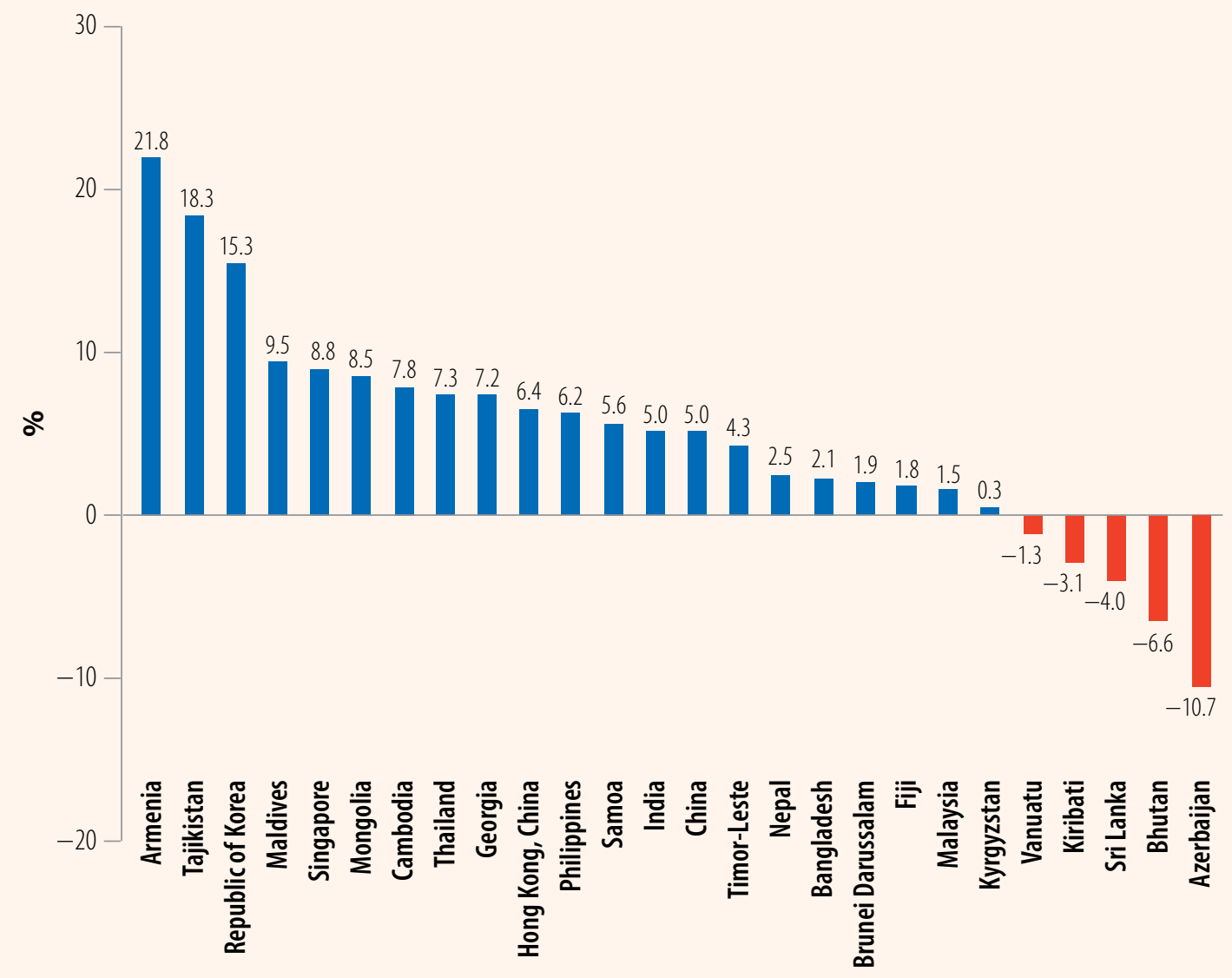

Sources: ESCAP Statistical Database, www.unescap.org/stat/data, ILO 2017, World Social Protection Report 2017-19: Universal social protection to achieve the Sustainable Development Goals http://www.social-protection.org/gimi/gess/Wspr.action 
Some programmes in developing Asia-Pacific countries have become the world's largest in terms of the numbers of beneficiaries. ${ }^{88}$ Countries such as China, Mongolia, Thailand and Viet Nam have emerged as global leaders due to the speed with which they have established social protection programmes with extensive coverage on selected issues related to health and unemployment.

Despite this encouraging progress, many gaps remain. Data suggest that nearly 60 per cent of the region's population now have access to health social protection. Nevertheless, the International Labour Organization estimates that only 4 in 10 people in the region have easy access to health care, and access is often limited for those who are covered. Only 30 per cent of the population have access to social assistance, and less than 20 per cent have access to social insurance. Only 21 of 49 countries in the region offer benefits to children and families, while only 1 in 5 working-age adults receive unemployment benefits. Lastly, just over half of all older people in the region receive a pension. In low-income countries, such as Cambodia, the Lao People's Democratic Republic and Myanmar, there are almost no cash-transfer-based social protection programmes in place. Reporting on labour market programmes remains highly incomplete, and questions around the adequacy and depth of existing coverage arise. Both issues have significant fiscal implications.

As efforts are made to enhance social protection systems in the region, there is an urgent need to factor current and future vulnerabilities into these programmes. The targeting of beneficiaries can be improved by using climate and disaster risk information. Integrated solutions to reduce risk and strengthen adaptive capacity through social protection programmes can be adopted. There is also a need for flexible design features to strengthen each programme's responsiveness to shocks.

Sources: ADB, 2018; ESCAP, 2017a; ESCAP Statistical Database, www.unescap.org/stat/data; Gassmann and Handayani, 2017

(82 per cent) and Pacific Island States such as Kiribati (70 per cent). The importance of finding more resilient approaches to infrastructure development, with a focus on protecting ecosystems, particularly connectivity and transport infrastructure such as roads, remains paramount. There are, however, critical trade-offs between some of the paths to greater infrastructure connectivity and wider objectives of promoting environmentally sustainable development and sustainable consumption. There may also be a risk that greater connectivity can undermine self-sufficiency and thereby resilience.

\section{Resilient marine ecosystems: SDG 14}

Target 14.2 aims to sustainably manage and protect marine and coastal ecosystems, including by strengthening their resilience. Yet, only 11.2 per cent of the region's marine areas are protected. ${ }^{89}$ In the Coral Triangle Region alone, more than 85 per cent of reefs are threatened by local stressors, such as overfishing and pollution (versus the global average of 60 per cent); this increases to 90 per cent when combined with stress from ocean warming and coral bleaching (versus the global average of 75 per cent). ${ }^{90}$ While only SDG 14 makes explicit reference to resilience, this is a crucial consideration for many other ecosystems as well. Efforts to strengthen the resilience of marine and coastal ecosystems must be accelerated significantly. 



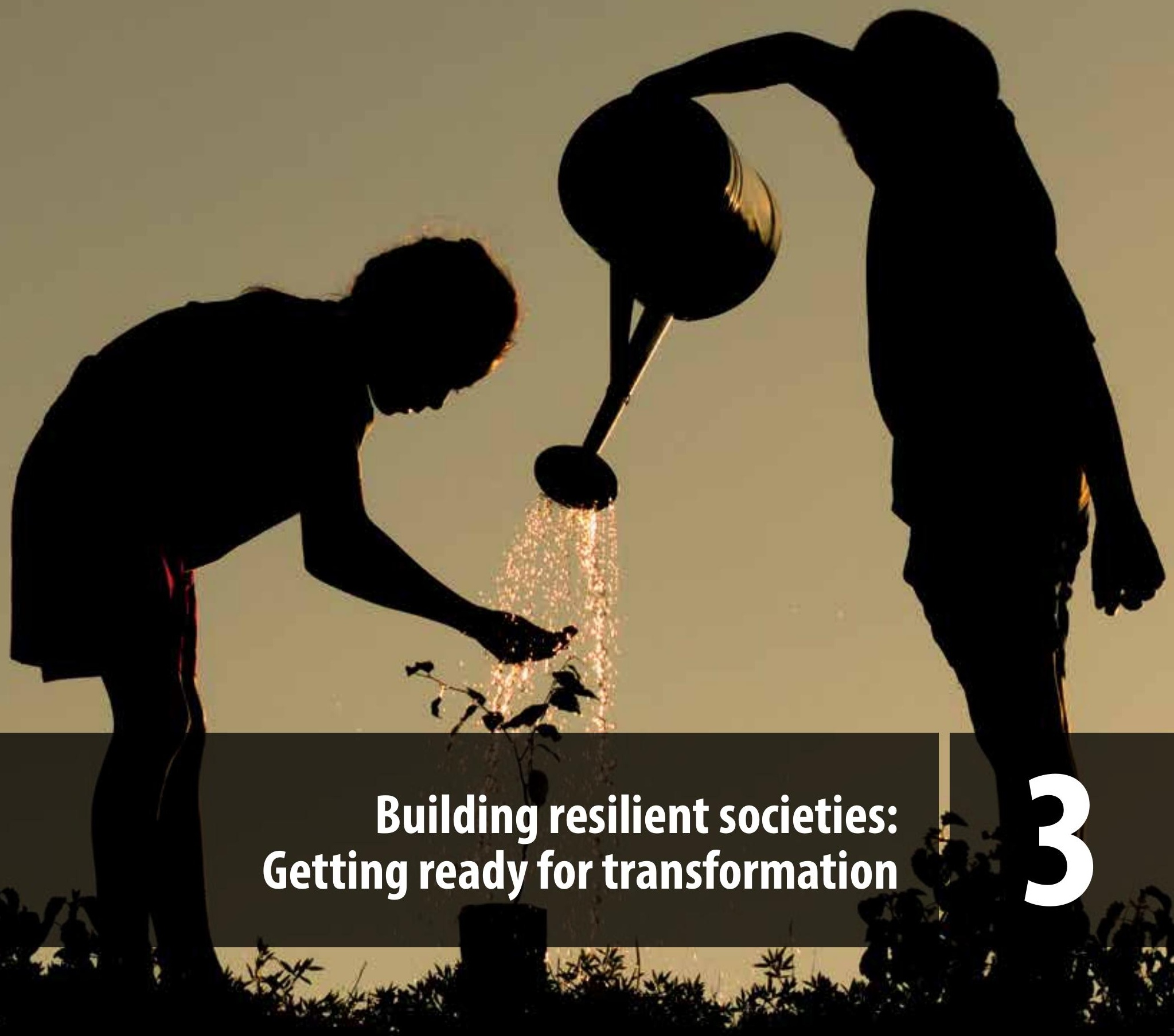




\subsection{How risk occurs}

Risks are becoming more complex over time. Individuals and households cannot manage them on their own. Building resilient societies therefore requires a conscious approach by policymakers to manage risks and prepare for shocks. This chapter presents selected examples of how anticipatory, adaptive, absorptive and transformative capacity can be built, exploring step 3 of the approach introduced in Chapter 1. On this basis, it draws insights into the key characteristics that individuals, organizations and societies need to strengthen their resilience.

The scale of risk is determined by the interactions of social and environmental processes. It depends on the combination of hazards, vulnerability and exposure of societies and socioecological systems. Thus, hazards are only one of the three elements of risk (see Figure 3.1).

Hazards are increasing, and skewed development processes can enlarge exposure and vulnerability, leading to an increasing scale of risk. A hazard combined with the wrong policy choices poses a risk before it happens; when it does occur, it creates a shock (e.g. a cyclone or tsunami). Poor policy choices increase the exposure and vulnerability of populations and can be associated with hazards of all kinds, including disasters, social conflicts, health issues, and economic and financial shocks.

\section{Figure 3.1 Three elements of risk}

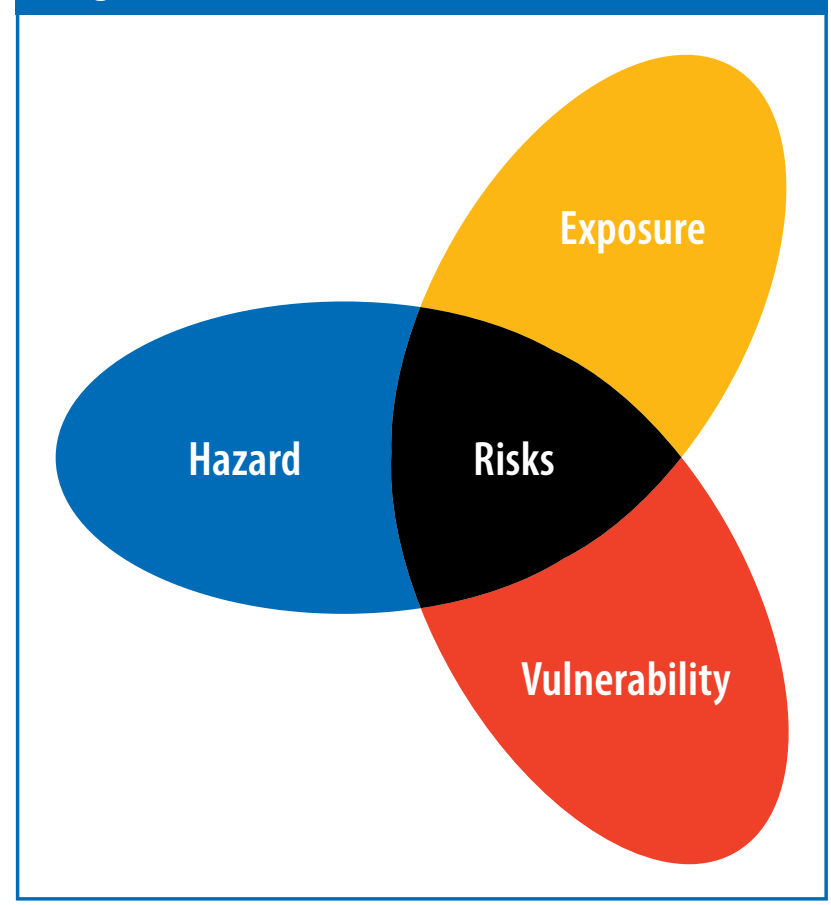

Source: Adapted from Lavell and others, 2012, with inputs from Deborah O'Connell
Therefore, there is a clear need for integrated and improved policy frameworks that can help transform societies and countries in the Asia-Pacific region and make them more resilient and sustainable. Building resilience requires policies and programmes that reduce the intersection or the scale of risks and shocks (see Figure 3.1). This can be achieved by:

- reducing the likelihood of hazards occurring, for example by mitigating climate change

- choosing policies that reduce people's exposure, for example by preventing human settlement in low-lying, flood-prone areas

- reducing people's vulnerability, for example by increasing their capacity to cope with a hazard by having appropriate infrastructure or resources.

Resilience-building requires the delivery of a combination of policy and programmatic interventions. ${ }^{91}$ Capital and assets help people withstand shocks, and accumulating these can contribute to inter-generational equity or sustainable development, if the choices made by a society, and the policies that govern them, do not increase exposure and vulnerability. ${ }^{92}$ As well as capital and assets, as discussed in Chapter 2, individuals' exposure and vulnerability depend on their social and economic status, and the area in which they live.

Often, poor and vulnerable people also need support from the state and society. An individual's livelihood, which in part determines their capital and assets, is influenced by policy decisions taken at the national, community and household levels. Government policies and societal choices, which are guided by existing values and institutions, therefore play a significant role in building resilience. This chapter covers this subject in more detail.

\subsection{Government policies and programmes for building resilience}

Building resilience requires both formal and informal strategies. Informal strategies include arrangements made by communities, for example whether to construct a small dam or diversify crops. Some communities also use informal insurance mechanisms, such as financial self-help groups in which members transfer resources or savings to support a member who suffers from a shock. Formal arrangements include market-based solutions, and public policies and programmes.

Informal and formal policies are interdependent. For example, public policies and the availability of formal mechanisms heavily influence how extensively informal arrangements are used for building resilience. The balance 
between these is also changing over time. With the interaction of trends such as climate change, economic integration, demographic changes and rural-urban transition, risks are becoming more complex. Increasingly, individuals and communities cannot address such complexity through their own informal measures; they need greater government support and solutions, in the form of formal measures that cover a broad spectrum of macrolevel and sectoral policies, as well as targeted policies (e.g. those focusing on particularly vulnerable groups).

Table 3.1 outlines some of the policies, programmes and projects implemented for building the four inter-related forms of resilience capacity - anticipatory, adaptive, absorptive and transformative - used in the Asia-Pacific region. While this chapter is structured around these different types of capacity, they are overlapping and most of the programmes and projects highlighted here include efforts to build more than one type.

\subsection{Building anticipatory capacity}

People anticipate risks based on their human capital: their knowledge, information and experience. Education can play a vital role in shaping their human capital. As Chapter 2 noted, there is an established link between the quality of education in countries and their resilience. Several countries introduced disaster management into their school and college curricula a long time ago, ${ }^{93}$ while shocks and stresses feature in the content of courses in various university faculties, such as economic shocks featuring in economics courses.

However, most people in poor communities anticipate risks in light of their experience only. As new risks emerge, they may not be well prepared unless they get information from governments or other stakeholders to raise their awareness of these risks. They need to be aware not just of the risks to themselves, but how a disaster might affect the capital and assets that they hold. Effective communication about risks therefore has a significant role to play in building anticipatory capacity. This has been evident in the Republic of Korea, where government information during the outbreak of Middle East Respiratory Syndrome (MERS) in 2015 helped to contain the spread of the epidemic, ${ }^{94}$ and in efforts to reduce the prevalence of dengue fever in the Philippines (Box 3.1).

\section{Table 3.1 Government policies and programmes for building resilience in the Asia-Pacific region}

\begin{tabular}{|c|c|c|c|}
\hline $\begin{array}{l}\text { Type of resilience } \\
\text { capacity }\end{array}$ & $\begin{array}{l}\text { Macroeconomic and } \\
\text { sectoral policies }\end{array}$ & $\begin{array}{l}\text { Targeted policies and } \\
\text { social protection }\end{array}$ & Examples of projects and programmes \\
\hline Anticipatory & $\begin{array}{l}\text { - Education policies } \\
\text { - Information and } \\
\text { communications } \\
\text { policies }\end{array}$ & - Early warning systems & $\begin{array}{l}\text { - Fighting dengue fever through } \\
\text { information, Philippines }\end{array}$ \\
\hline Adaptive & $\begin{array}{l}\text { Macroeconomic } \\
\text { policies (e.g. fiscal, } \\
\text { monetary and } \\
\text { exchange-rate policies) } \\
\text { - Sectoral policies (e.g. } \\
\text { agriculture) } \\
\text { - Climate change and } \\
\text { disaster risk reduction } \\
\text { policies }\end{array}$ & $\begin{array}{l}\text { - Social security policies } \\
\text { - Targeted price } \\
\text { subsidies } \\
\text { - Public health } \\
\text { - Access to microfinance } \\
\text { schemes } \\
\text { - Minimum wage and } \\
\text { labour market policies }\end{array}$ & $\begin{array}{l}\text { Managing financial crises, Republic of } \\
\text { Korea } \\
\text { - Small-scale farmland water } \\
\text { conservancy construction, China } \\
\text { - Sustaining agricultural biodiversity in } \\
\text { the face of climate change, Tajikistan } \\
\text { - Financial remittances for building the } \\
\text { adaptive capacity of flood-affected } \\
\text { households, India } \\
\text { - Creating a resilient community, Fiji }\end{array}$ \\
\hline Absorptive & $\begin{array}{l}\text { - } \text { Migration and } \\
\text { remittance policies } \\
\text { - Social policies }\end{array}$ & $\begin{array}{l}\text { - Social protection } \\
\text { programmes } \\
\text { - Food-for-work } \\
\text { programmes }\end{array}$ & $\begin{array}{l}\text { Enhancing resilience to natural hazards } \\
\text { and the effects of climate change, } \\
\text { Bangladesh } \\
\text { - Income and health security, Thailand }\end{array}$ \\
\hline Transformative & $\begin{array}{l}\text { - Climate change policy } \\
\text { - Energy policy } \\
\text { - } \text { Forestry policy }\end{array}$ & $\begin{array}{l}\text { Women's } \\
\text { empowerment policies } \\
\text { and programmes }\end{array}$ & $\begin{array}{l}\text { - Community forestry management, } \\
\text { Nepal } \\
\text { - Response to } 2015 \text { outbreak of MERS, } \\
\text { Republic of Korea } \\
\text { - Transformation towards renewable } \\
\text { energy, Philippines }\end{array}$ \\
\hline
\end{tabular}




\section{Box 3.1 Fighting dengue fever through an information campaign in the Philippines}

Dengue fever, a lethal mosquito-borne viral disease, used to affect more than 100,000 people in the Philippines every year, resulting in hundreds of deaths annually. To combat the disease, the Department of Health ran an information campaign to remind people how to prevent it from spreading. By distributing information posters, the Department aimed to communicate how easy it is to fight the disease - if people remember to keep their surroundings clean.

The main tool was a poster communicating information about ' 7 ways to prevent dengue fever'. These were distributed for people to display in their homes. The seven tips reminded people to replace water in flower vases, remove leaves from gutters, dispose of unused containers, clean water vessels weekly, cover water buckets and wear protective clothing. Even displaying the posters helped: they were coated with the mosquito repellent citronella oil to help drive away mosquitoes.

The posters were distributed from 1 January to 4 February 2012. According to the Department of Health's disease surveillance report, the incidence of dengue fever dropped by 60.5 per cent during this period, compared with the same period in 2011.

Source: Campaign, 2012

Several countries have set up early warning systems to avoid or reduce the impact of natural hazards such as floods, landslides, storms and forest fires. Communities are also establishing early warning systems. In the north-east region of Bangladesh, vulnerable people form committees that together create a network that can quickly communicate the arrival of flash floods and monitor the effectiveness of warning systems..$^{95}$

Many countries also run programmes and projects to improve people's awareness, knowledge and skills. Examples include China's 'Recovery to Resilience - Implementing Child-centered Disaster Risk Reduction' project and the 'Enhancing Resilience through Gender Equality' project.

\section{Building resilience to earthquakes in China}

Between 1964 and 2013, China experienced 151 earthquakes measuring 6.5 to 7.0 on the Richter scale, and has suffered several more since. Sichuan province, in the south-west of the country, is particularly prone to geological hazards including earthquakes, and the risks associated with these are increased due to rapid urbanization and overpopulation in the province.

In 2008, the devastating Wenchuan earthquake, which reached 7.9 on the Richter scale, caused over 90,000 deaths and missing persons. In response, Save the Children China launched the 'Recovery to Resilience - Implementing Child-centered Disaster Risk Reduction' project in 2012 to deliver long-term improvements in children's resilience and in their communities' capacities to reduce the impacts of disasters.

This programme introduced a new concept to the region, one that focused on risk reduction and resilience-building with a child-centred perspective. The Asian Disaster Preparedness Center and Save the Children China devised a strategy to safeguard children against the impacts of disasters by training parents, teachers, community leaders and government officials on disaster risk management, including the identification of hazards and vulnerabilities that exposed their communities to risks. Information collected during risks assessment was used to create hazard action plans that focused on the safety of children. ${ }^{96}$

Earthquakes are cyclical in nature, but big earthquakes only occur on cycles with long intervals. For example, Kathmandu in Nepal experienced an earthquake measuring 8.4 on the Richter scale in 1934. Another big earthquake occurred in 2015 - 81 years later. As a result of this lengthy interval, which spanned generations, in 2015 there were hardly any people alive with experience of the 1934 earthquake. If the government and development partners had not raised awareness, and implemented regulations to turn awareness into actions, the 2015 earthquake could have claimed even more than the 9,000 lives that were lost, and damaged far more property.

These examples illustrate the important role of education and communication. However, resilience not only requires communities to be better prepared for hazards such as earthquakes, but also governments in affected countries to have long-term visions and policies for making their societies more resilient. In countries affected by earthquakes, this can be done through measures such as enforcing rules about land-use planning and building standards to minimize damage and losses from hazards. The realization of anticipatory capacity therefore requires translating learning and knowledge into action. 


\section{Tackling gender inequality in resilience}

The 'Enhancing Resilience through Gender Equality in AsiaPacific' project, implemented by Care International in six countries (Cambodia, the Lao People's Democratic Republic, Papua New Guinea, Timor-Leste, Vanuatu and Viet Nam) has improved women's awareness and skills, helping them to anticipate risks better and adapt to shocks. For example, in Timor-Leste, female members of farmers' groups have increased their knowledge, skills and confidence to apply sustainable agricultural techniques to mitigate agricultural risks. ${ }^{97}$

This has not only helped their society to respond to disasters, but also empowered the women by improving gender relations and changing social structures. Building the resilience of poor and vulnerable groups has a higher pay-off than doing so for wealthier, less vulnerable groups, and contributes to realizing the principle in the 2030 Agenda to 'leave no one behind'.

\subsection{Building adaptive capacity}

Despite efforts made by states and society to anticipate and reduce risks, it is impossible to avoid all hazards. It is therefore important to take measures that can help people adapt and live with them. These can include ex-ante or risk adaptation measures; and ex-post or risk absorption measures. At times, it is difficult to make a clear distinction between the two measures, because the absorptive capacity of a society depends on how much adaptive capacity is built before a hazard occurs.

To build adaptive capacity, it is necessary to reduce the exposure and vulnerability of a society. This can be done through a variety of measures. For example, adaptive capacity can be improved by implementing macroeconomic policies that decrease the impact of economic shocks; through sectoral policies and programmes, such as agricultural development and irrigation improvement, that lead to an increase in incomes or diversified livelihood options or income sources; or by mainstreaming risk management into national and sectoral planning, such as through National Adaption Plans (NAPs).

\section{Macroeconomic policies}

Over the past three decades, regional cooperation and integration have benefited the Asia-Pacific region, driving trade, economic growth and stability. Asia had a combined GDP of $\$ 17$ trillion in 2010 ; this could reach $\$ 174$ trillion by 2050, accounting for almost half of global GDP.98 But while economic integration has increased investment and trade, resulting in economic growth, the region is still at risk from shocks that can affect its economic systems.
These shocks can be contagious. When global supply chains are disrupted, a shock can have impacts far beyond the country in which it originated. The 2011 Tōhoku earthquake and tsunami, which struck off the coast of Japan, damaged and shut down several major ports and airports, disrupting global supply chains such as those for semiconductor equipment and materials, for which Japan's production comprises 20 per cent of the world market. ${ }^{99}$

A globalizing economy creates both opportunities and challenges. The Republic of Korea adopted a series of economic policies and expansionary policies to aid coordination with other countries; these helped to attain a fast recovery from the 2008 financial crisis. The Republic of Korea's experiences illustrate the role of regional cooperation in supporting resilience against economic and financial shocks (see Box 3.2).

Not all countries and communities are in a position to adapt to global shocks by themselves, however. There remains a need for stronger global and regional cooperation. Several cooperation initiatives are already being pursued in the Asia-Pacific region, including the 2013 Bangkok Declaration on Regional Economic Cooperation and Integration in Asia and the Pacific, which focuses on: (1) the formation of an integrated market; (2) the development of seamless connectivity across the region in the areas of transport, energy and information and communications technology; (3) enhancing financial cooperation; and (4) increasing economic and technical cooperation to address shared vulnerabilities and risks. ${ }^{100}$

\section{Agricultural development}

Historically, most successful industrialization processes began with progress in agriculture. In recent years, the experiences of China, India and Viet Nam have shown how agricultural growth can lay the foundations for the subsequent growth of industry and other economic sectors. ${ }^{101}$ Even though the traditional development path from agriculture to industry to services - is now changing, agriculture remains an essential sector in most developing countries as the mainstay of poor people. Many smallholder family farmers are poor and food insecure, and have limited access to markets and services. ${ }^{102}$

The food crisis that emerged in 2008 demonstrated yet again the vulnerability of these people to adverse long-term trends and unexpected shocks. For example, smallholder family farms in the informal sector often have limited access to credit and other facilities, which means they lack a potential coping mechanism when crises hit. Many also lack knowledge and skills about how to manage risks. They are often very risk averse compared to large-scale farmers, 
The Republic of Korea was hit hard by the 1997 Asian financial crisis. Learning from this, it improved its macroeconomic and financial management systems to minimize the risks from similar shocks in the future. For example, the government enhanced the soundness of financial and non-financial sectors by strengthening the regulation and supervision of financial institutions and markets; and by regularly monitoring foreign exchange liquidity conditions, paying serious attention to the management of foreign exchange reserves.

Despite these efforts, the country could not avoid all the impacts of the 2008 global financial crisis. It suffered from a loss of confidence among foreign investors, resulting in large capital outflows. This resulted in a capital account deficit of $\$ 42.6$ billion in the last quarter of 2008 , which was over 20 per cent of GDP. In addition, its exports decreased substantially, aggravating the liquidity crunch further.

To prevent further losses, the government, together with other advanced economies, implemented an expansionary policy to encourage demand and stimulate economic growth. ${ }^{103}$ These interventions complemented the work done after the 1997 crisis to bolster the nation's financial institutions and engage the corporate sector in rebuilding. The economy of the Republic of Korea managed to rebound relatively quickly, once the global market started to recover from March 2009.

This experience reinforces the case for regional cooperation to strengthen regional financial safety nets. A notable initiative in this regard is the Chiang Mai Initiative of currency swapping. Continued efforts to develop regional capital markets, such as the Asian Bond Markets Initiative, can play a complementary role.

Moreover, the Republic of Korea still needs to look out for trends such as ageing and low birth rates, which can depress economic growth, while top-down visions (such as pursuing green growth) still require substantial bottom-up support to achieve the desired transformation.

Sources: ESCAP and others, 2016; Kim, 2017; Lee and Rhee, 2012

because of their limited capital and assets. These factors mean they remain vulnerable unless they are provided with a package of services, as well as the motivation to use those services (see Box 3.3).

Irrigation is a critical input to agricultural development; irrigation projects, even small-scale systems, can also increase the resilience of smallholder farmers to shocks and stresses. This was the case for farmers in China's Hongta District. For many years, they relied on precipitation for their irrigation. The unpredictability and scarcity of this led to low agricultural production, income instability and poor living standards. The 'Small-scale Farmland Water Conservancy Construction' project, implemented by the government, enhanced their adaptive capacity by providing more efficient small-scale irrigation systems that required less water, as well as water conservation facilities including solarpowered pumping stations, cisterns, pools and pipelines.

The results have been dramatic. Farmers can now cultivate crops all year round, which makes them more resilient to shocks. They have also switched to horticultural crops that provide better returns. Overall, the project has led to an increase in food production of 1.33 million kilograms per year, and an increase in the value of cash crops of
RMB 12.4 million (approximately $\$ 1.8$ million) per year. Farmers' incomes have doubled thanks to year-round irrigation, bringing more stable livelihoods and a better standard of living, which has accelerated socioeconomic development. ${ }^{104}$ Their increased capital and assets will also help make them more resilient to future shocks.

\section{Diversifying income sources}

Various resilience-building programmes seek to widen people's options for earning an income. Incomes enable people to absorb the impacts of shocks and adapt to cope with future shocks. However, relying on one income source makes people vulnerable in the case of that source being affected by a shock. Thus, diversifying income sources helps communities to cope with risks.

Most income-diversification programmes apply a livelihoods approach, such as an off-farm cultivation project in Bangladesh that aimed to mainstream alternative livelihood options in flood-prone areas. ${ }^{105}$ Some programmes take a mixed approach: as well as aiming to diversify sources of income, they aim to protect biodiversity as a further way to manage risks.

One example is the 'Community Based Conservation of Biological Diversity in the Mountain Landscape of Mongolia's 


\section{Box 3.3 Providing support to enhance climate-resilient agriculture}

For years, cotton farmers in Tajikistan lacked access to finance and technology and, being risk averse, were unwilling to grow new crops or try new farming methods. To address this problem, the government implemented the 'Sustaining Agricultural Biodiversity in the Face of Climate Change' project, which aimed to improve the welfare of 3,300 farmers by providing finance and technology to promote climate-resilient crops.

The project contributed to building farmers' adaptive capacity by improving their knowledge and skills on adaptation issues, farm management and productivity. This was achieved through training and workshops on issues such as climateresilient and biodiversity-friendly farming practices, crop diversification, financial management, and using equipment such as solar dryers.

The project improved access to finance, for example through micro-credit schemes, as well as establishing agroprocessing shops and more resilient and profitable agribusinesses. As a result, farmers' incomes increased by 40 per cent on average. It also helped to change the risk-averse attitude of the farmers, persuading them to try new farming methods by demonstrating the economic benefits of these.

Source: Dougherty-Choux and others, 2015

Altai Sayan Eco-Region' project, in which herders diversified their livelihoods and enhanced their resilience to external shocks such as severe winters ( $d z u d)$, and to reduce pressure on overgrazed pastures. The project provided loans and grants to community groups to help them develop tourism, grow vegetables, repair winter shelters and improve the quality of their milk and wool products. Furthermore, 7,000 herders received training in new trades, including weaving and felt-making, processing and marketing of dairy products, tourism, and wildlife monitoring and management. ${ }^{106}$ With a wider range of income sources, the herders were more resilient to shocks.
Further approaches to diversifying livelihoods include skills development and the formation of savings and credit groups. Labour migration and remittances may also play a role (Box 3.4). However, while several developing countries in the Asia-Pacific region have built their financial capital through remittances, there is generally a lack of appropriate policy measures to diversify sources of capital. Banerjee and others $(2016,2017)$ suggest that the adaptation potential of remittances can only be realized if there are policy incentives to use this source of financial capital to build other types of capital.

\section{Box 3.4 Using remittances to build household-level adaptive capacity in the Eastern Brahmaputra sub-basin}

Floods have major impacts on people living in the flood-prone areas of Assam, India. On average, the state loses crops worth an estimated \$47 million each year due to floods, while damage to homes and livelihoods affects about 3 million people. In the Eastern Brahmaputra sub-basin, people's livelihoods are heavily reliant on natural resources, which further increases their exposure to flood risks.

Labour migration has emerged as a livelihood diversification option for many people. Almost 90 per cent of households have one migrant worker, and nearly 10 per cent have had two migrant workers over the past 30 years. These workers send back money in the form of remittances, and households receiving these are more likely than non-recipient households to have access to services such as formal financial institutions, insurance and communication devices - all of which increase their resilience.

Remittances have had a positive effect on the structural changes made by households to reduce the impacts of floods, enabling them to invest in resilience-building strategies such as farm mechanization. The money received from migrant labour also supports households to participate in collective activities that focus on flood relief, recovery and preparedness. 


\section{Building adaptive capacity to climate change}

Climate change is one of the critical trends that will have a major influence on efforts to achieve sustainable development in the Asia-Pacific region. People throughout the region will need support as they are forced to adapt to a future with new and greater climate-related risks. Encouragingly, many countries are already acting to build the adaptive capacity of their societies. Nationally Appropriate Mitigation Actions (NAMAs), Nationally Determined Contributions (NDCs), National Adaptation Programmes of Action (NAPAs) and NAPs are all important instruments that help countries to implement climate change policies and programmes. ${ }^{107}$

NAPAs were established to help least developed countries to identify priority activities for adapting to their most urgent and immediate needs in relation to climate change. This is essential, as delays in taking these actions would increase their vulnerability and/or result in higher costs if enacted at a later stage. ${ }^{108}$ Many NAPAs include ecosystem-based adaptation, which increases the resilience of vulnerable communities and of the ecosystems on which they depend. In the Asia-Pacific region, one approach is to expand and connect protected areas to conserve intact forests, wetlands, mangroves and coral reefs, all of which provide a natural buffer for vulnerable communities against disasters intensified by climate change. ${ }^{109}$

While there were many ways in which the NAPA process could have been strengthened, the experience has greatly informed understanding of adaptation planning in developing countries. Building on this experience, countries have started developing NAPs. Approximately half of the middle-income, developing countries in the Asia-Pacific region are developing medium-to-long-term, cross-sectoral and cross-scale processes to formulate and implement their NAPs, which are aimed at reducing vulnerability and integrating climate change adaptation into planning and budgeting processes. ${ }^{110}$

Environmental problems have become more complicated and complex; consequently, there is an increasing need for regional, inter-regional and global responses. ClimaEast ${ }^{111}$ is an example of an inter-regional project that has achieved significant results in terms of building the adaptive capacity of countries in the Asia-Pacific region and Eastern Europe (Box 3.5).

\section{Box 3.5 ClimaEast: Building resilience using an ecosystem-based approach}

The ClimaEast project (2012-2017) operated in seven countries: Armenia, Azerbaijan, Georgia and the Russian Federation in the Asia-Pacific region, and Belarus, Moldova and Ukraine in Eastern Europe. The project used an ecosystem-based approach, which combines issues of rural development, sustainable land management and sustainable livelihoods to establish community-based solutions to the challenges of climate change. Activities under the project focused on the integrated management of land, water and natural resources that have a vital role to play in climate change mitigation and adaptation, including peatland, permafrost landscapes, boreal forests and pasturelands.

The programme had two components: country pilot projects and policy. The country pilot projects demonstrated that intact ecosystems can have a strong and cost-effective impact on both climate change mitigation and adaptation. They also showed how valuable an integrated approach and strong regional cooperation can be, and showcased the need for ecosystem-based approaches for tackling climate change.

Under the policy component, the project contributed to improved climate policy and planning processes, better sectoral climate policies, and better climate change modelling and reporting processes. The seven countries now have greater capacity to reduce greenhouse gas emissions, and stronger cross-country engagement and partnerships, including partnerships between national stakeholders in regional climate debates and actions. All of these contribute to the sustainability and resilience capacities of the countries involved.

Overall, ClimaEast had a significant impact. It built the adaptive capacity of 192,000 people by strengthening their livelihoods and providing social security benefits; it protected 72,000 hectares of ecosystems vulnerable to climate change. Further, it reduced greenhouse gas emissions in the project countries, for example by replacing fossil fuels with biomass for energy in Belarus and by restoring and improving the carbon absorption capacity of peatlands (Russian Federation, Ukraine), forests (Armenia, Moldova, Russian Federation) and pasturelands (Armenia, Azerbaijan, Georgia and Moldova). 
Building adaptive capacity through disaster risk reduction programmes

Chapter 2 documents the heavy toll that natural hazards have exacted on the region. Looking ahead, the Asia-Pacific region is expected to have greater vulnerability to natural hazards than other regions, and could account for 40 per cent of global economic losses from disasters in the future. This could lead to annual GDP losses of 4 per cent in small island developing states and 2.5 per cent in least developed countries. $^{112}$

As noted, the 2030 Agenda for Sustainable Development aims to leave no one behind. But if governments are to protect their most vulnerable people, they must ensure that national development strategies are firmly grounded in disaster resilience. To realize this, the international community has placed disaster risk reduction at the heart of sustainable development, in the Asia-Pacific region and elsewhere.

Since the adoption of Hyogo Framework for Action in 2005, progress has been made in reducing disaster risk at local, national, regional and global levels. This has been guided by a comprehensive global framework that aims to tackle these risks. In 2015-2016 alone, governments established several separate but inter-related agreements, including the Sendai Framework for Disaster Risk Reduction 2015-2030 (see the Special Feature). ${ }^{13}$ However, more than a decade after the adoption of the Hyogo Framework, disasters continue to undermine efforts to achieve sustainable development. ${ }^{114}$

Within the Asia-Pacific region, the Pacific island countries and territories are extremely vulnerable to climate change and natural hazards. The experiences of tropical cyclone Winston in 2016, tropical cyclone Pam in 2015 and numerous other natural hazards have all reinforced the need for actions on climate change and disaster risk management to be better understood, planned for, funded and coordinated at the local, national, regional and international levels.

Encouragingly, there has been progress on this front. For example, the Pacific Risks Resilience Programme (20152018) works with Pacific island countries and their people to mainstream the risks they face from climate change and disasters into development planning and processes. ${ }^{115}$ Under this initiative, several Pacific countries, including Fiji, Solomon Islands, Tonga and Vanuatu, have adopted an approach that incorporates risk-informed planning and budgeting. One of the projects implemented under this programme was the relocation of Tukuraki village in Fiji to avoid the risk of landslides (Box 3.6).

\subsection{Building absorptive capacity}

Absorptive capacity generally refers to the measures that people use to cope in the wake of shocks and disasters. However, some of these measures reduce or degrade their human and financial capital and assets. For example, people might reduce their food consumption, change the type of food they eat, reduce family expenses, take out loans, sell their livestock and assets, or take their children out of school. One crucial aspect of building absorptive capacity is therefore to increase people's income-earning options, so that they can meet their basic needs in times of crisis (such as buying food). World Food Programme (WFP) projects, such as the 'Enhancing Resilience to Natural Disasters' project in Bangladesh, have contributed to building the capacity of individual households, ensuring that they have less need to turn to potentially damaging coping measures (Box 3.7).

\section{Social protection programmes}

Social protection systems can play an important role in building absorptive capacity. They play two major roles: to ensure income security and health security. These systems ensure that children, adults and older people all have some form of income and access to essential health care to absorb the impacts of a shock. ${ }^{116}$ United Nations agencies have, in the last decade, emphasized social protection systems as a way to address the impacts of a number of global crises, including shocks to food, fuel and financial systems. ${ }^{117}$

Social protection provides opportunities to attain growth in a manner that protects poor and excluded groups. It does so by smoothing patterns of income generation and consumption so that shocks cause less disruption, and by maintaining political and social stability, among other ways. ${ }^{118}$ Social protection programmes tend to focus on wider goals than just income generation and can play a critical role in reducing poverty. They are designed to help people maintain an adequate standard of living and good health and to build their overall human capital and thus break intergenerational cycles of poverty and vulnerability. For example, social protection programmes can seek to increase food security (e.g. through the provision of regular and reliable cash transfer programmes), improve the health of women and children (e.g. through free antenatal care for women), promote access to education (e.g. through child grants or school stipends) or provide income transfers to older people (e.g. through old-age pensions). Some programmes are specifically focused on emergency relief efforts. 


\section{Box 3.6 Creating resilient communities in Fiji under the Pacific Resilience Programme}

In January 2012, a major landslide swept rocks and mud down the steep incline above Tukuraki village, Fiji. More than half of the village was submerged by mud and debris; in one house, a family of four were buried as they slept inside. The village was declared unsafe and villagers were asked to leave; many ended up living in makeshift homes close by. Following this, tropical cyclone Evan, a Category 4 cyclone that hit in December 2012, and cyclone Winston, a Category 5 cyclone that hit in February 2016, caused further damage to what was left of Tukuraki.

In the aftermath of these disasters, the government, through the Commissioner Western's Office and the National Disaster Management Office, consulted with the affected community about how to reduce their vulnerability. The decision made was to relocate the village to a safer place. Financing for the new village infrastructure was secured under the 'Building Safety and Resilience in the Pacific' project. This enabled the construction of 10 new houses, a community hall, a water supply system and an access road, as well as other risk-management measures.

Climate change and disaster risk considerations were built into the project management process from the start. Risk maps were used to identify a new site for the village, using a new geographic information systems platform and data from the Ministry of Agriculture. Consultations and risk assessments fed into the project design, including three community consultations to identify a new site, consider future disaster and climate risks, and possible mitigation measures to address these. The project included planning for risk management measures such as cyclone-resistant infrastructure, storm-water drains, retaining walls, waste management and storage measures, and roads situated to act as fire breaks.

Further, a task force was set up to monitor project implementation and ensure compliance with regulations. Social inclusion issues were included in the design of the relocated village, including railings and walkways for elderly and disabled people. The Tukuraki Women's Committee and other women's committees were central to the redevelopment process, helping to ensure gender considerations were factored in. This holistic, multi-stakeholder, multi-sector approach was adopted to increase community resilience. In support of this, the non-governmental organization Live and Learn Environmental Education provided development planning expertise to increase the community's resilience in their new village.

The project is now being used as a successful example of risk-informed development, in order to scale up this approach in the Pacific. For example, Tukuraki is being used in training for divisional planners across Fiji.

Source: Moortaza Jiwanji, 2017

Income and consumption patterns vary with age: young and older people have less income than their consumption. Social protection programmes for children and older people can tackle these life-cycle vulnerabilities. The pace at which income deficits and consumption costs change with age varies from country to country, however. For example, in countries such as Japan, per capita consumption in old age increases sharply, whereas per capita labour income decreases more rapidly than in Thailand (Figure 3.2).

Social protection programmes are funded from taxes and other sources of revenue. Tax-financed social protection, including cash transfers and universal health coverage, should provide minimum income security and ensure everyone has access to essential health care. This is particularly important in the Asia-Pacific region, where 60 per cent of the labour force works in the informal sector. ${ }^{119}$

Contributory social insurance schemes allow income earners to smooth their consumption over the course of their life.
Many countries adopt mandatory public contributory schemes that are tied to employment. Here, contributions basically function as a form of insurance, where employees contribute a share of their labour income while working and, when a contingency occurs (e.g. unemployment, disability or old age), ensure a higher income-replacement benefit than would be provided by tax-financed, non-contributory schemes.

Major shocks and crises, such as disasters triggered by natural hazards and external economic crises, can cause significant damage to individuals and to national economies, if the families affected resort to damaging coping strategies such as selling their productive assets. Social protection programmes can increase household resilience to shocks; they have enabled families to cope with sharp drops in commodity prices or when drought hits. With social protection, families can bounce back to higher productivity more quickly once the crisis dissipates. ${ }^{120}$ 


\section{Box 3.7 Enhancing resilience to natural hazards in Bangladesh}

People living in the southern coastal belt and north-west flooding zones of Bangladesh are vulnerable to the frequent natural hazards that affect these regions. For example, people along the coast suffered extensively from cyclone Sidr in 2007 and cyclone Aila in 2009, while those in the north-west were hit by the floods of 2004 and 2007, when river embankments were breached. These hazards caused billions of dollars' worth of damage, displaced millions of people and created long-term food insecurity and the widespread loss of household assets. People's vulnerability was heightened by the high rates of poverty found in both regions, and climate change is expected to increase both of these risks in the future.

The 'Enhancing Resilience to Natural Disasters' project was implemented in both regions in 2012 to address this vulnerability and strengthen the resilience of the rural population, especially the ultra-poor. Key activities included local-level planning; assets creation and employment generation; disaster risk reduction and life skills training and capacity-building for local stakeholders, including government and non-government agencies and community-based organizations; and cash grants for investment in productive assets.

In 2015, WFP Bangladesh evaluated the project's effectiveness in improving beneficiaries' resilience. This evaluation found that the project activities contributed to building both the absorptive and adaptive capacity of affected populations. Compared to non-beneficiaries, project beneficiaries appeared to have a lower propensity (5-16 per cent lower) to engage in detrimental responses to crises, such as reducing their food consumption, changing the type of food consumed, reducing their family expenses or taking out loans. The evaluation concluded that the beneficiaries now have a greater capacity to recover from future shocks.

\section{Figure 3.2 Annual per capita consumption and labour income in Japan and Thailand}
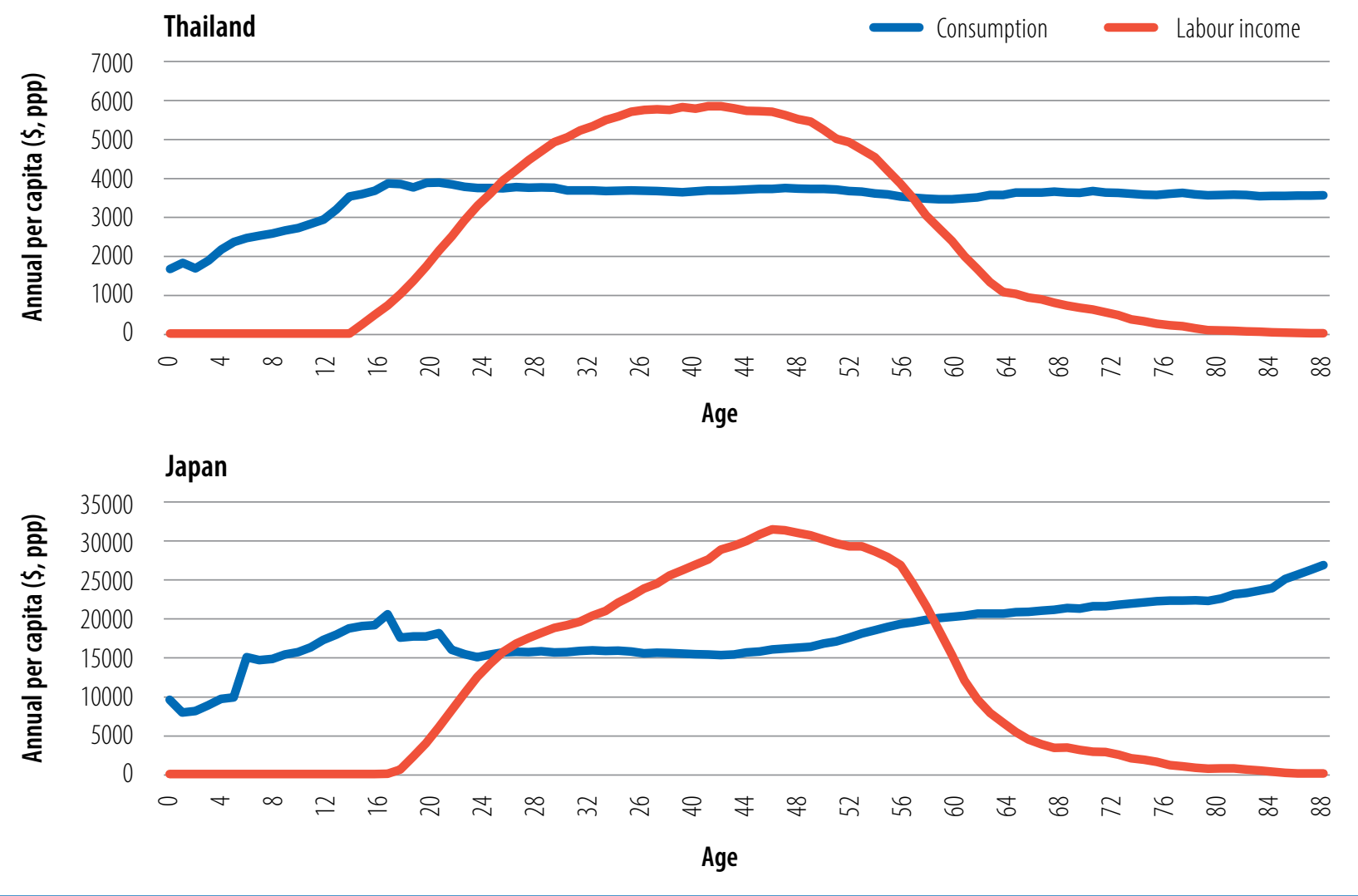

Source: Lee and Mason, 2011 


\section{Pensions for income security in old age}

Guaranteeing basic income security for older people can be achieved through pension schemes. Worldwide, 68 per cent of older people receive contributory or noncontributory pension payments. However, this coverage varies widely, from 22.7 per cent in sub-Saharan Africa to 100 per cent in North America. In the Asia-Pacific region, this figure is 55.2 per cent; however, there is considerable subregional variation. Effective coverage ranges from 23.6 per cent in South Asia to 77.3 per cent in East Asia, where China, Japan and Mongolia have all achieved 100 per cent coverage.

While gaps in income security for older people remain throughout the region, there has been notable progress in extending coverage. For example, with strong political will, the Maldives has achieved 99.7 per cent coverage of older people through a mix of contributory and non-contributory pension schemes; the non-contributory scheme alone reaches 90.6 per cent of all women and men aged 65 years and above. Thailand is moving towards universal pension coverage, and has already achieved universal health coverage (Box 3.8).

Many countries have implemented non-contributory pensions, called social pensions, to increase coverage. But often the level of payments is insufficient to meet basic needs. These low payments are concerning, as entire family units often rely on pension payments to increase access to nutrition, education, health and other essential goods and services. Adequate pension payment levels that provide basic income security, at least at a nationally defined minimum, are vital to build resilience and protect older persons and families against losses due to shocks.

To ensure that all older persons receive sufficient benefits to make them resilient, as stipulated in the Madrid International Plan of Action on Ageing, ${ }^{121}$ greater investments in health care and adequate, sustainable social security systems are a necessity. ${ }^{122}$ As the number of people aged 65 years and above in the Asia-Pacific region is set to almost double, from 556 million today to an estimated 1.29 billion by 2050 , countries need to begin and continue designing and implementing pension schemes that will ensure all older persons have access to basic income security. ${ }^{123}$

\subsection{Building transformative capacity}

Transformative capacity refers to the ability of a society to create and move to a fundamentally new system, so that a risk is avoided, or will have a limited impact if it does occur. This section examines transformations made in different systems - forest management, health care and climate change mitigation - to illustrate how such shifts can be achieved.

In each of the case studies described, the building of transformative capacity was underpinned by a fundamental rethink of the way in which natural resources are allocated and managed (see Box 3.9), the ability to bring diverse stakeholders together around a single goal, and the ability to access and generate knowledge in new ways. These issues are explored further in Chapter 4.

\section{Box 3.8 Income and health security in Thailand}

The pension system in Thailand is a mix of several contributory schemes for public sector officials, private sector employees and informal economy workers. This covers about a quarter of the population above 60 years of age. To cover the gap, the government has implemented a non-contributory old-age allowance (or social pension) that provides some level of income security to old people who are without access to regular pension payments. The monthly amount is THB 6001,000 , equivalent to $\$ 18-30$, which is less than half of the poverty line. The amount of social pension increases with age: those who are at the age of 60 receive only THB 600 . However, this is the only form of pension for many people who worked in the informal economy.

Thailand implemented its Universal Health-care Coverage Scheme in 2001, consolidating several health insurance schemes. It is based on the principle of universality, irrespective of economic and vulnerability status. The scheme is financed through taxes and provides free health care at the point of service. The benefit package under the scheme is comprehensive: it includes general medical care and rehabilitation services, high-cost medical treatment and emergency care. As a universal scheme, it controls costs and ensures its financial sustainability by fixing the annual budget and capping provider payments. The scheme has encouraged the development of health infrastructure and increased access to health services, reaching many people who were not covered earlier, such as those in the informal sector. ${ }^{124}$

Source: ILO, 2017 


\section{Transforming health systems to cope with shocks}

Transformation is rarely achieved by just one project intervention; rather, it requires a series of changes, including reforms to legislation and policies. In health systems, for example, shocks such as disease outbreaks lead to a series of major policy shifts, as was the case with the Republic of Korea's response to the MERS outbreak (Box 3.10).

In other cases, shocks to health systems are longerterm trends. As discussed in Chapter 2, air pollution is a major threat to human health and well-being in many parts of the Asia-Pacific region, particularly urban areas. Encouragingly, there are some good transformative practices being implemented to reduce air pollution. In Singapore and Seoul, Republic of Korea, the authorities have focused their attention on emissions-reducing public transport programmes as a way to reduce health risks. Similarly, Ahmedabad, India, has established a bus rapid transit system to promote a shift towards public transport and curb air pollution. Thailand has strengthened its fuelquality and vehicle-emission standards. In Japan, practices include controlling volatile organic compound emissions ${ }^{125}$ through target setting and a mix of regulatory controls and voluntary efforts. ${ }^{126}$

Some countries have started addressing air pollution from brick kilns. For example, Viet Nam has successfully transformed its energy-inefficient brick production by switching to kilns that use liquefied petroleum gas. Viet Nam's Bat Trang village once used to be covered with dust and filled with smoke, and its residents suffered from respiratory diseases; now, they have started breathing clean, fresh air. ${ }^{127}$ Similarly, Kathmandu municipality started building cleaner and safer brick kilns after the 2015 earthquake. These government efforts have contributed to reducing the vulnerability of air pollution-related health risks. Without these, the incidence of non-communicable diseases would have been higher.

Governments, together with development partners, have been driving wider innovation for transformation in the health sector. For example, the Government of India has been supporting a Universal Immunization Programme, under which an electronic vaccine intelligence network is enabled with a smart mobile application. The network - an online, real-time vaccine logistics management system - is a ground-breaking technological innovation that aims to ensure equity through efficient distribution and the timely availability of vaccines. It provides real-time information on stocks, flows and storage temperatures for all vaccine storage points, for 12 states at present. This empowers frontline health-care workers and supports the government's ambitious Universal Immunization Programme, which aims to immunize more than 156 million people every year. ${ }^{128}$

\section{Transformation towards environmental sustainability}

Combating climate change requires countries to reduce their greenhouse gas emissions and transition to lowcarbon development models. This requires integrating climate change measures into national policies, strategies and planning, as set out in target 13.2 of the SDGs. Over recent decades, developing countries have deepened their efforts to reduce emissions in the context of efforts to pursue development goals. In this context, since 2007 developing countries have formulated NAMAs.

NAMAs include both national-level actions as a formal submission declaring mitigation intent, and individual actions at the sector or industry level that will help a country realize its intentions. Developing countries voluntarily pledged NAMAs as an outcome of international climate policy negotiations during the 2009 Conference of the

\section{Box 3.9 Shifting forest management from the government to communities}

Forests used to be considered as national property in Nepal, protected and policed by the government under the Forest Nationalization Act of 1957. However, this act detached communities from any role in forest management, which led to their rapid depletion and degradation. This process was so severe that some people predicted, as early as 1988, that Nepal's Himalaya would become 'bald' within 25 years. ${ }^{129}$

In the face of this, the government concluded that the active involvement of local people in forest management was essential for their conservation. Accordingly, the Forest Act of 1993 enacted a radically different approach: one which guaranteed the rights of local people in community forest management programmes, as well as in the use of forest resources. In doing so, Nepal became the first country to enact forest legislation that allowed local communities to take full control of government forests. Since its implementation, this transformative policy has helped Nepal to conserve its forest resources better and protect its mountainous regions from being denuded.

Sources: Bhattrai, 2016; Pearce and others, 1990 


\section{Box 3.10 Responding to the MERS outbreak in the Republic of Korea}

The 2015 outbreak of MERS in the Republic of Korea was triggered by a 68-year-old man who returned from the Middle East and quickly suffered from high fever and respiratory problems. After the first MERS case was confirmed in May, 186 further cases were detected, with a death toll of 38 by the end of December, and more than 16,000 people were put into isolation.

The outbreak had high cost implications. The emergency response placed an extra cost on health-care facilities of more than KRW 178 billion (about $\$ 160$ million). Tourism and other industries suffered severe economic losses due to a drop in the number of visitors to the country. Figure 3.3 illustrates the timeline of the event.

\section{Figure 3.3 Escalation of the MERS outbreak, 2015}

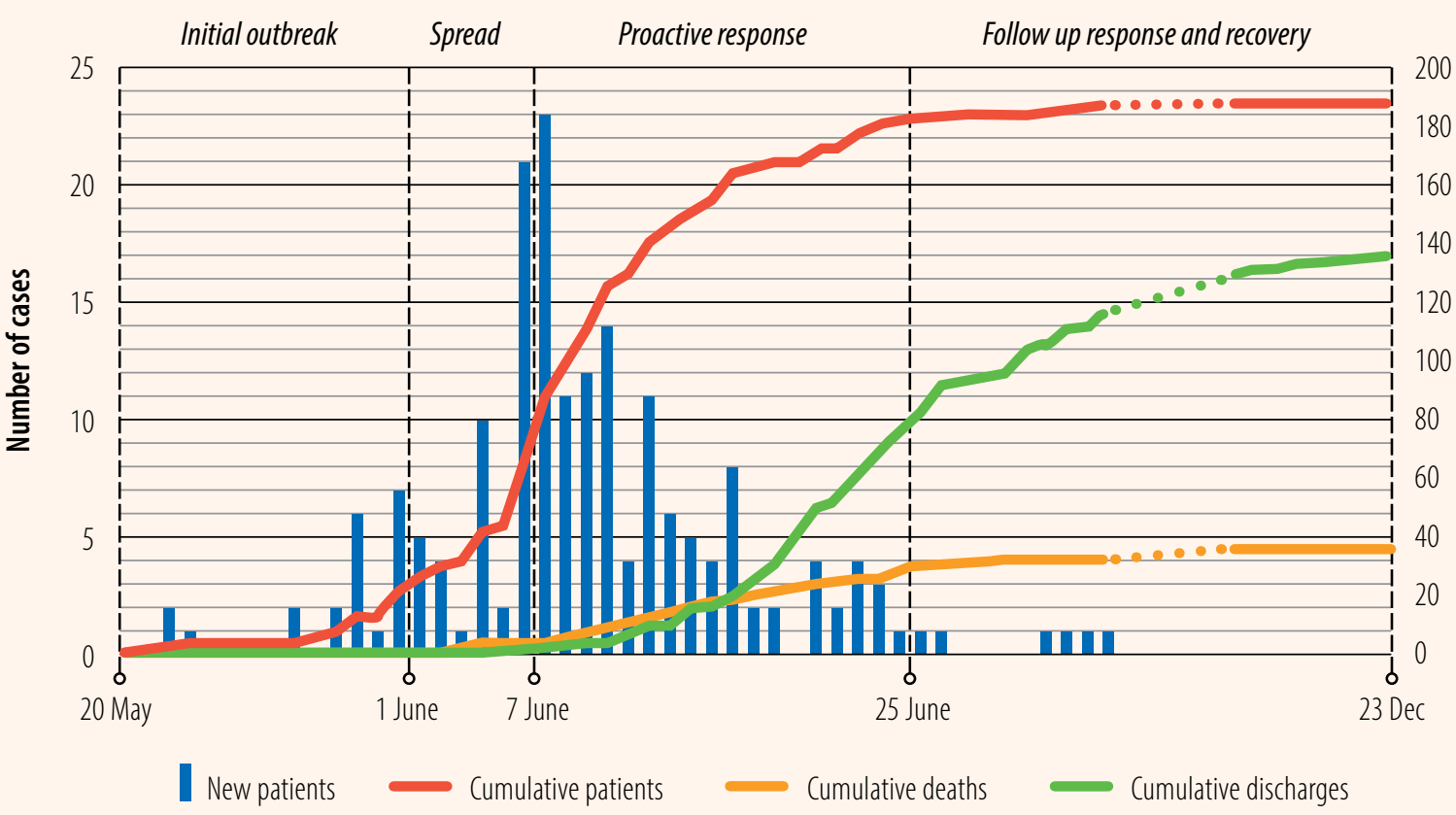

Source: Ministry of Health and Welfare, 2015

As an initial response, on 7 June, the Korea Center for Disease Control and Prevention (KCDC) took several measures. It upgraded the alert level for communicable diseases, strengthened quarantine inspections at airports, traced everyone who had had contact with the first patient and isolated them, put a 24-hour response taskforce into operation, and reported regularly to WHO.

Despite these initiatives, the lack of information, epidemiologic inspectors and facilities to detect MERS and isolate those affected hampered efforts to control its spread. Compounding this were overcrowded emergency rooms in hospitals and the Korean custom of visiting friends in hospital, which accelerated the spread of the disease. Other factors contributing to the outbreak were the delayed release of information about the disease and inefficient communication among government departments, local authorities and medical institutions. These factors also contributed to the widespread public fear about MERS.

Based on comprehensive consultations with the National Assembly, health expert groups, WHO, the media and other stakeholders, in September 2015 the government introduced 48 reforms to enhance its capacity to prevent, detect and respond to emerging infectious disease threats and public health emergencies like MERS. These focused on: installing 
a state-of-the-art, point-of-entry quarantine system; a rapid and effective emergency response system; investment in controlling disease infections; transforming the management of infectious diseases; and creating an enabling environment to reduce infections within medical institutions.

- In doing so, the Republic of Korea translated the lessons learned from the MERS outbreak into concrete actions. It not only revised its legislation, but also provided the funding needed to implement the new legislation. The result is a transformed health system, one that is far more resilient to disease outbreaks. For example: Dedicated divisions have been established in the KCDC, such as the Emergency Operations Center, to strengthen event-based surveillance, information collection, risk assessment and emergency operations.

- Technical capacities with the potential for high public health impacts have been strengthened, including systems to maintain high levels of immunization coverage in the population, and to monitor and control outbreaks related to food safety.

- National laboratory systems have been equipped with the capacity to test a wide range of pathogens from human, food and environmental samples.

- Dedicated teams have been established for the mitigation, surveillance and risk assessment of antimicrobial resistance.

- Public health emergency response systems and risk communication systems have been improved, especially those related to internal coordination and coordination with partners, as well as communication with affected communities. ${ }^{130}$

While MERS was a major shock, it was also a trigger that resulted in systemic changes. As a result, the Republic of Korea is now more alert to, and better prepared for, new and emerging diseases. The response to MERS was a full package of interventions, starting from creation of awareness to planning and putting system and institution in place and taking actions. This suggests that transformation requires a package of interventions and their effective implementation. This episode also served as a reminder that regional and international collaboration, and sharing medical measures and health experts, increases societies' resilience to public health emergencies.

Source: Authors

Parties of the United Nations Framework Convention on Climate Change (UNFCCC). The targets set in NAMAs have varied substantially. For example, China pledged to reduce $\mathrm{CO}_{2}$ emissions per unit of GDP by $40-45$ per cent ${ }^{131}$ and India by $20-25$ per cent by 2020 compared to 2005 levels. The Republic of Korea set a target to reduce emissions by 30 per cent below 'business as usual' levels by 2020. These pledges built on national efforts to develop climate change responses in the lead up to the Conference.

These plans provided a foundation for deepening action on low-carbon and climate-resilient development. Developing countries built on their NAMAs and other climate-related planning efforts, including NAPAs, NAPs and Technology Needs Assessments, to develop Intended Nationally Determined Contributions of climate action in the lead up to the Paris Agreement on Climate Change in 2015. Fiftyone countries in the Asia-Pacific region submitted an NDC with a mitigation target. ${ }^{132}$ With the entry into force of the
Paris Agreement on climate change, these now represent firm commitments.

The nature of NDC development differed across countries in the Asia-Pacific region. In many cases, independent assessments suggested the potential for greater ambition in the future. ${ }^{133}$ Most countries focused on mitigation opportunities in energy and energy efficiency, such as in the Philippines, which has been transforming its energy sector by switching to clean and renewable energy (Box 3.11). Agriculture, forestry and land use also received substantial focus.

A range of efforts are now underway to support countries to implement their NDCs, including developing concrete investment plans and implementation strategies. Support to countries to meet their mitigation and adaptation goals, priorities and actions according to their NDCs needs to be accelerated, and aligned with the 2030 Agenda, the Sendai Framework and other international agreements. 
Several countries have taken steps towards environmental sustainability through the efficient use of energy and by adopting clean energy solutions. In Indonesia, the lack of a pro-environment policy and business environment meant that companies producing tofu and tempeh, two foodstuffs made from soybeans, were inefficient. This not only reduced their profitability and productivity, but also led to environmental damage due to high emissions and wastes. To tackle this, the 'Soybean Processing' project was launched to reduce energy consumption and increase sustainable growth in the sector, for example by promoting the use of energy-efficient technologies. The project reduced emissions from all the companies involved by 83,200 tonnes per year and improving energy efficiency by 27 per cent. There were further environmental benefits, with a reduction in water pollutants and in water use, from 15 litres per 1 kilogram of soybeans processed..$^{134}$ There were also health benefits, due to reduced levels of smoke from the production process.

As a major rice-producing country, Cambodia generates large amounts of husks from rice processing. The rice sector also emits significant levels of carbon from the diesel used in its inefficient mills. The 'Waste to Energy in Rice Milling' project, implemented in 2012-2015, addressed these issues by introducing biomass as a fuel source to 150 rice millers. This reduced energy consumption by 65 per cent by replacing the diesel used in rice mills, which led to a cut in greenhouse gas emissions of 7,732 tonnes per year (a 12 per cent reduction). The project also reduced the amount of solid waste produced by 25 per cent, for example by encouraging the use of rice husk ash as a soil stabilizer. Further benefits included a rise in income for those working in the sector, which built their adaptive capacity. ${ }^{135}$

\subsection{Conclusions and policy implications}

The four forms of resilience capacity outlined here are inter-related and serve the same end purpose: to make societies more resilient to shocks. However, they operate at different levels of change. Anticipatory capacity provides the information needed to prevent a risk or mitigate the impact of a shock. Absorptive capacity refers to persistent changes, adaptive capacity to incremental changes, and transformative capacity to dramatic changes. Thus, as noted in Chapter 1, they can be seen as a continuum and, as

\section{Box 3.11 Transformation towards renewable energy in the Philippines}

The situation of vulnerable energy security, combined with rising oil prices and greater environmental awareness, led to a strong commitment to clean energy by the Government of the Philippines, which passed the Renewable Energy Act in 2008. This is considered to be the first comprehensive legislation on renewable energy in South-East Asia.

The cornerstone policy instrument in this act was the feed-in tariff incentive scheme, which offers preferential rates for electricity sales for qualified renewable energy producers. This has been crucial in attracting private investment into the sector. Since deliberation began in June 2010, the Energy Regulatory Commission has adjusted rates to maintain an optimal balance between an acceptable rate of return for power producers and end-use pricing for consumers.

Since the feed-in tariff incentive scheme was put in place in 2012, and thanks to the sharp decline in the cost of technologies such as solar and onshore wind, the Philippines has made significant progress in renewable energy deployment. Fuelled by growing domestic and overseas investments, the renewable energy industry has grown rapidly and transformed energy markets and business models. ${ }^{136}$ As of 2015, the Philippines had the world's second-largest geothermal power generation. ${ }^{137}$ Currently, some 30 per cent of electricity production is from renewable sources, which makes the Philippines one of the leaders in renewable electricity production in the region. ${ }^{138}$

Measures to facilitate private sector participation in the electricity sector, supported by the Philippines Energy Regulatory Commission, helped to create an environment that allowed renewable energy producers to play a growing role. The new National Renewable Energy Programme, launched in 2011, should lead to both diversification and further expansion of renewable energy contributions over the next two decades. To meet the growing demand, the programme aims to increase the installed capacity of renewable energy sources by 200 per cent from 2011 to 2030, which would represent an increase of nearly 10 gigawatts of capacity. The Philippines is aiming to position itself as one of the green power producers in the region by becoming both the world's largest geothermal energy producer and the largest wind energy producer in South-East Asia.

Sources: APERC, 2016; IEA, 2017; IRENA, 2017 
individuals move along this - from absorptive to adaptive to transformative - they change their behaviour and actions, which ultimately leads to a more sustainable and resilient society.

The policies and programmes outlined in this chapter identify some of the characteristics needed for individuals, organizations and societies to become resilient. These include awareness, diversity and integration.

It is through awareness and information that people can expect a certain hazard to occur, and plan to manage and adapt to the risk. A person needs to be aware of their own capacity, which is defined by their environment (including human dynamics, natural systems, infrastructures and service provisions) and how they interact with this environment. Creating knowledge and raising awareness is an important component of most of resilience-building programmes, and is required at an early stage - before actions to increase adaptation or absorption capacities. Creating awareness requires an assessment of risks, which means identifying hazards and assessing how a society is exposed to a hazard, and the extent to which it is vulnerable. Disaggregated levels of information about concentrations of people and wealth, infrastructure and services, as well as other features, are necessary for enhancing resilience.

Diversity refers to the different sources of capital, assets, infrastructure and services that an individual or society needs. For example, there is a need to diversify types of capitals and assets so that if one fails in the face of a shock, another comes to action. This also applies to provisioning systems: a variety of sources can make a society resilient. For example, if poor people cannot produce enough food, they can get it from public food distribution systems, such as those found in India, ${ }^{139}$ or through participating in workfare programmes. Having redundancy and reserves in a system can help it to operate smoothly during a crisis; for example, a backup supply of electricity from a generator in hospitals is essential when the main power supply fails.

There is a need to move away from the 'silo' approach, where an individual government ministry works on only one aspect of resilience-building, and move towards greater integration. As an example, the project working with cotton farmers in Tajikistan (Box 3.3) comprised many components and activities, ranging from raising awareness, improving access to technology (e.g. solar dryers) and finance (e.g. micro-credit schemes), and introducing new skills and knowledge (e.g. about agro-biodiversity-friendly practices, crop diversification and financial management). This required support from several different departments and ministries in the government, and effective coordination and integration between these was essential to the project being successful.

Integration includes the need to ensure meaningful and effective engagement with all stakeholders, not just policymakers but also the private sector. In conclusion, building the resilience of different groups in a society requires not just one policy, but a package of policies and interventions that reduce vulnerability as well as exposure to hazards. 



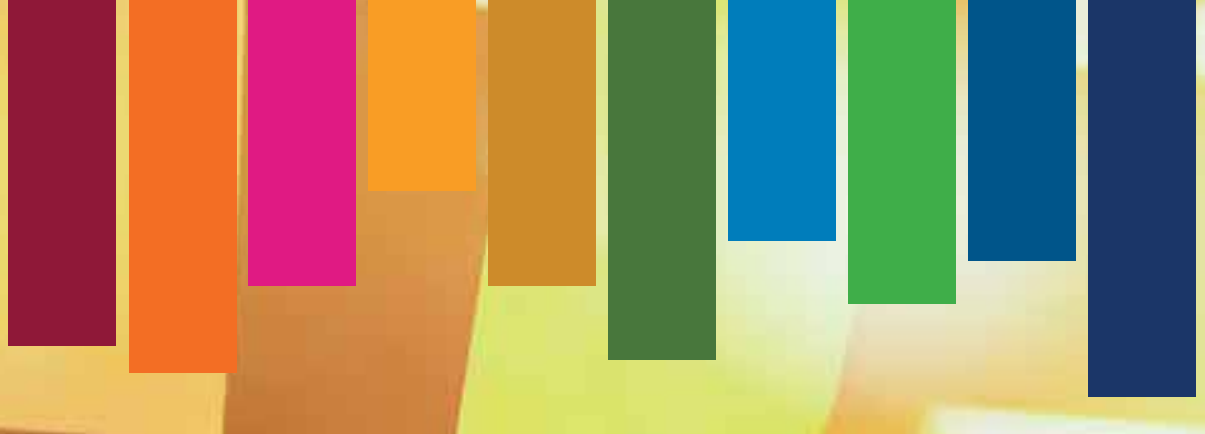

Enabling transformations towards sustainable and resilient societies 


\section{"We are determined to take the bold and transformative steps which are urgently needed to shift the world on to a sustainable and resilient path."}

- The 2030 Agenda for Sustainable Development

\subsection{Introduction}

The SDGs set out a vision for transformed societies that are prosperous, peaceful, meet the needs of all people, and protect the planet. There are many goals which the AsiaPacific region is far from achieving, and a transformation in focus and approach will be needed if we are to attain them. ${ }^{140}$ Processes of transformation are often long term, however, requiring system-level changes.

A sound understanding of opportunities, risks and challenges will be essential. Commitment to change, often reinforced by social momentum to support new ideas and actions, can help steer these efforts. Purposeful transformation to achieve the SDGs can be supported by a shared vision, and collective understanding of the avenues available for change in response to risks, opportunities or crises.

This report has highlighted the changing nature of risk in the Asia-Pacific region, the impacts of shocks and stresses on human systems, and emerging efforts to build resilience capacities at multiple levels. The most vulnerable people in society are disproportionately affected when risks materialize. All four resilience capacities discussed in this report - absorptive, anticipatory, adaptive and transformative - are essential to deal with increasingly complex risks. Strategies for building capacity to support transformation are among the least understood, however.

This concluding chapter builds on the insights presented in Chapter 3 to identify strategies to help build capacity for transformation. It suggests areas in which regional and subregional cooperation can support transformation through strengthened resilience.

\subsection{Barriers to transformation}

A legacy of past decisions, built infrastructure, knowledge systems and cultural norms, among other factors, define a set way of doing things. Breaking through this 'path dependency' means addressing some major barriers. The following discussion highlights some of the major barriers.

\section{Human and institutional capacity}

Human and institutional capacity can constrain options for, and participation in, societal transformations that may be initiated by government policy, but sustained and disseminated by the private sector, by households, by institutions and by other actors in society. Constraints may include insufficient investment in addressing vital knowledge gaps at the institutional, community, stakeholder-group or individual level. They may also arise from limited financing to sustain critical functions. Social and cultural issues can also have a significant influence. Indeed, inequality in access to information has been found to be correlated with income inequality. ${ }^{141}$

\section{Institutional rigidity}

Institutional rigidity can be a key challenge in responding to new shocks and building resilience. Rigidity - the lack of openness to, or mechanisms for, change in institutions with specific functions in a policy cycle - can block opportunities for rethinking development pathways and the delivery of public goods. For example, the report commissioned by the President of the United Nations General Assembly ${ }^{142}$ in the wake of the international financial crisis highlighted institutional rigidity as a significant issue in failing to prevent that crisis and slowing response efforts. The report identified the need for deeper reflection on basic assumptions about the most appropriate options for the future.

Where institutions lack established processes for evolution, the gap between the services needed by a society and the services that are provided can increase. Institutions often reflect the society in which they operate, and so several factors can influence institutional rigidity, including sociocultural beliefs, gender and other dimensions of inequality, and imbalances in access to decision-making.

Chapter 1 noted that where there is strong adaptive capacity, there is often a trade-off with transformative capacity. The capacity of institutions to identify and implement shortterm, adaptive measures can also reduce incentives for the deeper thinking and institutional reforms needed to drive transformation.

\section{Inadequate momentum for change}

The need for broad-based support for a new vision for development, informed by the SDGs, was raised earlier in this chapter. The process of establishing a national 'vision' has long been an important feature of national development planning efforts in countries across the Asia-Pacific region. In many cases, however, the transformation needed for these visions to be realized has remained out of reach. One factor may be inadequate engagement of stakeholders in bringing about change, including citizens and the private 
sector. Governance approaches and policy incentives that can bring the key elements of society together around a shared vision can support transformation processes.

\subsection{Strategies for transformation}

Strategies for transformation towards resilient and sustainable societies must address these barriers. They can be informed by the resilience principles introduced in Chapter 1: maintain diversity and redundancy; manage connectivity; manage 'slow' variables (such as ageing) and feedbacks; foster complex adaptive systems thinking; encourage learning; broaden participation; and promote polycentric governance systems.

This chapter highlights four strategies that can support transformation: (1) transformative learning; (2) deeper social engagement; (3) social enterprises and effective partnerships; and (4) diversifying financing and investment.

\section{Transformative learning}

As the preceding chapters have stressed, resilience approaches emphasize learning as a way to better understand and anticipate threats and opportunities. This needs to include learning about the impacts of past policies, the realities of the policy environment, changing risk profiles, and the perspectives of people most vulnerable to these risks. However, examples of public institutions that are committed to and equipped for transformative learning are not easily identified. This is explained in part by the persistence of long-standing challenges such as corruption and inequality.

Three factors can support transformative learning. The first is the creation of explicit learning processes as part of the policy cycle, especially during phases in which problems are framed and strategic goals are set. ${ }^{143}$ These may be linked to more informal opportunities for dialogue with stakeholders and learning. Methods and mechanisms that enable transformative institutional learning provide opportunities to reassess the underlying values, beliefs and views that have underpinned previous approaches to policy, and to take stock of changes in the wider context. ${ }^{144}$

Foresight institutions have the role of looking beyond the short term to highlight dangers, alternatives and choices; raise awareness; contribute to more diverse public dialogue and better-informed decision-making; and support institutional evolution. ${ }^{145}$ Several governments in the AsiaPacific region have established offices of strategic foresight that are beginning to take on such challenges.

A second factor is the use of analytical methods that can deal with complexity and support a better understanding of causal and systemic issues. Such methods integrate information from different disciplines (e.g. environmental sciences and economics) and different stakeholder perspectives. Analysis of the interactions between different human systems is critical for defining solutions that cross the lines of sectoral and institutional responsibilities, enabling a coherent response.

Processes, methods and institutional mandates for collective problem-framing, addressing dissent and controversy, dealing with uncertainty, peer review and more transparent metrics for evaluation can support these efforts. ${ }^{146}$ Specialized methods for learning and analysis that engage people are especially needed where there is social conflict. ${ }^{147}$

Third, better understanding and awareness of risk required to support transformative learning requires better access to data. Having information and data about potential risks and impacts before a shock occurs is particularly important, so that a society can take measures to prevent or mitigate the impacts of potential shocks. Chapter 2 provided some examples of efforts to invest in data to support such anticipatory capacity by identifying hazards and assessing exposures and vulnerabilities. While a disaster can hit a whole society, its impact will often be felt by individuals, which requires even more disaggregated data about risks, and individual assets and capacities to cope with these risks.

\section{Deeper social engagement}

Broad-based stakeholder support for change can play a vital role in enabling transformation. Harnessing or shaping shared values and providing the right incentives can enable the propagation of ideas and technologies, and diversify and expand access to information, financing and other resources. For example, in the Republic of Korea, national support for a shared change agenda shaped by citizens, the private sector and government supported efforts to rebound from the 1997 financial crisis, as discussed in Chapter $2 .^{148}$

Social mobilization is another critical step, for example in efforts to support recovery from conflicts and disasters. It can enable people to understand their new situations, and to organize and initiate action for their recovery, exercising initiative and creativity. ${ }^{149}$ In practice, this can be supported by governance approaches and institutional mandates that bring different groups of stakeholders together to act.

Effective processes for social mobilization involve participatory approaches that engage civil society in constructive dialogue and public participation. Change often requires a degree of creative conflict, as there will 
inevitably be opposing views and entrenched positions. Governments need to become more adept at balancing diverse perspectives. Balancing the interests of different stakeholders to ensure that the most vulnerable are protected is critical. Although many governments have expressed a commitment to better involve stakeholders in efforts to implement the 2030 Agenda, legislative changes and, in some cases, extra-judiciary actions have constrained the space for social dialogue in several countries. Strengthened legal mandates for civic participation, robust civic education, an active and effective media, and measures to build trust between stakeholders are among the foundations for effective public participation strategies. ${ }^{150}$

\section{Social enterprise}

Social enterprises use commercial strategies to provide socially supportive services that respond to a specific need. They have the potential to connect poverty alleviation, sustainability and resilience-strengthening objectives with economic objectives in ways that can transform communities. Social enterprises can provide locally relevant solutions to development challenges, be they technology driven, ${ }^{151}$ focused on adapting learning to cultural contexts, ${ }^{152}$ or reliant on the 'activation' of groups of people that may have been previously overlooked as sources of innovation. ${ }^{153}$

In the Asia-Pacific region, many social enterprises are found in the agricultural sector ${ }^{154}$ - a sector which plays a critical role in food systems and thus strongly influences development outcomes across several SDGs. Some types of social enterprise hold particular potential to enable locallevel transformations (see Box 4.1).

Social enterprise is being actively promoted in countries such as the Philippines and the Republic of Korea. For example, the comprehensive and sustained social enterprise strategies adopted by the Seoul Metropolitan government have created awareness about the social economy, supported intermediary organizations and developed a market for social enterprise products. ${ }^{155}$

Partnerships often help social enterprises scale up their reach and impacts. Whether involving the private sector ${ }^{156}$ or governments, ${ }^{157}$ they multiply and diversify the ways in which resources can be accessed and mobilized.

The transformative potential of social enterprises built on effective partnerships is highlighted by examples in which actors have been brought together to increase the value added across the agricultural supply chain (e.g. through fair-trade certification) and have played an important role in improving development outcomes for households, communities and entire sectors, as shown by a benchmark analysis on agricultural value chains ${ }^{158}$ conducted in Indonesia, the Philippines, Thailand and Viet Nam. By contrast, limiting the roles of farmers and farming communities to being merely suppliers of goods reduces opportunities for transforming livelihoods and communities. ${ }^{159}$

\section{Diversifying finance and investment}

Each of the shocks discussed in Chapter 2 highlighted the diversity of ways in which financing is essential though not sufficient - for building more sustainable and resilient societies. A growing range of risks, particularly from climate change and disasters, threaten the viability of core development investments, such as infrastructure and social services. Increased resilience and strengthened transformative capacity both require fiscal systems to be flexible when the worst happens. Responses can take diverse forms: they can, among others, provide emergency funds to conduct relief efforts and undertake repairs after disasters; harness climate finance; or mitigate the effects of budget deficits, particularly to safeguard spending on vital public and social services.

\section{Box 4.1 Social enterprises with poor people as the primary stakeholders}

Research covering Bangladesh, India, Indonesia and the Philippines has defined a specific type of social enterprise: the 'Social Enterprise with the Poor as Primary Stakeholders', which strengthens resilience while also responding to poverty, inequality and wider social challenges. These enterprises have three common characteristics:

1. They explicitly pursue a social mission, such as poverty reduction or alleviation, as their primary objective.

2. They create wealth with due regard to social and environmental costs.

3. They have a distributive enterprise philosophy, meaning that unlike typical businesses, much of the wealth they create is distributed in ways that directly benefit poor people as their primary stakeholders, rather than accumulated by a few.

Source: Dacanay, 2012 
International financial institutions play an important role in helping countries to find the fiscal space to cope with this diversity of risks. In addition to fiscal flexibility, innovative mechanisms that ensure that access to finance is inclusive and provided through effective channels are needed.

Developing these mechanisms depends on the convergence of multiple factors, discussed previously in this chapter, including information, technology, governance, policies, regulations and human capacities. ${ }^{160}$ Partnerships around information and communications technology can open new paths to financial inclusion, building essential resilience and creating the conditions for potentially wider social transformations. For example, in India efforts are being made to bring together programmes aimed at increasing access to bank accounts, providing digital identity and mobile technology together through the Jan Dhan-Aadhaar-Mobile Trinity programme. ${ }^{161}$

Financial systems can also be designed to help countries reflect and cope with risk. For example, countercyclical financing ${ }^{162}$ can be used to help cushion or mitigate the impacts of economic shocks on a country. Efforts to build and deepen insurance markets in the Asia-Pacific region, where access to affordable and effective insurance is often quite limited, is another important tool. Indeed, there is growing interest in the potential to design and deploy micro-insurance to better support communities and households to cope with the effects of shocks and stresses. Such measures to invest in risk reduction and prevention can help reduce the amount of emergency financing needed to support recovery efforts.

Continued - and greater - efforts to factor emerging risks into investment design and choices are needed. Many financing institutions are increasingly aware of such risk and are beginning to adopt tools and practices that help them assess these issues, though much remains to be done.

\subsection{In conclusion}

This report has highlighted opportunities to strengthen public policy to support transformation towards resilient and sustainable societies, and the achievement of the 2030 Agenda, by investing in resilience capacities.
It shows how capacity-building and institutional interventions - from the household level through the community level to the national level - can increase resilience. It underlines that the likelihood of achieving some of the most urgent transformations advocated by the 2030 Agenda can be increased by better understanding the context of risk and focusing on resilience-building. It has stressed opportunities to support transformations that can support more resilient development, including through a focus on learning, deeper stakeholder engagement, innovative partnerships and financing for resilience.

Considering the commonalities in the risk profiles of countries across the Asia-Pacific region, there is significant scope for regional action, including to support learning. There is a need for a greater regional focus on capacitybuilding and institution-building to strengthen governance.

The Asia-Pacific Forum on Sustainable Development is just one forum in which emerging risks can be discussed and collective responses can be developed. Stronger partnerships and greater collaboration between countries need to go beyond these types of interventions, however. There is also a need for a continued focus on investments in individual resilience capacities, especially in the context of delivering on the Agenda 2030 pledge that no one is left behind.

Efforts to eradicate poverty and reforms to address the structural aspects that create marginalization and vulnerability in society all contribute to empowerment and agency. ${ }^{163}$ Investments in strengthening social protection systems can also play a critical role in strengthening individual and society-level resilience. The findings of this report, prepared to support regional dialogue on the theme of the 2018 High-level Political Forum on sustainable development, are also highly relevant to efforts to empower people to support progress towards the SDGs and promote equality. They offer insights that may also inform regional dialogue on the 2019 High-level Political Forum theme of 'Empowering people and ensuring inclusiveness and equality'. 


\section{References}

\section{Chapter 1}

ADB (2017). ARegion at Risk:The Human Dimensions of Climate Change in Asia and the Pacific. Manila: Asian Development Bank. Available from www.adb.org/publications/region-atrisk-climate-change.

Bahadur, A.V. and others (2015). The 3AS: Tracking resilience across BRACED. BRACED Working Paper. London: Farm Africa. Available from www.farmafrica.org/downloads/ braced.pdf.

Béné, C. and others (2012). Resilience: New utopia or new tyranny? Reflection about the potentials and limits of the concept of resilience in relation to vulnerability reduction programmes. IDS Working Paper 405. Brighton: Institute of Development Studies. Available from www.ids.ac.uk/ publication/resilience-new-utopia-or-new-tyranny.

Biggs, R., M. Schlüter and M.L. Schoon, eds. (2015). Principles for Building Resilience: Sustaining Ecosystem Services in Socialecological Systems. Cambridge: Cambridge University Press.

Cardona, O.D. and others (2012). Determinants of risk: exposure and vulnerability. In Managing the Risks of Extreme Events and Disasters to Advance Climate Change Adaptation, C.B. Field and others, eds. A Special Report of Working Groups I and II of the Intergovernmental Panel on Climate Change (IPCC). Cambridge and New York: Cambridge University Press (pp. 65-108).

Compton J., S. Wiggins, and S. Keats (2010). Impact of the Global Food Crisis on the Poor: What is the Evidence? London: Overseas Development Institute. Available from www.odi. org/sites/odi.org.uk/files/odi-assets/publications-opinionfiles/6371.pdf.

ESCAP (2017). Leave No One Behind: Disaster Resilience for Sustainable Development, Asia-Pacific Disaster Report 2017. Bangkok: United Nations Economic and Social Commission for Asia and the Pacific.

Hendrix, C. and H.-J. Brinkman (2013). Food insecurity and conflict dynamics: Causal linkages and complex feedbacks. Stability: International Journal of Security and Development, vol. 2, No. 2, Art. 26.
Institute for Societal Resilience (n.d.). Institute for Societal Resilience. Amsterdam: Vrije Universiteit. Available from https://fsw.vu.nl/en/research/institute-for-societal-resilience.

Jeasakul, P., C.H. Lim and E. Lundback (2014). Why was Asia resilient? Lessons from the past and for the future. IMF Working Paper. WP/14/38. Washington, DC: International Monetary Fund.

Kharrazi, A. (2018). Examining the resilience of agricultural and food commodity trade networks in the Asia and Pacific region. Technical Working Paper. Asia-Pacific SDG Partnership. Available at http://sdgasiapacific.net.

ND-GAIN (2016). Notre Dame Global Adaptation Initiative Index. Available at https://gain.nd.edu/our-work/countryindex.

Porkka, M. and others (2013). From food insufficiency towards trade dependency: A historical analysis of global food availability. PLoS One, vol. 8, No. 12.

Presutti,W.D.J.(1992). The single source issue:US and Japanese sourcing strategies. International Journal of Purchasing and Materials Management, vol. 228, No. 1, pp. 2-9.

Rockefeller Foundation (n.d). 100 resilient cities. New York: Rockefeller Foundation. Available from www. rockefellerfoundation.org/our-work/initiatives/100resilient-cities.

Tanner, T. and others (2017). Challenges for resilience policy and practice. Working Paper 519. London: Overseas Development Institute. Available from www.odi.org/sites/ odi.org.uk/files/resource-documents/11733.pdf.

\section{Chapter 2}

ADB (2010).Asian DevelopmentOutlook2010:Macroeconomic Management Beyond the Crisis. Manila: Asian Development Bank. Available from www.adb.org/publications/asiandevelopment-outlook-2010-macroeconomic-managementbeyond-crisis.

ADB (2011). Asian Development Outlook 2011: South-South Economic Links. Manila: Asian Development Bank. Available from www.adb.org/publications/asian-development-outlook2011-south-south-economic-links. 
ADB (2012). Asian Development Outlook 2012: Confronting Rising Inequality in Asia. Manila: Asian Development Bank. Available from www.adb.org/publications/ asian-development-outlook-2012-confronting-risinginequality-asia.

ADB (2013a). Investing in Resilience - Ensuring a Disasterresistant Future. Manila: Asian Development Bank. Available from www.adb.org/publications/investing-resilience-ensuringdisaster-resistant-future.

ADB (2013b). Food Security in Asia and the Pacific. Manila: Asian Development Bank. Available from www.adb.org/ publications/food-security-asia-and-pacific.

ADB (2013c). Asian Development Outlook 2013: Asia's Energy Challenge. Manila: Asian Development Bank. Available from www.adb.org/publications/asian-development-outlook2013-asias-energy-challenge.

ADB (2014). Asian Development Outlook 2014: Fiscal Policy for Inclusive Growth. Manila: Asian Development Bank. Available from www.adb.org/publications/asian-development-outlook2014-fiscal-policy-inclusive-growth.

ADB (2015). Asian Development Outlook 2015: Financing Asia's Future Growth. Manila: Asian Development Bank. Available from www.adb.org/publications/asian-development-outlook2015-financing-asias-future-growth.

ADB (2016a).Asian Development Outlook2016:Asia's Potential Growth. Manila: Asian Development Bank. Available from www.adb.org/publications/asian-development-outlook2016-asia-potential-growth.

ADB (2016b). Asian Economic Integration Report 2016: What Drives Foreign Direct Investment in Asia and the Pacific? Mandaluyong City: Asian Development Bank. Available from www.adb.org/publications/asian-economic-integrationreport-2016.

ADB (2017a). A Region at Risk: The Human Dimensions of Climate Change in Asia and the Pacific. Mandaluyong City: Asian Development Bank. Available from www.adb.org/ publications/region-at-risk-climate-change.

ADB (2017b). Asian Development Outlook 2017: Transcending the Middle-Income Challenge. Manila: Asian Development Bank. Available from www.adb.org/publications/asiandevelopment-outlook-2017-middle-income-challenge.
AIDMI (2017). India floods 2017. southasiadisasters.net, Issue 161. Ahmedabad: All India Disaster Mitigation Institute. Available from https://reliefweb.int/sites/reliefweb.int/files/ resources/SouthAsiadisasters\%20no.161.pdf.

Aon Benfield (2017). Global Catastrophe Recap October 2017. London: Aon Benfield. Available from http:// thoughtleadership.aonbenfield.com/Documents/ 20171109-ab-analytics-if-october-global-recap.pdf.

ASEAN. Specialized Meteorological Center. Jakarta: Association of Southeast Asian Nations. Available from http://asmc.asean.org/home.

Bach C. and others (2013). Critical Infrastructures and Disaster Risk Reduction. New Delhi: National Institute of Disaster Management; and Eschborn: Deutsche Gesellschaft für Internationale Zusammenarbeit.

Crippa, P. and others (2016). Population exposure to hazardous air quality due to the 2015 fires in equatorial Asia. Scientific Reports, vol. 6, No. 37074.

EM-DAT. The Emergency Events Database. Universite catholique de Louvain, Brussels. Available from www. emdat.be.

Fajarnes, P. (2011). An Overview of Major Sources of Data and Analyses Relating to Physical Fundamentals in International Commodity Markets. Rome: Food and Agriculture Organization of the United Nations.

Hallegatte, S. and others (2017). Unbreakable: Building the Resilience of the Poor in the Face of Natural Disasters. Climate Change and Development. Washington, DC: World Bank. Available from http://documents.worldbank.org/curated/ en/512241480487839624/Unbreakable-building-theresilience-of-the-poor-in-the-face-of-natural-disasters.

Hansen, M.C. and others (2013). Hansen/UMD/Google/ USGS/NASA Tree Cover Loss and Gain Area. University of Maryland, Google, USGS and NASA. Accessed through Global Forest Watch (www.globalforestwatch.org) on 20 November 2017.

IMF (2016). Caucasus and Central Asia: Battered by External Shocks. Regional Economic Outlook. Update. Washington, DC: International Monetary Fund.

IMF (2017). Regional Economic Outlook. Middle East and Central Asia. October. Washington, DC: International Monetary Fund. 
Inoue, T. and T. Okimoto (2017). Measuring the effects of commodity price shocks on Asian economies. ADBI Working Paper Series, No. 693. Tokyo: Asian Development Bank Institute. Available from www.adb.org/sites/default/files/ publication/233906/adbi-wp693.pdf.

Jambeck, J. and others (2015). Plastic waste inputs from land into the ocean. Science, vol. 347, No. 6223. Available from http://science.sciencemag.org.

Joshi, P. (2017). Mumbai swamp, comparing July 2005 to August 2017. Mumbai: The Indian Express. Available from http://indianexpress.com/article/opinion/mumbaifloods-swamp-excessive-rains-drainage-system-july-2005august-2017-4823348.

Kadri, F. and others (2014). The impact of natural disasters on critical infrastructures: A domino effect-based study. Journal of Homeland Security and Emergency Management, vol. 11, No. 2, pp. 217-241.

Koplitz, S.N. and others (2016). Public health impacts of the severe haze in equatorial Asia in September-October 2015: Demonstration of a new framework for informing fire management strategies to reduce downwind smoke exposure. Environmental Research Letters, vol. 11, Art. 094023.

Kusumaningtyas, S.D.A. and E. Aldrian (2016). Impact of the June 2013 Riau province Sumatera smoke haze event on regional air pollution. Environmental Research Letters, vol. 11, Art. 075007.

Landrigan, P.J. and others (2017). The Lancet Commission on pollution and health. The Lancet, vol. 391, No. 10119, pp. 462-512.

Muttarak, R. and W. Lutz (2014). Is education a key to reducing vulnerability to natural disasters and hence unavoidable climate change? Ecology and Society, vol. 19, No. 1, p. 42.

OCHA (2017). South Asia: Flooding - humanitarian snapshot (as of 01 September 2017). New York: United Nations Office for Coordination of Humanitarian Affairs. Available from https://reliefweb.int/sites/reliefweb.int/files/resources/ SouthAsia_010917.pdf.

ReliefWeb (2015). Floods projected to cost South Asia over \$215 billion per year. New York: ReliefWeb. Available from https://reliefweb.int/report/world/floods-projected-costsouth-asia-over-215-billion-year.
Save the Children (2017). Bangladesh: Monsoon floods threated children's right to education. Education Disrupted, Education Denied Series, No. 3. London: Save the Children. Available from https://resourcecentre. savethechildren.net/node/12445/pdf/55206_bangladesh educationdisruptedsep2017.pdf.

Sharma, M. and O. Dikshit (2016). Comprehensive Study on Air Pollution and Green House Gases (GHGs) in Delhi. Delhi: IIT Kanpur, Delhi Pollution Control Committee and Department of Environment.

UNCTAD and FAO (2017). Commodities and Development Report 2017: Commodity Markets, Economic Growth and Development. Geneva: United Nations Conference on Trade and Development. Available from http://unctad.org/en/ pages/PublicationWebflyer.aspx?publicationid=1916.

UNICEF (2017). 16 million children affected by massive flooding in South Asia. UNICEF press release, 2 September. New York: United Nations Children's Fund. Available from www.unicef.org/media/media_100719.html.

United Nations News Center (2014). Plastic waste causes $\$ 13$ billion in annual damage to marine ecosystems, says UN agency. 23 June. New York: United Nations. Available from www.un.org/apps/news/story.asp?NewsID=48113\#. Wnk8saiWblU.

UNU-IEHS (2016). World Risk Report 2016: Focus: Logistics and Infrastructure. Berlin/Bonn: Bündnis Entwicklung Hilft (Alliance Development Works) and United Nations University - Institute for Environment and Human Security. Available from http://weltrisikobericht.de/wp-content/ uploads/2016/08/WorldRiskReport2016.pdf.

WEF (2018). The Global Risks Report 2018. Geneva: World Economic Forum. Available from www.weforum.org/ reports/the-global-risks-report-2018.

WHO (2011) Global Status Report on Noncommunicable Diseases 2010. Geneva: World Health Organization. Available from www.who.int/nmh/publications/ncd_report2010/en.

WHO (2016). WHO global urban ambient air pollution database (update 2016). Geneva: World Health Organization. Available from: www.who.int/phe/health_ topics/outdoorair/databases/cities/en.

World Bank (2015). Low commodity prices and weak currencies. Washington, DC, World Bank. Available from http://documents.worldbank.org/curated/en/88228146 8562677894/Low-commodity-prices-and-weak-currencies. 
World Bank (2016). The cost of fire: An economic analysis of Indonesia's 2015 fire crisis.Indonesia Sustainable Landscapes Knowledge Note 1. Jakarta: World Bank. Available from http://documents.worldbank.org/curated/ en/776101467990969768/The-cost-of-fire-an-economicanalysis-of-Indonesia-s-2015-fire-crisis.

World Bank. World Bank Databank. World Bank Commodity Price Data (The Pink Sheet). Washington, DC: World Bank. http://www.worldbank.org/en/research/commoditymarkets

World Bank. World Bank Databank. World Development Indicators. Washington, DC: World Bank. Available from http://databank.worldbank.org/data/home.aspx.

World Bank and Institute for Health Metrics and Evaluation (2016). The Cost of Air Pollution: Strengthening the Economic Case for Action. Washington, DC: World Bank. Available from: http://documents.worldbank.org/curated/ en/781521473177013155/pdf/108141-REVISED-Cost-ofPollutionWebCORRECTEDfile.pdf.

\section{Special feature}

ADB (2017). Meeting Asia's Infrastructure Needs. Manila: Asian Development Bank. Available from www.adb.org/ publications/asia-infrastructure-needs.

ADB (2018, forthcoming). Strengthening Resilience Through Investments in Social Protection Programs. Manila: Asian Development Bank.

Burke, L. and others (2012). Reefs at Risk Revisited in the Coral Triangle. Washington, DC: World Resources Institute. Available from http://pdf.wri.org/reefs_at_risk_revisited_ coral_triangle.pdf.

EM-DAT (n.d.). The Emergency Events Database. Universite catholique de Louvain, Brussels. Available from www. emdat.be.

ESCAP (2017a). Asia-Pacific Disaster Report 2017 - Leave No One Behind. Bangkok: United Nations Economic and Social Commission for Asia and the Pacific. Available from www. unescap.org/publications/asia-pacific-disaster-report2017-leave-no-one-behind.

ESCAP (2017b). Statistical Yearbook for Asia and the Pacific 2016: SDG Baseline Report. Bangkok: United Nations Economic and Social Commission for Asia and the Pacific. Available from www.unescap.org/sites/default/files/ESCAP_ SYB2016_SDG_baseline_report.pdf.
ESCAP. ESCAP Statistical Database. Bangkok: United Nations Economic and Social Commission for Asia and the Pacific. Available from http://data.unescap.org/escap_stat.

ESCAP, ADB and UNDP (2017). Asia Pacific Sustainable Development Goals Outlook. Bangkok: United Nations Economic and Social Commission for Asia and the Pacific; Manila: Asian Development Bank; and New York: United Nations Development Programme. Available from www. adb.org/publications/asia-pacific-sdg-outlook.

Gassmann, F. and S.W. Handayani (2017). Closing the gap: Potential contribution of social assistance for achieving Sustainable Development Goals. ADB Briefs 80. Manila: Asian Development Bank. Available from www.adb.org/ sites/default/files/publication/336006/adb-brief-80.pdf.

Hallegatte, S. and others (2017). Unbreakable: Building the Resilience of the Poor in the Face of Natural Disasters. Climate Change and Development. Washington, DC: World Bank. Available from http://documents.worldbank.org/curated/ en/512241480487839624/Unbreakable-building-theresilience-of-the-poor-in-the-face-of-natural-disasters.

United Nations Department of Economic and Social Affairs. SDG Indicators Global Database. New York: United Nations Department of Economic and Social Affairs. Available from https://unstats.un.org/sdgs/indicators/database.

World Bank (2016). Measuring Rural Access: Using New Technologies. Washington, DC: World Bank. Available from http://documents.worldbank.org/curated/en/367391472 117815229/Measuring-rural-access-using-new technologies.

\section{Chapter 3}

ADB (2011). Asia 2050: Realizing the Asian Century. Manila: Asian Development Bank. Available from www.adb.org/ publications/asia-2050-realizing-asian-century.

ADPC (2016). Protecting Children Through Community Capacity Building and Risk Reduction. Bangkok: Asian Disaster Preparedness Center. Available from www.adpc. net/igo/contents/Publications/publications-Details. asp?pid=1109\#sthash.glft6BrJ.dpbs.

Amadeo, K. (2018). Japan's 2011 earthquake, tsunami and nuclear disaster: Economic impact on Japan and the rest of the world. The Balance, 10 January. Available from www. thebalance.com/japan-s-2011-earthquake-tsunami-andnuclear-disaster-3305662. 
Amponin, J.A. and J.W. Evans (2016). Assessing the intended nationally determined Contributions of ADB developing members. ADB Sustainable Development Working Paper Series, No. 44. Available from www.adb.org/sites/default/ files/publication/189882/sdwp-044.pdf.

APERC (2016). APEC Energy Demand and Supply Outlook, 6th Edition. Tokyo: Asia Pacific Energy Research Centre. Available from http://aperc.ieej.or.jp/publications/reports/ outlook.php.

Banerjee, S. and others (2016). Role of remittances in building farm assets in the flood affected households in Koshi Sub-Basin in Nepal. In Migration, Risk Management and Climate Change: Evidence and Policy Responses, A. Milan and others, eds. Available from www.researchgate. net/publication/310540157_Role_of_Remittances_ in_Building_Farm_Assets_in_the_Flood_Affected_ Households_in_Koshi_Sub-Basin_in_Nepal.

Banerjee, S. and others (2017). Do financial remittances build household-level adaptive capacity? A case study of flood-affected households in India. KNOMAD Working Paper 18. KNOMAD.

Bauer, A. and others (2009). Global crisis and fiscal space for social protection. A paper prepared for the 3rd China-ASEAN Forum on Social Development and Poverty Reduction, December 2009. Manila: Asian Development Bank.

Bhattrai, B. (2016). Status of community forestry in Nepal. International Journal of Current Multi-Disciplinary Studies, vol. 2, No. 5, pp. 227-234.

Campaign (2012). Case study: How the Manila Department of Health fought dengue fever. Campaign, 25 September. Hong Kong, China/Singapore: Campaign. Available from www.campaignasia.com/article/case-study-howthe-manila-department-of-health-fought-denguefever/316804.

ClimaEast (2016). ClimaEast Policy Project: Overview of Results. Brussels: ClimaEast. Available from http://1067656943. n159491.test.prositehosting.co.uk/wp-content-sec/ uploads/2017/04/Clima-East-Final-Brochure-2017.pdf.

Deshpande, V. (2011). Disaster management as part of curriculum for undergraduate and postgraduate courses: The symbiosis model. Indian Journal of Occupational and Environmental Medicine, vol. 15, No. 3, pp. 97-99. Available from www.ncbi.nlm.nih.gov/pmc/articles/PMC3299105.
Dougherty-Choux, L. and others (2015). Adapting from the Ground Up: Enabling Small Businesses in Developing Countries to Adapt to Climate Change. New York: United Nations Development Programme and World Resources Institute. Available from www.undp.org/content/undp/en/home/ librarypage/climate-and-disaster-resilience-/adaptingfrom-the-ground-up.html.

ESCAP (2008). Economic and Social Survey of Asia and the Pacific 2008: Sustaining Growth and Sharing Prosperity. Bangkok: United Nations Economic and Social Commission for Asia and the Pacific. Available from www.unescap.org/ publications/economic-and-social-survey-asia-and-pacific2008-sustaining-growth-and-sharing.

ESCAP (2013). Ministerial Conference on Regional Economic Cooperation and Integration in Asia and the Pacific, 17-20 December. Bangkok: United Nations Economic and Social Commission for Asia and the Pacific. Available from www. unescap.org/events/mcrei.

ESCAP (2017a). Leave No One Behind: Disaster Resilience for Sustainable Development - Asia-Pacific Disaster Report 2017. Bangkok: United Nations Economic and Social Commission for Asia and the Pacific. Available from https://reliefweb. int/report/world/leave-no-one-behind-disaster-resiliencesustainable-development-asia-pacific-disaster.

ESCAP (2017b). Addressing the Challenges of Population Ageing in Asia and the Pacific. Bangkok: United Nations Economic and Social Commission for Asia and the Pacific. Available from www.unescap.org/sites/default/files/ publications/Addressing $\% 20$ the $\% 20$ Challenges $\% 20$ of $\% 20$ Population\%20Ageing\%20in\%20Asia\%20and\%20the\%20 Pacific.pdf.

ESCAP (2017c). Responding to the climate change challenge in Asia and the Pacific: Achieving the Nationally Determined Contributions (NDCs). Bangkok: United Nations Economic and Social Commission for Asia and the Pacific.

ESCAP (2018, forthcoming). Why We Need Social Protection. Bangkok: United Nations Economic and Social Commission for Asia and the Pacific.

ESCAP and others (2016). Transformations for Sustainable Development: Promoting Environmental Sustainability in Asia and the Pacific. Bangkok: United Nations Economic and Social Commission for Asia and the Pacific. Available from www.unescap.org/publications/transformation-for-sdg. 
FAO (n.d.). Smallholders and family farming. Family farming knowledge platform. Rome: Food and Agriculture Organization of the United Nations. Available from www. fao.org/family-farming/themes/small-family-farmers/en.

IEA (2017). Southeast Asia Energy outlook 2017. Paris: Organisation for Economic Co-operation and Development/ International Energy Agency.

ILO (2017). World Social Protection Report 2017-19: Universal Social Protection to Achieve the Sustainable Development Goals. Geneva: International Labour Organization. Available from www.ilo.org/global/publications/books/ WCMS_604882/lang--en/index.htm.

ILO (n.d.). Informal economy in Asia and the Pacific. Geneva: International Labour Organization. Available from www.ilo. org/asia/areas/informal-economy/lang--en/index.htm.

ILO and WHO (2009). The Social Protection Floor: A Joint Crisis Initiative of the UN Chief Executives Board for Co-ordination on the Social Protection Floor. Geneva: International Labour Organization and World Health Organization. Available from www.un.org/ga/second/64/socialprotection.pdf.

IRENA (2017). Renewables Readiness Assessment: The Philippines. Abu Dhabi: International Renewable Energy Agency.

Kim, K-t. (2017). Yionhap News Agency, 19 November. Available from http://english.yonhapnews.co.kr/business/ 2017/11/18/0502000000AEN20171118003500320. html (accessed 4 December 2017).

Koshimura, S. and others (2014). The impact of the 2011 Tohoku earthquake tsunami disaster and implications to the reconstruction. Soils and Foundations, vol. 54, No. 4, pp. 560-572.

Lavell, A. and others (2012). Climate change: New dimensions in disaster risk, exposure, vulnerability, and resilience. In Managing the risks of extreme events and disasters to advance Climate Change Adaptation, C.B. Field and others, eds. A Special Report of Working Groups I and Il of the Intergovernmental Panel on Climate Change (IPCC). Cambridge and New York: Cambridge University Press.

Lax, J. and J. Krug (2013). Livelihood assessment: A participatory tool for natural resource dependent communities. Thünen Working Paper 7. Hamburg: Johann Heinrich von Thünen Institute. Available from www. econstor.eu/bitstream/10419/87578/1/767805186.pdf.
Lee, R. and A. Mason, ed. (2011). Population Ageing and the Generational Economy: A Global Perspective. Cheltenham: Edward Elgar.

Lee, H. and C. Rhee (2012). Lessons from the 1997 and the 2008 crises in the Republic of Korea. ADB Economics Working Paper Series, No. 298. Manila: Asian Development Bank. Available from www.adb.org/publications/lessons1997-and-2008-crises-republic-korea.

Ministry of Health and Welfare (2015). The 2015 MERS Outbreak in the Republic of Korea: Learning from MERS. Seoul: Government of Korea. Available from http:// cdc.go.kr/CDC/cms/cmsFileDownload.jsp?fid=70039\& field Name $=$ attach 1 \&index $=1$.

NAP Global Support Programme (2017). Regional briefing on National Adaptation Plans: Asia-Pacific in focus. New York: United Nations Development Programme/UN Environment/Global Environment Facility. Available from http://globalsupportprogramme.org/sites/default/files/ resources/regional_briefing_on_naps_asia-pacific_1.pdf.

OCHA (2017). South Asia: Flooding - Humanitarian snapshot (as of 01 September 2017). New York: United Nations Office for Coordination of Humanitarian Affairs. Available from https://reliefweb.int/sites/reliefweb.int/files/resources/ SouthAsia_010917.pdf.

Pearce, D. and others (1990). Sustainable Development: Economics and Environment in the Third World. London: Earthscan.

Practical Action (2013). Good Practices for Community Resilience. Dhaka: Practical Action Bangladesh. Available from https://practicalaction.org/docs/ia1/good-practicescommunity-resiliance-052009.pdf.

Steinbach, D. and others (2017). Building resilience to climate change: MGNREGS, drought and flooding in Odisha. IIED Issue Paper. London: International Institute for Environment and Development. Available from http://pubs. iied.org/pdfs/10187IIED.pdf.

Sterrett, C.L. (2016). Gender Equality and Women's Voice in Asia-Pacific Resilience Programming. Geneva: CARE. Available from https://careclimatechange.org/wp-content/ uploads/2016/08/Gender-Equality.pdf.

Switchasia (2015). Promoting eco-friendly production in Indonesian tofu and tempeh industry. Impact Sheet, Soybean Processing Project. Jakarta: Switchasia. Available from www.switch-asia.eu/publications/promoting-eco-friendlyproduction-in-indonesian-tofu-and-tempeh-industry. 
Switchasia (2016). Sustainable biomass technology enhances Cambodia's rice milling sector. Impact Sheet, Waste to Energy Project. Phnom Penh: Switchasia. Available from www.switch-asia.eu/publications/sustainable-biomasstechnology-enhances-cambodias-rice-milling-sector.

Tiwari, B.N. (2010). Social protection against global crises in Nepal: Some challenges. Paper presented at Research Meeting on Social Protection in South Asia, 18-19 March, New Delhi.

United Nation (2015). Sendai Framework for Disaster Risk Reduction 2015-2030. New York: United Nations.

UN DESA (2017). World Population Ageing 2017 - Highlights. New York: United Nations Department of Economic and Social Affairs. Available from www.un.org/en/development/ desa/population/publications/pdf/ageing/WPA2017_ Highlights.pdf.

UNDP (2014). Human Development Report 2014. Sustaining Human Progress: Reducing Vulnerabilities and Building Resilience. New York: United Nations Development Programme.

UNDP (2015). Bangladesh: Community-based early warnings against flash flood. Bangkok: United Nations Development Programme. Available from www.asia-pacific. undp.org/content/rbap/en/home/ourwork/developmentimpact/innovation/projects/bangladesh-flood.html.

UNDP (2016). Risk governance: Building blocks for resilient development in the Pacific. Policy brief. Suva: United Nations Development Programme. Available from www. nab.vu/sites/default/files/documents/PRRP\%20Risk\%20 Governance-Policy\%20Brief.pdf.

UNDP (2017). Games About Change: An Activity Book Highlighting the Impacts of Energy, Infrastructure, Transport, Technology Projects in Asia and the Pacific. Available from https://reliefweb.int/report/world/games-about-changeactivity-book-highlighting-impacts-energy-infrastructuretransport.

UNDP (n.d.). Improving efficiency of health care system in multiple states. New Delhi: United Nations Development Programme. Available from www.in.undp.org/content/ india/en/home/operations/projects/health/improvingefficiency-of-health-care-system-in-multiple-states.html.

UNDP and EU (n.d.). ClimaEast - Shifting Ground. New York: United Nations Development Programme. Available from www.adaptation-undp.org/sites/default/files/resources/ undp-climaeastpublication_web_final_pages_1_0.pdf.
UNEP (2017). Towards a pollution-free Asia-Pacific. Discussion document for agenda item 8 on the theme: Towards a Pollution-Free Planet. Second Forum of Ministers and Environment Authorities of Asia Pacific, Bangkok, 5-8 September. Bangkok: United Nations Development Programme.

UNFCCC (n.d.). NAPA received by Secretariat. New York: United Nations Framework Convention on Climate Change. Available from http://unfccc.int/adaptation/workstreams/ national_adaptation_programmes_of_action/items/4585. php.

Varma, A. and L. Yutong (2017). Building smallholders' resilience through an innovative water conservancy project in Hongta District of China. Box contribution prepared for the 2018 Annual Thematic Report: Transformation Towards Sustainable and Resilient Society.

WFP (2016). Impact Evaluation of the WFP Enhancing Resilience to Natural Disasters and the Effects of Climate Change Programme. Rome: World Food Programme. Available from https://reliefweb.int/sites/reliefweb.int/files/ resources/Report\%20on\%20Enhancing\%20Resilience $\% 20$ to\%20Natural\%20\%20Disasters_310ct16.pdf.

\section{Chapter 4}

Agarwal, P.K. and others (2016). Pradhan Mantri Jan-Dhan Yojana (PMJDY): A new route of financial as well as social inclusion. International Journal of Management Research \& Review, vol. 6, No. 10, pp. 1443-1451. Available from http://ijmrr.com/admin/upload_data/journal_Punit\%20 Kumar\%20Agarwal\%20\%2010oct16mrr.pdf.

Camdessus, M. (1999). Crisis, restructuring, and recovery in Korea. Remarks by former Managing Director of IMF. Washington, DC: International Monetary Fund. Available at www.imf.org/en/News/Articles/2015/09/28/04/53/sp120299.

Cornell, S. and others (2013). Opening up knowledge systems for better responses to global environmental change. Environmental Science \& Policy, vol. 28, pp. 60-70. Available from https://www.sciencedirect.com/science/ article/pii/S1462901112002110.

Dacanay, M.L. (2012). Social enterprises and the poor enhancing social entrepreneurship and stakeholder theory (Thesis). Doctoral School of Organisation and Management Studies, PhD Series. Copenhagen: Business School Handelshøjskolen. Available from: http://openarchive.cbs. dk/bitstream/handle/10398/8513/Marie_Lisa_Dacanay.pdf. 
de Kraker, J. (2017). Social learning for resilience in socialecological systems. Current Opinion in Environmental Sustainability, No. 28, pp. 100-107. Available from www. researchgate.net/publication/320160071_Social_learning for_resilience_in_social-ecological_systems.

ESCAP, ADB and UNDP (2017). Eradicating Poverty and Promoting Prosperity in Asia and the Pacific. Bangkok: United Nations. Available from http://sdgasiapacific.net/download/ AP_SDG_Thematic-Report_2017.pdf.

ESCAP and STEPI (2017). Innovative Financing for Development in Asia and the Pacific. Government Policies on Impact Investment and Public Finance for Innovation. Bangkok: United Nations Economic and Social Commission for Asia and the Pacific. Available from www.unescap.org/ publications/innovative-financing-development-asia-andpacific.

Goyal, S. and V. Gupta (2009). Sulabh International - Social transformation through sanitation. Vikalpa Journal, No. 34, Issue 1, pp. 89-106. Available from www.vikalpa.com/pdf/ articles/2009/vol-34.1-89-105.pdf.

Hargrove, R. (2008). Masterful Coaching (3rd edition). Hoboken: Pfeiffer, Wiley.

ISEA and Oxfam (2017). A pathway to sustainability in agriculture value chains. Benchmarks for transformational partnerships that impact on women and men small scale producers in AVC. Working Paper. Quezon City: Institute for Social Entrepreneurship in Asia and Oxford: Oxfam.
Kennedy, P. and A. Prat (2017). Where do people get their news? Columbia Business School Research Paper No. 17-65. New York: Columbia Business School. Available from https:// papers.ssrn.com/sol3/papers.cfm?abstract_id=2989719.

Lukensmeyer, C. (2012). Bringing Citizen Voices to the Table: A Guide for Public Managers. Indianapolis: Jossey-Bass.

Slaughter, R. (2004). Futures Beyond Dystopia: Creating Social Foresight. London: Routledge.

UN-Habitat (2008). People's Process in Post-disaster and Postconflict Recovery and Reconstruction. Nairobi: United Nations Human Settlements Programme. Available from www.ifrc. org/PageFiles/95751/B.d.04.\%20People's\%20Process\%20 in\%20Post-disaster\%20and\%20Post-conflict\%20Recov\%20 and\%20Reconst_UN-Habitat.pdf.

United Nations (2009). Report of the Commission of Experts of the President of the United Nations General Assembly on Reforms of the International Monetary and Financial System. New York: United Nations. Available from www.un.org/ga/ econcrisissummit/docs/FinalReport_CoE.pdf.

Viswanath, K. (2016). Safetipin: A tool to build safer cities for women. In Asia: Weekly Insight and Analysis. San Francisco: The Asia Foundation. Available from https://asiafoundation. org/2016/05/11/safetipin-tool-build-safer-cities-women.

Westley, F. (2013). Social innovation and resilience: How one enhances the other. Stanford: Stanford Social Innovation Review (SSIR). Available from https://ssir.org/articles/entry/ social_innovation_and_resilience_how_one_enhances_ the_other. 


\section{Endnotes}

\section{Chapter 1}

1 ADB, 2017.

2 ESCAP, 2017.

3 Adapted from the formulation of human systems in ADB, 2017. This is a simplified version of the concept of social-ecological systems used in the literature, acknowledging that the interaction between society and the environment is mediated and guided by institutions and governance arrangements.

4 Hendrix and Brinkman, 2013.

5 Institute for Societal Resilience, n.d.

6 Adapted from Rockefeller Foundation, n.d.

7 For a definition of hazards, exposure and vulnerability, see Cardona and others, 2012.

8 Adapted from ADB, 2017.

9 Redundancy refers to the presence of multiple components that can perform the same function, thereby allowing for backup options or insurance within systems.

10 Variables that change slowly often determine the properties of a system. Once these variables cross certain thresholds, they can affect the functioning of the system as a whole; hence the need to manage slow variables.

11 Biggs and others, 2015. Governance systems refer to the norms and rules governing human interactions, including how actors and institutions interact, coordinate and work to make and enforce rules.

12 Béné and others, 2012.

13 Béné and others, 2012; Tanner and others, 2017.

14 Jeasakul and others, 2014.

15 Bahadur and others, 2015.

16 In preparation for the fifth session of the Asia-Pacific Forum on Sustainable Development, ESCAP, ADB and UNDP facilitated five multi-stakeholder subregional discussions in 2017, during which the three-step analytical framework was applied and found useful in guiding the deliberations. These events were held in Almaty, Kazakhstan, 27-28 September; Beijing, China, 10-11 October; Bangkok, Thailand, 18-19 October; Apia, Samoa, 1-2 November; and Kathmandu, Nepal, 1-2 November. They were attended by government officials, civil society, academia and representatives from business sectors.

17 ADB, 2017.
18 The vulnerability of food systems to climate change incorporates aspects such as projected changes in crop yields, demographic changes (e.g. projected population trends) and sensitivity factors (i.e. countries' dependency on food imports). For full details of all six components of the vulnerability index of food systems, see ND-GAIN, 2016.

19 Porkka and others, 2013.

20 Kharrazi, 2018.

21 One of the potential driving factors of this phenomenon in the region is Preferential Trade Agreements (PTAs). The Asia-Pacific region has been a major contributor to the growth of PTAs; 167 of existing PTAs - 63 per cent of the global total - were established here. The growth of PTAs increases the drive towards further regional trade liberalization. ESCAP analyses show that there is a close association between the proliferation of PTAs and a reduction in the resilience of food trade networks.

22 Presutti, 1992.

23 In this study, redundancy, which measures the degree of freedom or diversity of pathways within any network, was used as a measure of resilience.

24 Compton and others, 2010.

25 ADB, 2017.

\section{Chapter 2}

26 WEF, 2018.

27 WEF, 2018.

28 For further discussions on this topic, see WHO, 2011.

29 The focus is on the most heavily affected countries: Bangladesh, India and Nepal.

30 Data from EM-DAT. This database records hazard events as disasters if the event leads to 10 or more deaths; 100 or more people affected, injured or made homeless; a declaration by a country of a state of emergency; or an appeal for international assistance. Geophysical disasters refer to hazards originating from solid earth, such as earthquakes and volcanic activities. Meteorological disasters are caused by short-lived extreme weather and atmospheric conditions, including heat waves, severe winters and storms. Climatological disasters are caused by long-lived atmospheric conditions such as droughts and wildfires. Hydrological disasters are caused by water occurrence and movements, such as floods and landslides. 
neutralize the antisocia effects of economic shocks and/or'slow down' cycles. They include measures such as encouraging spending during downturns (through stimulus packages) or tightening credit during inflationary periods.

48 ADB, 2016b.

49 World Bank World Development Indicators Meta Data, https://data.worldbank.org/indicator/GB.XPD.RSDV.GD.ZS.

50 Jambeck and others, 2015.

51 www.amis-outlook.org

52 United Nations News Center, 2014.

53 United Nations News Center, 2014.

54 Comprising air pollution, unsafe water and sanitation, and lead exposure.

55 Landrigan and others, 2017.

$56 \mathrm{WHO}, 2016$.

57 Landrigan and others, 2017.

58 World Bank and the Institute for Health Metrics and Evaluation, 2016.

$59 \mathrm{PM}_{2.5}$ is particulate matter 2.5 micrometres or less in diameter. These fine particles are particularly harmful to human health because they can travel deep into people's lungs and bloodstream. See http://zeenews. india.com/news/health/tips/air-pollution-what-is-pm25-and-how-does-it-harm-our-health_1831858.html

60 Sharma and Dikshit, 2016.
61 Sharma and Dikshit, 2016.

62 Koplitz and others, 2016.

63 Kusumaningtyas and Aldrian, 2016.

64 Koplitz and others, 2016.

65 As measured by the Pollution Standards Index, an air quality index that measures the level of pollutants.

66 Crippa and others, 2016.

67 World Bank, 2016.

68 World Bank, 2016.

69 World Bank, 2016.

70 Landringan and others, 2017.

\section{Special Feature}

71 These indicators are categorized as Tier 3 (no internationally established methodology or standards are yet available, but methodology/standards are being, or will be, developed or tested) or Tier 2 (indicator is conceptually clear, has an internationally established methodology and standards are available, but data are not regularly produced by countries).

72 ESCAP, 2017a.

73 1990-2016 average.

74 ESCAP, 2017a.

75 ESCAP statistical database. Available from http://data. unescap.org/sdg (accessed 8 February 2018).

76 Data from the EM-DAT. The database includes biological and extraterrestrial disasters, but these have not been included in this chapter.

77 EM-DAT, www.emdat.be.

78 The classification of disaster events is based on mortality and housing destruction. Events in which fewer than 30 people are killed or fewer than 600 houses destroyed are classified as extensive events. If more than 30 people are killed, or 600 or more houses destroyed, the event is classified as an intensive event.

79 Hallegatte and others, 2017.

80 ESCAP, 2017b.

81 ESCAP, 2017a.

82 ESCAP, ADB and UNDP, 2017.

83 ESCAP, 2017a.

84 ADB, 2017.

85 ADB, 2017.

86 World Bank, 2016.

87 ESCAP, 2016.

88 Gassmann and Handayani, 2017.

89 Asia-Pacific SDG Partnership's SDG Data Portal, http:// data.unescap.org/sdg

90 Burke and others, 2012. 


\section{Chapter 3}

91 Steinbach and others, 2017.

92 Under the sustainable livelihoods approach, the wellbeing of a household or community depends on a system with five different categories of capital and assets: human, social, natural, physical and financial. For further details of these categories, see Lax and Krug, 2013.

93 Deshpande, 2011.

94 This is discussed in more detail later in the chapter, in relation to transformative capacity.

95 UNDP, 2015.

96 ADPC, 2016.

97 Sterrett, 2016.

98 ADB, 2011.

99 Amadeo, 2018. In total, 561 square kilometres along Japan's Pacific coast were affected by the tsunami. The economic impacts were estimated at JPY 16-25 trillion. For details, see Koshimura and others, 2014.

100 ESCAP, 2013.

101 ESCAP, 2008.

$102 \mathrm{FAO}$, n.d.

103 An expansionary policy is a macroeconomic policy that seeks to expand money supply or cut interest rates and taxes, or increase transfer payments and government spending, to encourage demand and economic growth.

104 Varma and Yutong, 2017.

105 Practical Action, 2013.

106 UNDP, 2014.

107 These policies and programmes fall into two broad categories: those designed to minimize the extent of climate change - mitigation - and those intended to minimize risks and seize upon new opportunities adaptation.

108 About 51 countries had submitted their NAPAs to the UNFCCC Secretariat, including 14 Asia-Pacific countries: Afghanistan, Bangladesh, Bhutan, Cambodia, Kiribati, the Lao People's Democratic Republic, Maldives, Myanmar, Nepal, Samoa, Solomon Islands, Timor-Leste, Tuvalu and Vanuatu. See UNFCCC, n.d.

109 UNDP, 2014.

110 NAP Global Support Programme, 2017.

111 www.climaeast.eu

112 ESCAP, 2017a; OCHA, 2017.

113 The other agreements include: the 2030 Agenda for Sustainable Development (see Box 1.1); the Paris Agreement under the UNFCCC (http://unfccc.int/paris_ agreement/items/9485.php); the Agenda for Humanity (www.agendaforhumanity.org); the New Urban Agenda 2016 (http://habitat3.org/the-new-urban-agenda); and the Addis Ababa Action Agenda (www.un.org/esa/ffd/ wp-content/uploads/2015/08/AAAA_Outcome.pdf).

114 United Nations, 2015.

115 UNDP, 2016.

116 National social protection floors should comprise at least the following four social security guarantees, as defined at the national level: (1) access to essential health care, including maternity care; (2) basic income security for children, to ensure they have access to nutrition, education, care and other necessary goods and services; (3) basic income security for people of working age, who are otherwise unable to earn a sufficient income, in particular in cases of sickness, unemployment, pregnancy and disability; and (4) basic income security for older people. See ILO, n.d.

117 ILO and WHO, 2009.

118 Bauer and others, 2009; Tiwari, 2010.

119 ILO, n.d.

120 ESCAP, 2018 (forthcoming).

121 The World Assembly on Ageing adopted the Madrid International Plan of Action on Ageing in 2002 to create a "society for all ages". The 2030 Agenda for Sustainable Development also recognizes the specific resilience challenges facing the elderly. For example, SDG indicator 1.3.1 measures the proportion of the population covered by social protection systems, including older persons.

122 ESCAP, 2017b.

123 UN DESA, 2017.

124 ILO, 2017.

125 Volatile organic compounds include a variety of chemicals, some of which may have adverse short- and long-term health effects. See www.epa.gov/indoor-airquality-iaq/volatile-organic-compounds-impact-indoorair-quality

126 UNEP, 2017.

127 UNDP, 2017

128 UNDP, n.d.

129 Sunday Times, 11 September 1988, cited in Pearce and others, 1990.

130 Ministry of Health and Welfare, 2015.

131 It also pledged to increase the share of non-fossil fuels in primary energy consumption to 15 per cent by 2020, and increase forest coverage by 40 million hectares and forest stock volume by 1.3 billion cubic metres by 2020, from 2005 levels.

132 ESCAP, 2017c.

133 Amponin and Evans, 2016.

134 Switchasia, 2015.

135 Switchasia, 2016. 
136 IRENA, 2017.

137 IEA, 2017.

138 APERC, 2016.

139 For details, see http://dfpd.nic.in/index.htm

\section{Chapter 4}

140 ESCAP, ADB and UNDP, 2017.

141 Kennedy and Prat, 2017.

142 United Nations, 2009.

143 de Kraker, 2017.

144 See Hargrove, 2008. An example of transformative learning can be found in the wake of typhoon Yolanda in 2013. The response to the disaster, which caused the loss of around 6,300 lives and damage valued at $\$ 2.86$ billion, was evaluated with respect to its impact on poverty reduction goals. This exercise also resulted in rethinking the response to this humanitarian crisis, shifting towards a greater emphasis on bottomup approaches that more directly involve target communities, and which, in the spirit of 'building back better', supported poverty reduction efforts as well as disaster recovery.

145 Slaughter, 2004.

146 Cornell and others, 2013.

147 de Kraker, 2017.

148 Camdessus, 1999.

149 UN-Habitat, 2008.

150 Lukensmeyer, 2012.

151 Viswanath, 2016.
152 Goyal and Gupta, 2009.

153 Westley, 2013.

154 Dacanay, pers. comm.

155 ESCAP and STEPI, 2017.

156 Several examples are found in the region, including in the areas of reforestation and carbon offsetting (e.g. the Pur Project, Thailand); technological knowledge and research development (e.g. 1001 fountains, Cambodia); or the sustainable use of natural resources (e.g. Future of fish - seafood and ocean conservation). By scaling up niche models, private companies can contribute to wider transformation.

157 For example, the largest philanthropic organization in Indonesia, Dompet Dhuafa, has evolved from a model where it provided free health-care services (raising money by collecting zakat) to one in which it reaches many more people and accesses more resources through partnerships with the government. To be effective in supporting transformation, they require recognition, supportive governance structures, and accountability and responsibility among all actors.

158 ISEA and Oxfam, 2017.

159 ISEA and Oxfam, 2017.

160 ESCAP and STEPI, 2017.

161 Agarwal and others, 2016.

162 This includes measures such as reducing spending and raising taxes during periods of economic boom, and increasing spending and cutting taxes during recessions.

163 This was underlined in the previous report in this series: ESCAP, 2017. 


